New Policies to Promote Youth Inclusion

Accommodation of diversity in the Nordic Welfare States
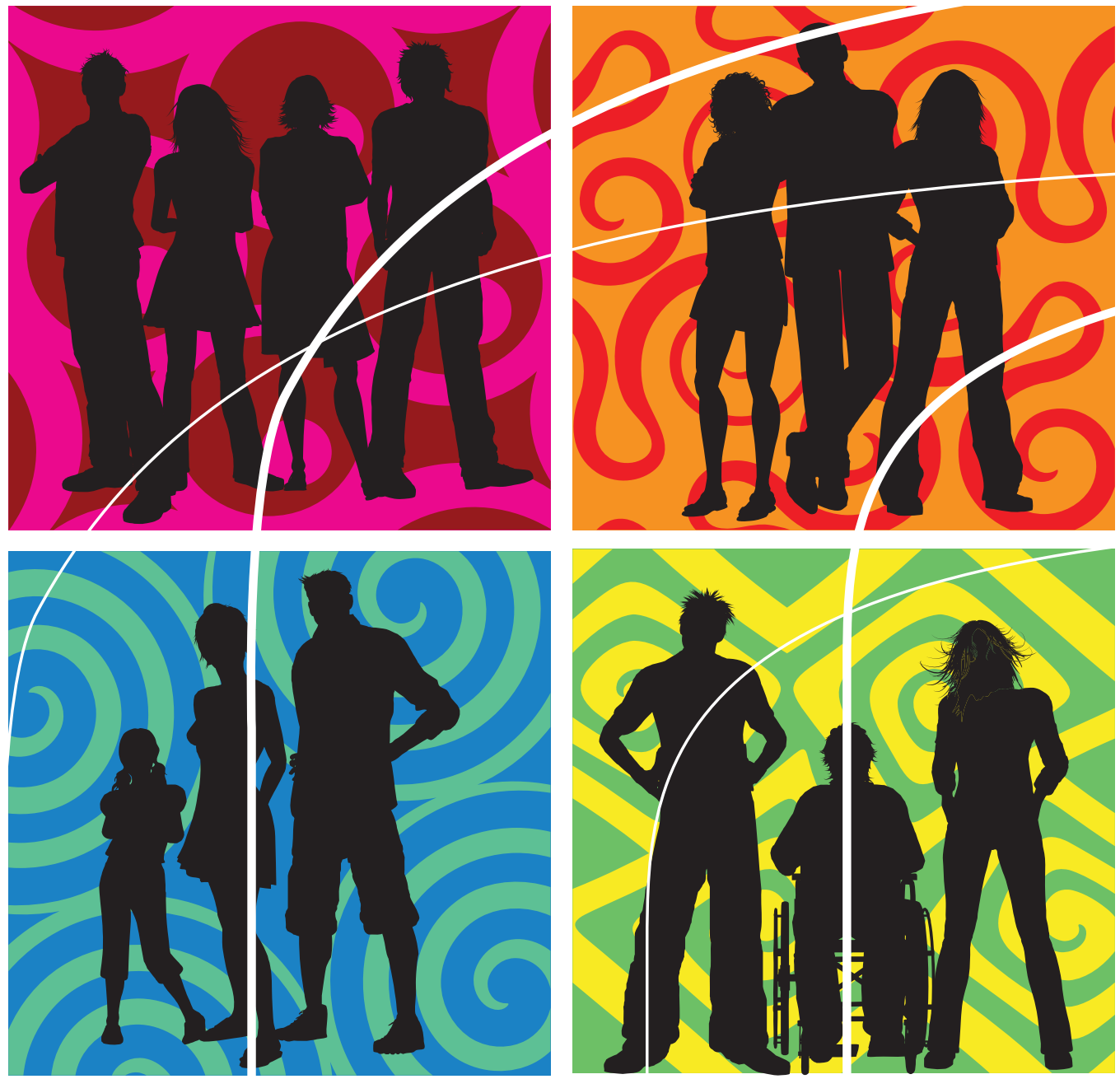

I nordon 



\section{New Policies to Promote Youth Inclusion}

Accommodation of diversity in the Nordic Welfare States

Rune Halvorsen and Bjørn Hvinden

TemaNord 2014:564 
New Policies to Promote Youth Inclusion

Accommodation of diversity in the Nordic Welfare States

Rune Halvorsen and Bjørn Hvinden

ISBN 978-92-893-3868-4 (PRINT)

ISBN 978-92-893-3870-7 (PDF)

ISBN 978-92-893-3869-1 (EPUB)

http://dx.doi.org/10.6027/TN2014-564

TemaNord 2014:564

ISSN 0908-6692

(C) Nordic Council of Ministers 2014

Layout: Hanne Lebech

Cover photo: Signelements

Print: Rosendahls-Schultz Grafisk

Copies: 100

Printed in Denmark

This publication has been published with financial support by the Nordic Council of Ministers. However, the contents of this publication do not necessarily reflect the views, policies or recommendations of the Nordic Council of Ministers.

www.norden.org/en/publications

\section{Nordic co-operation}

Nordic co-operation is one of the world's most extensive forms of regional collaboration, involving Denmark, Finland, Iceland, Norway, Sweden, and the Faroe Islands, Greenland, and Åland.

Nordic co-operation has firm traditions in politics, the economy, and culture. It plays an important role in European and international collaboration, and aims at creating a strong Nordic community in a strong Europe.

Nordic co-operation seeks to safeguard Nordic and regional interests and principles in the global community. Common Nordic values help the region solidify its position as one of the world's most innovative and competitive.

\section{Nordic Council of Ministers}

Ved Stranden 18

DK-1061 Copenhagen $\mathrm{K}$

Phone (+45) 33960200

www.norden.org 


\section{Content}

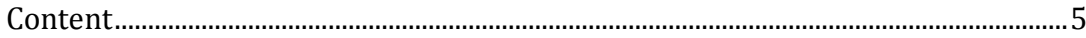

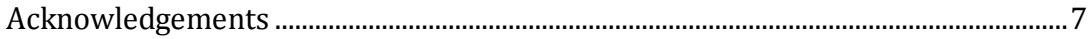

1. Introduction: Changing conditions for labour market inclusion ...........................9

1.1 Changing conditions for labour market participation..................................

1.2 Challenges for the labour market inclusion of young adults....................11

1.3 Consequences of exclusion from the labour market..................................14

1.4 The Nordic model of labour market inclusion ..........................................15

1.5 Scope of the present report: focus on social regulation............................18

1.6 Why compare disability and ethnicity? ......................................................20

1.7 "Minority ethnic youth" or youth with "immigrant background"? ?......22

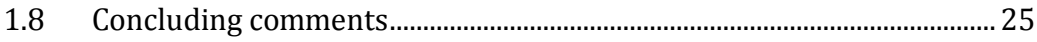

2. Understanding the policy mix ..............................................................................2

2.1 Social regulation and recognition of diversity ……………………….........31

2.2 Labour Market Inclusion as the result of social interaction......................36

2.3 Concluding comment.................................................................................... 37

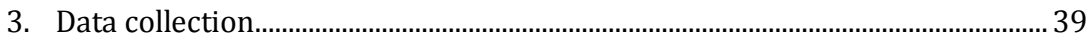

3.1 Time series data and outcome measures....................................................39

3.2 Data on ethnicity in the Nordic countries.................................................... 41

3.3 Data on disability in the Nordic countries ................................................... 42

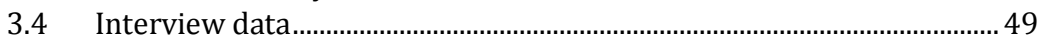

3.5 Policy documents and legal data................................................................ 51

3.6 Concluding comment.................................................................................... 51

4. Changing balances in Nordic social protection systems .......................................53

4.1 Nordic labour market inclusion policy and vulnerable youth................53

4.2 Social benefit subsystem: health and residence as criteria .......................54

4.3 Social services subsystem: education and on-the-job training...............56

$4.4 \quad$ Social regulation subsystem .........................................................................59

4.5 Summary of priorities in Nordic labour market inclusion policy for vulnerable youth groups .......................................................................... 64

5. The employment opportunities and prospects of youth with disabilities

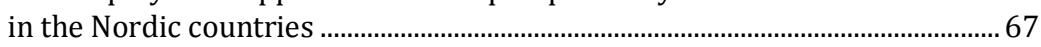

5.1 Disability in the Nordic labour markets ......................................................67

5.2 Employment rates among youth with disabilities ....................................... 70

5.3 Education rates among youth with disabilities........................................... 75

5.4 NEET-rates among youth with disabilities................................................... 79

$5.5 \quad$ Concluding comment.................................................................................. 83 
6. The employment opportunities and prospects of minority ethnic youth in the Nordic countries

6.1 Ethnic stratification in the Nordic labour markets......................................85

6.2 Employment rates among minority ethnic youth.....................................88

6.3 Employment rates: more about Denmark.................................................92

6.4 Employment rates: more about Finland …..................................................93

6.5 Employment rates: more about Norway.................................................94

6.6 Employment rates: more about Sweden...................................................95

6.7 Education rates among minority ethnic youth ...........................................96

6.8 Education: More about Denmark...................................................................98

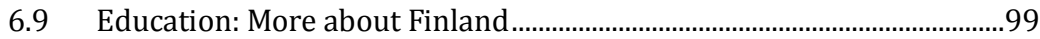

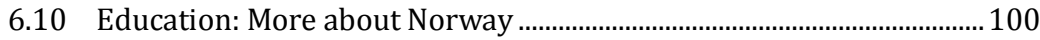

6.11 Education: More about Sweden .............................................................. 101

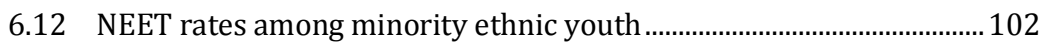

6.13 NEET rates: more about age and gender ................................................ 102

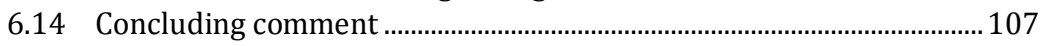

7. Implementing social regulation - local negotiations......................................... 109

7.1 Negotiations between employers and vulnerable youth ......................111

7.2 The role of a third partyin finding and keeping paid work ................... 124

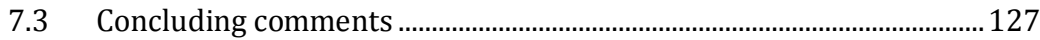

8. Concluding discussion: Regulating diversity in the labour market................. 131

8.1 Ethnicity and disability in Nordic social protection policy ...................132

8.2 Social regulation vs social redistribution in the Nordic countries .....133

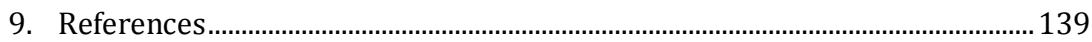

10. Norsk sammendrag: Ny politikk for å fremme inkludering av ungdom i arbeidsmarkedet? Tilpasning av mangfold $\mathrm{i}$ arbeidslivet.

Annex: Employment, education and NEET among minority ethnic youth in the Nordic countries. 


\section{Acknowledgements}

This thematic report presents the main findings of a research project commissioned in 2011 by the Nordic Council of Ministers, the Nordic Committee of Senior Officials for Labour; "Social regulation in Nordic Welfare States: The Impact on Employment among Youth from Ethnic Minorities and Youth with Disabilities" (Project No. 11143). The report provides new knowledge about what practical impact regulatory social provisions have on the employment opportunities and prospects of the two youth groups.

In preparing this report we have benefited from the assistance of the other team members. The team members have been Susan Kuivalainen (Finland), Maria Ventegodt Liisberg (Denmark), James Rice (Iceland), Susan Niknami (Sweden), Lena Schröder (Sweden), Rannveig Traustadóttir (Iceland), Eskil Wadensjö (Sweden) and Mandana Zarrehparvar (Denmark). Additionally the Nordic research team has benefited from the support and guidance from three international experts: Ed Berendsen (Dutch National Social Security Administration), Jan Monsbakken (Rehabilitation International) and Roy Sainsbury (University of York). The research team has been coordinated by Rune Halvorsen and Bjørn Hvinden at NOVA Norwegian Social Research.

The research team has met five times during 2011-2013: in Stockholm, Copenhagen and Oslo. Three of the workshops were organized by generous support and assistance from the Danish Institute for Human Rights. Two of the workshops were organized in collaboration with the Nordic Centre of Excellence - Reassessing the Nordic Welfare Model (REASSESS) which had received funding from NordForsk to organize two workshops on the transition from school to work. The two workshops included a larger number of junior and senior experts from the Nordic countries and other European countries. We appreciate the discussions with these other colleagues about our data collection and analysis. 
In preparing this report we have benefited from additional funding from the Research Council of Norway, the project "Trygd i kontekst Rettferdighet, Effektivitet, Fordeling" (TREfF).

Time series data have been purchased from the Nordic statistics bureaus in Denmark, Finland, Norway and Sweden. In collecting the data we have benefited from the assistance of Christian Raunkjær, Jonas Kylov Gielfeld and Sofie Weiskopf (Statistics Denmark), Veli Rajaniemi and Topias Pyykkönen (Statistics Finland), Bjørn Olsen and Bjørg Rydh (Statistics Norway), and Peter Beijorn (Statistics Sweden). While we aimed to collect statistics from Iceland the capacity to provide relevant figures appears to have been limited in their national statistics bureau. The EU-SILC data on disability and comments to the EU-SILC data have been provided by Susan Kuivalainen and Kati Ahonen.

During the project life-time we have benefited from the support and assistance of the secretaries of the Nordic Committee of Senior Officials for Labour, Finn Ola Jølstad, Mattias Nilsson and Tryggvi Haraldsson.

We are grateful for all the comments and suggestions we received from the Nordic Committee of Senior Officials for Labour to a draft version of this report. We have sought to take these comments and suggestions into considerations when amending the document. The responsibility for remaining shortcomings remains with us.

Oslo, November 2014

Rune Halvorsen and Bjørn Hvinden 


\section{Introduction: Changing conditions for labour market inclusion}

This report examines changes over time among two categories of young adults that have experienced particular difficulties in achieving and retaining paid work in the ordinary labour market: youth with family background from non-Nordic countries and youth with disabilities in the Nordic countries. The report identifies processes and mechanisms enabling or preventing the labour market prospects of the two youth groups. The report focuses on policy measures aiming at tackling demand-side barriers to employment for the two youth groups.

This chapter argues that inclusion in the labour market depends on several interrelated processes. First we examine the changing conditions for labour market participation. Second, we identify the challenges for the labour market inclusion of young adults. Third, we explain the policy relevance of comparing the Nordic countries. Fourth, we account for the more specific aims and scope of the report and the choice of terminology. Fifth, we conclude by summarising what the report aims at.

\subsection{Changing conditions for labour market participation}

The transition from industrial society to knowledge society has changed the conditions for entering the labour market and in this respect becoming "adult", i.e. economically independent and being consider a responsible citizen (Bell 1973, Stehr 2004). The transitions from school to employment seem to have become more difficult or variable. Larger demands for complex skills, individual management of the work-life balance and 
needs updating of skills have forced young adults to more active planning of their future and anticipation of the risks involved in their transitions between education, training and employment. Different from the early 1900 s the transition from education to work is not any longer necessarily a linear one-way process but involves more complex dynamics between education and work (e.g. circular processes or combinations of educations and work) (Allen and Velden eds. 2011).

Changing occupational structures and new skills requirements have changed the conditions for inclusion of young adults in the economy. The knowledge-based economy is different from the industrial economy after the Second World War in the sense that knowledge plays a greater role as the driver of economic growth and productivity. With the changes in occupational structure, increasing demands for communication skills and social skills in the work place, competence in information processing and knowledge production, the conditions for participating in the labour market have changed. Transitions from education to work have been postponed and entrance criteria to the labour market have changed with the increasing expectations to higher and more formal education. Such expectations stimulate longer total periods in education and together with the more prominent role of temporary or precarious jobs they delay many young people's establishment both in labour and housing markets.

In knowledge society education is becoming increasingly important for the competitiveness of the European economies and consequently for the sustainability of current levels of income and welfare provisions in these countries. The Nordic countries are no exception. The educational level of the labour force is crucial to be able to process and develop new knowledge and information, and transform the expertise to goods and services that people have reasons to demand. As the new knowledge economy rest on a skilled and flexible work-force that easily adapt to rapidly changing needs in the economy, young adults are exposed to new expectations and conditions to succeed in the labour market.

Inclusion in the labour market is not one single transition but depends on several interrelated and largely parallel transitions; from education to paid work as main activity, from living in parents' household to being established in your own household, from being off-spring of your parents to having your own family and off-spring, from being dependent on par- 
ents advice and support to being economically independent and making independent choices. Overall these transitions tend to take longer time than before and difficulties in one may delay others. For instance, having children before you have finished education delays the completion of education and achievement of paid work. Fluctuation between paid work and education, temporary positions and part-time work has been associated with risk of financial dependency of parents or social security benefits for shorter or longer time spells. Lack of affordable and relevant accommodation affects geographic mobility and consequently the ability to seek higher education and find paid work. Similarly a segregated housing market is likely to be associated with systematic differences in appreciation of education and school performance depending on social class (parents' education, income and occupation) and differences in language skills between kindergartens, schools and after-school programmes.

\subsection{Challenges for the labour market inclusion of young adults}

The complexity of the transitions is associated with four interrelated challenges for the labour market inclusion of young adults: school drop-out, lack of employment opportunities, labour market segmentation and early exit and termination of contracts.

First, in knowledge society school drop-out has become a challenge in itself. Educational reforms in the Nordic countries have changed the balance between theoretical education and vocational training, including the availability of apprenticeship schemes, giving more emphasis to theoretical knowledge at the expense of practical skills even in vocational subjects in secondary education (post compulsory education). Not only has the content changed. Also the duration (longer formal education) and organisation of the education (more "tailor made" educational trajectories taking into account the talents and interests of the individual) have changed in many countries. Yet, despite such educational reforms more pupils and students are at risk of dropping out from school.

Second, young adults within sufficient qualifications and low formal qualifications risk being conceived as unattractive and unqualified for the 
job by employers. As the number of jobs available for unskilled workers has declined students with incomplete compulsory education and/or higher education or weak school achievements may have problems in entering the labour market. They face a lack of employment opportunities and risk entrapment in active labour market training programmes not necessarily providing qualifications to ordinary paid work. A particular case is immigrant youth who experience difficulties in having their foreign education recognised in their new host country. Other young immigrants experience unreasonable or disproportional skills and proficiency requirements related to the dominant language in the host country.

Another reason for the lack of entrance opportunities for young adults have been discrimination on grounds of inter alia ethnic origin, religious belief or disability in regard to recruitment and hiring of employees. Research has demonstrated the prevalence of negative valuation in the market place of personal characteristics of the worker that are unrelated to worker productivity, i.e. employers emphasising personal characteristics that are irrelevant for the job performance (Arrow 1973). According to US economist Garry Becker (1957) discrimination arises because employers are unable to observe directly the productive ability of individuals and therefore use characteristics such as gender, disability, or "race" as proxies. Based on ignorance or prejudice the employer assumes that certain groups of workers are less productive than others and is therefore less likely to hire them, or pay them a wage or salary that fairly reflects their productivity, experience and applicability for a particular job.

Third, a related problem is that especially young adults with difficulties in entering the ordinary labour market are at risk of entrapment in temporary contracts, and low paid and unskilled jobs. As young adults are making their way from education and training to employment, the period of transition may be of some duration. Such experience of short-term transition problems, sometimes referred to as "frictional unemployment", can be due to imperfect coordination of demand and supply in the labour market and resulting from employers and job-seekers having incomplete information about each other. Young adults seeking full-time work for their first time may lack resources to finding the company that has a position that is both available and suitable for him or her. In other cases, employers may abstain from hiring new staff due to difficulties in recruiting 
qualified individuals. However, a long period of transition from education to employment can have detrimental effects for the individual's further their life-course. Such transitions from education to employment are more likely to prolong in periods of economic recession.

Fourth, young adults are at risk of early exit and termination of employment contracts. In periods of economic recession young adults risk being hit first and hardest. If employers are reducing their workforce to adjust to a lower turnover, young adults without work experience are less likely to be hired and - due to seniority rules in many countries - often the first to be dismissed from their employment contract.

Another reason for early exits is the exclusion risk inherent in treating all employees in the same manner. On occasions an individual's characteristics such as gender, religion, belief or disability can result in the inability to perform a particular function of job unless the difference is accommodated by the employer (Waddington 2007: 631). Young adults with care obligations, ethnic and religious minorities and/ or disabilities may require "reasonable accommodation" of the work place, working hours or tasks to be able to perform the main functions. In general terms, to accommodate means to take something into consideration and let this consideration influence social arrangements, i.e. the workplace. The term reflects a claim for the need to move beyond tolerating and respecting difference to actually accommodating and taking into consideration the difference. The argument is that simply being treated in the same way as others may result in exclusion from the workplace, whereas different treatment could be essential to achieving equal opportunities in occupation and employment. The emergence of accommodation as a legal duty means that duty bearers need - within reasonable limits - to treat relevant individuals differently from the way in which they treat others (ibid.).

Lack of recognition or acceptance of diversity in the workplace may further that employers or co-workers believe the employee in question does not fit in or live up to the expectations of co-workers. If the diversity in an employee's needs is not accommodated the employee may find it impossible to continue working for the employer or the employer may come to see the lack of conformity with the standard way of performing the job as a reason to release the person from the employment contract. 


\subsection{Consequences of exclusion from the labour market}

For various reasons the four interrelated challenges for the labour market inclusion of young adults in the Nordic countries (school drop-out, entrance troubles, segmentation and early exit) have given rise to concern among national, regional and supranational policy makers. Unless today's young adults are able to establish themselves in the labour market the next generation's labour force will decrease and fewer people will contribute to the economy, be economically independent and able to pay taxes.

Young adults excluded from the labour market are at risk of becoming dependent on social security, especially means-tested minimum income support (Hammer and Julkunen, 2003). Due to scarce employment experience and weak entitlements to social insurance benefits young adults out of paid work tend to be at high risk of relative poverty (Kuivalainen and Nelson, 2012). Young adults with long-lasting welfare dependency and inactivity (neither in education, training nor employment) have larger risks of recurrent time spells of unemployment and remain in unskilled, part-time and temporary work (Nilsson and Bäckman, 2014, Hammer and Hyggen, 2006). The young adult is also at risk of learned dependency on public welfare. Proponents of discouraged workers theory have argued that persons with marginal or no attachment to the labour market may prefer social security to employment not so much because of the economic disincentives as because of the secondary gains and self-protection of avoiding exposure to new and degrading experiences of failure or shortcomings in the labour market, or they assume that no work is available to them (e.g. Bjørnstad 2006). Associated with this, young adults with low educational attainments and no or little work experience have risked permanent exclusion from the labour market (Bell and Blanchflower 2010; 2011).

A key concern is the prevalence of self-reinforcing mechanisms implying that initially short-time and apparently insignificant incidences of school drop-out, periods of unemployment or inactivity will set off a vicious circle leading to discouragement, skills-deterioration and stigma, which again exacerbates the degree of detachment from work and education (Raaum et al. 2009:173). The idea that some unemployment some- 
times leads to more unemployment is empirically well established, particularly for youth (Kieselbach 2004, Raaum and Røed 2006). Aside from the social degradation and discouragement associated with joblessness, there is a "scarring effect" whereby the experience of unemployment reduces employability (attractiveness in the labour market); skills gained in training depreciate when they are not used and employers are deterred from hiring applicants who show extended periods of unemployment (Bell and Blanchflower 2010, 2011; Fagan et al. 2012:135).

For young adults education is a source of self-worth and pride in itself and considered appropriate for their stage in life and in line with dominant expectations to sequencing of life events. Until their twenties schooling is conceived as appropriate and the students are considered fulfilling social obligations to acquire professional skills and increase the competence to be able to participate in the labour market. However, during their twenties young adults are usually expected to achieve paid work. For young adults who fail to succeed in education and/or employment the social costs (social devaluation, stigma) are high, especially in societies with high rates of persons completing post-secondary education and high employment rates, such as the Nordic countries.

\subsection{The Nordic model of labour market inclusion}

In general, Nordic labour markets have been characterized by high employment rates compared to other European countries in the population aged 15-64.

Table 1.1: Employment rate in different age cohorts. 2012. Percent

\begin{tabular}{lccc} 
Country & Age 15-64 & Age 20-24 & Age 25-29 \\
Iceland & $78.3-87.1$ & $66.5-80.3$ & $72.4-87.3$ \\
Norway & $71.9-78.1$ & $58.7-72.8$ & $76.5-83.9$ \\
Denmark & $73.6-77.9$ & $66.5-74.6$ & $73.2-83.3$ \\
Sweden & $68.3-74.4$ & $49.3-63.7$ & $70.3-80.6$ \\
Finland & $59.7-71.1$ & $41.5-65.1$ & $65.9-79.3$ \\
EU12 average & $59.5-66.8$ & $51.1-57.8$ & $69.7-75.7$ \\
\hline
\end{tabular}

Source: Eurostat LFS Database 2013. 
Also for young adults in general the employment rates were higher in the Nordic countries than in most other European countries. For young adults of age 20-24 the employment rates were highest in Iceland, Denmark and Norway while Sweden and Finland were closer to the EU27 average. For young adults of age 25-29 the employment rates were highest in Iceland, Norway and Denmark while Sweden and Finland were closer to the EU27 average (Table 1.1).

The Nordic welfare model has largely made the individual independent of the family, e.g. public authorities have to a larger extent than most other European countries assumed responsibility for providing care services for the sick and elderly and for kindergartens for children (Esping-Andersen 1999). For such reasons women have more easily been able to participate in the labour market and earn their own social rights from labour market participation rather than relying on a male breadwinner model (Ellingsæter and Leira 2006).

Since the 1960-70s the Nordic governments have adopted accommodation duties for employers in relation to pregnancy, maternity and parental leave. Such accommodation of the needs of parents and caregivers has contributed to comparatively high employment rates among Nordic women. The last couple of decades the employment rate among Nordic women has been the highest in Iceland (76.2-83.8\%), Denmark (67.0-74.1\%), Norway (67.7-75.4\%), and Sweden (66.4-72.6\%) while Finland (58.1-69.0\%) has been closer to the EU12 average (48.8-59.6\%) (Eurostat LFS Database 2013). At the same time the Nordic labour market has been more gender segregated than many other European countries. A large proportion of Nordic women work part-time and in public sector, especially in education, health and social services (Jensberg et al. 2012, Teigen 2010).

Of the Nordic countries Iceland had the highest employment rates in all age groups both among men and women during the 1990s and 2000s, even after the financial crisis which hit Iceland particularly hard in 2008. Compared to other European countries the Nordic countries have had high employment rates both among young men and women. Since 2008 the Nordic have experienced much less unemployment and inactivity among young adults than the crisis-ridden Southern European welfare systems.

Why then bother to examine the Nordic labour market inclusion policies and how they fare in terms of youth inclusion? Although the global econom- 
ic turbulence of recent years hit the Nordic countries to a lesser extent than other European countries several lessons can be learned by examining the Nordic experiences. Four observations are relevant in this regards:

First, the relative success of the Nordic countries makes a case for examining the policy lessons and scope for policy learning and transfer for non-Nordic countries. We may ask what the Nordic countries have done to maintain high employment rates, even among young adults.

Second, given that the Nordic countries have been relatively prosperous and in advantaged economic situations compared to other European countries they ought to have been financially well positioned to deal with the difficulties in ensuring effective transition from education to employment for young adults with different needs and abilities. The question is how the Nordic countries have spent their resources and to what extent they have succeeded in including all youth groups in the labour market.

Third, we find not insignificant differences between the Nordic countries in their employment rates for young adults. To the extent that the Nordic countries differ in their labour market inclusion policy we identify the scope for policy learning and transfer between the Nordic countries, and what policy lessons can be learned from the cross-national comparisons for other and non-Nordic countries.

Fourth, while young adults in the Nordic countries in general have been in a more advantaged position than their peers in other European countries, the position of Nordic youth who are neither in employment, education nor training (NEET) are likely to have been more ambiguous. Social control mechanisms are likely to take other forms in prosperous welfare states and work-oriented societies than in societies with low employment rates and mass unemployment. In a country with a predominantly wealthy population and high employment rates the life situation of young adults out of paid work and with low formal qualifications can easily come to be seen as self-inflicted.

Especially in the service-intensive and activation-oriented Nordic welfare states young adults out of paid work and regular education have probably been more exposed to the help, control and moral concern of others. In other words we assume that Nordic youth out of paid work and regular education in certain respects have met more formal help and social control than young adults in countries with mass unemployment and 
welfare states giving lower priority to active labour market measures. Different from the Nordic countries, youth in less prosperous countries and small welfare states may subjectively or objectively lack resources or be out of paid work, but nevertheless not be conceived as in need of help or assistance by others (Hvinden 1995).

\subsection{Scope of the present report: focus on social regulation}

As the Nordic countries are shifting towards advanced knowledge societies where high levels of education, research and innovation are the keys to continued growth and competitiveness in the market, low education and poor school performance are main barriers to inclusion in the labour market. Given structural changes in the market we may ask whether the educational systems in the Nordic countries are able to furnish groups at risk with the qualifications they need to find suitable jobs. Additionally we may ask if we find systematic differences in employment rates which cannot be attributed to differences in school performance and education. The present report is mainly focusing on responses to the latter, i.e. social regulation of the demand side in working life.

When we in this report use the term "social regulation" we basically refer to three kinds of policy measures aiming to enable minority ethnic youth and youth with disabilities to find and retain suitable employment: policy measures to prevent negative discrimination (ensure difference blindness), policy measures to compensate for disadvantages in a transition phase through affirmative action programmes (quotas, wage subventions, targeted training programs) and policy measures to provide reasonable accommodation of employees' needs in working life. The report examines under which conditions social regulation provisions are most likely to enhance the labour market inclusion of minority ethnic youth and youth with disabilities, in the context of other provisions of significance for these two groups.

While the project started by asking what practical impact social regulation provisions have on the employment opportunities and prospects of minority ethnic youth and youth with disabilities, the team has increasingly 
discussed how the outcomes of social regulation needs to be considered as interacting with differences between the Nordic educational systems (e.g. degree of selectivity and work experience within the school system), redistributive social services (especially active labour market training), and social benefits (income maintenance schemes). The report takes into account the role of existing redistributive arrangements and possible synergies or incompatibilities between regulatory and redistributive provisions.

Nevertheless, as much as the redistributive influence employment opportunities and prospects of disadvantaged youth groups, the main focus of this report is on the role of social regulation policies (legislation, financial incentives, information) and their functional equivalents (informal norms and expectations about employers' duties).

By focusing on the cross-national comparison of the Nordic welfare systems we are able to analyse variation in policy, legal design and impact within a group of countries with a more or less shared priority given to redistribution-oriented provisions (both social benefits and services). Additionally they have largely similar responses to supranational and domestic expectations to adopt new and statutory social regulation instruments to ensure non-discrimination in the labour market. At the same time we are taking into consideration the variation in overall performance between the countries and the specific combination of policy elements in each of the five countries.

Based on combined analyses of new statistical data, legal developments and interview data, the report explores the overall significance of social regulation (wage subsidy schemes, non-discrimination legislation, reasonable accommodation, employment protection, voluntary agreements) and their functional equivalents (informal norms and expectations about employers' duties or corporate cultures internalizing such obligations) in promoting labour market inclusion of young adults. More specifically the report examines what impact social regulation provisions have had on the employment opportunities and prospects of persons belonging to two vulnerable youth groups: minority ethnic youth and youth with disabilities. 


\subsection{Why compare disability and ethnicity?}

According to a popular notion of equal opportunities all people should be treated in the same way to ensure fair competition in the labour market. This notion overlooks that in many instances, treating persons who find themselves in different social and economic circumstances in exactly the same way will reproduce or even reinforce such differences (Kymlicka 2002, Lawson 2008). Difference blind rules may disadvantage minority ethnic youth and young adults with disabilities in relation to the majority population youth. In these cases, equality in labour market participation can only be achieved by treating different persons in dissimilar ways. Accommodating or compensating for the initial differences between these persons is not only a question of different values and wants, but of recognizing different social and economic conditions.

So far the literature has not systematically examined how the legitimacy (recognition or misrecognition) of minority ethnic youth and youth with disabilities have impacted the accommodation of their needs in the Nordic countries. Our report aims to cover this gap in the literature.

The report assesses the case for seeing misrecognition and lack of accommodation as significant factors behind troubled transitions from school to work, and the case for regarding social regulation (or selfregulation) as important ways of preventing, counteracting and correcting exclusionary factors in the transition from school to work in the Nordic countries. Focusing on the cases of minority ethnic youth and youth with disabilities the report examines how the legitimacy (recognition or misrecognition) of the two target groups influences the design and implementation of public policies to promote labour market inclusion.

Following Schneider and Ingram (1993) we may ask to what extent the social construction of ethnic minority youth and youth with disabilities influence the design and implementation of the labour market inclusion policy. Target groups of welfare policy measures tend to be attributed rights and duties, benefits and burdens dependent on whether they are conceived as responsible citizens making valuable contributions to society, persons who are worthy of help and assistance from others, or as immoral persons and scroungers of the welfare state. 
If a person is believed to be the cause of his or her own disability policy makers may view the person as irresponsible. In contrast, an external reason of the disability suggests nothing about the integrity or character of the individual. This is consistent with the existing social psychology literature which demonstrates that, in a variety of contexts, external attributions of responsibility for an event lead to a greater willingness to provide help and assistance (Mitchell and Kovera 2006).

Social regulation to ensure equal opportunities for ethnic minorities and persons with disabilities has evolved in analogy. As the first country to adopt social regulation to ensure equal opportunities the US first adopted such policy measures to protect and promote the inclusion of minorities and later adopted the same legal principles to protect and promote the inclusion of persons with disabilities. Affirmative action programs to end discrimination of ethnic minorities in working life was first adopted in the US in 1961. Later the 1964 Civil Rights Act outlawed discrimination in employment. The term "reasonable accommodation" was born in the United States and was first adopted in 1972 as a duty to accommodate the religious beliefs of employees. Later the 1973 Rehabilitation Act and accompanying administrative regulations required executive agencies to practice non-discrimination, affirmative action and reasonable accommodation for persons with physical or mental impairments, current or past, or only imagined (Dobbin 2009:38, Lawson 2008:5). Later this kind of social regulation has been introduced or reinforced in the EU member states and Norway by the adoption of the EU race directive (EC/43/2000) and the employment framework directive (EC/78/2000).

For a long time, Nordic governments, researchers and the affected groups framed disability policy in terms of "welfare", "redistribution" and "capacity-building", while the same actors tended to frame ethnic minority policy in terms of "multiculturalism", societal recognition and intergroup justice. Yet, even disability law and policy have to an increasing extent been based on notions of discrimination, misrecognition and oppression and modelled as parallels to the social regulation policy developed in the context of ethnicity and ethnic relations.

Disability is different from ethnicity in the sense that many persons with impairments behave, work, speak and walk differently from others or have a reduced working capacity. Despite the continuing discussion 
about the "social construction of disability" we often find visible and tangible differences between persons with and without disabilities (Shakespeare 2006). These differences may be job-relevant and require to be accommodated to enable to person with a disability to contribute equally at the workplace. The need for accommodation at the workplace will usually be less of a concern in the case of ethnicity, although e.g. demand for opportunities to observe religious rituals during or outside the work day may require accommodation on the part of employers. How and to what extent such differences between ethnic minority youth and youth with disabilities are reflected in the policy design and implementation in the Nordic countries will be examined in the next chapters of this report.

\section{7 "Minority ethnic youth" or youth with "immigrant background"?}

A recurring question during the preparation of this report has been how we should refer to youth with background from non-Nordic countries as "minority ethnic youth" or youth with "immigrant background". Is it more relevant to emphasise that they represent and are members of a minority culture or that they have (family) background from of a different country? The question is whether we want to focus on the responses from the majority population to differences in culture (language spoken between the group members, religion, customs and traditions, norms and values, clothing) or the transitions from a foreign country to the new host country (validation of foreign education, acquirement of language skills, education, housing and settlement, adjustments to the new labour market). Obviously the two processes are interrelated: the responses from the majority population is likely to depend on the how successful the transition to the new country is. Newcomers who learn to master the dominant language of the new host country are more likely to receive positive response from the majority population. Likewise, the coping strategies adopted by the newcomers in their efforts to acquire knowledge of the dominant language, achieve recognition of foreign education or follow education in the new host country, and achieve paid work are likely to be adjusted to reactions from the majority population. 
When referring to the population as "minority ethnic youth" we are interested in the reactions of the majority population; e.g. to what extent the particular needs of the individuals as members of specific cultures be acknowledged in the workplace. As argued by Charles Taylor (1992) "our identity is partly shaped by recognition or its absence, often by the misrecognition of others, and so a person or group of people can suffer real damage, real distortion, if the people or society around them mirror back to them a confining or demeaning or contemptible picture of themselves." Social identity is not achieved monologically. Rather ethnic groups are socially constructed and maintained through interaction between members of society.

If we focus on the transition to the new host country the immigration ("foreign background") is more relevant. From this perspective the focus is on whether the individual manage to achieve sufficient knowledge of and master the dominant language, sufficient formal qualifications and eventually paid work. One concern is whether we find differences in school performance and labour market participation dependent on the country they immigrated from and whether such differences persist in the next generation. A second concern is whether the individual is provided with the necessary resources and opportunities to participate as full members in all arenas of society - including the labour market. Although this does not preclude an examination of intermediary mechanisms (e.g. the coping strategies adopted by immigrants and the reactions of the majority population), the focus is to a large extent on the individual and their abilities to adjust to the needs and requirements of the new country.

A risk inherent in this perspective is that issues of recognition of collective rights as a cultural minority is ignored or less focused upon. In a Nordic context "ethnic minorities" have more commonly been used to refer to national minorities and indigenous populations with a long history in the country. Persons with parents who have immigrated from other countries have more easily been referred to as "second generation immigrants" rather than ethnic minorities. For the majority population or official representatives of society a concern has been whether population groups who more recently have arrived in the country has legitimate demands to group rights equal to those of the Sami population, Jews or Roma or rather should be considered as individuals irrespective of any 
group affiliation or identity. From the perspective of the persons who have immigrated it has been a concern how long they need to live and work in the country before they are recognised as full members of society, and on whether their cultural differences are respected.

When examining the practical impact regulatory social provisions have on the employment opportunities and prospects of stigmatized young adults we are interested in the interaction between the majority and minority population, i.e. the action choices and counter-actions (reactions) of the minority and majority population. This suggests that "ethnic minority" is the more relevant term. At the same time and vexing with this we examine how regulatory social provisions interact with education, vocational training and other services in cash and in kind. Previous research has examined the impact ("effect") of education on the prospects of labour market participation and whether differences in education level and school performance disappear from parents who have immigrated to the next generation who are native born ("second generation immigrants"). Our report discusses the relevance of the findings from research on education for our assessment of the practical impact regulatory social provisions.

As our main focus and concern is with the reactions from the majority population to differences in culture in ensuring inclusion in the labour market we find it more accurate to refer to "minority ethnic youth". The policy analysis and our in-depth interviews with young adults and employers provide data on this. As is often the case in statistical analysis, our quantitative data only provide information about country of origin and not self-definition or culture (language, religion, life-style) as such(Heath et al., 2008: 214). ${ }^{1}$ The choice of terminology depends, however, more on the perspective and research questions addressed than the data that are available per se.

\footnotetext{
1Jonsson 2007: 463 argues that available survey and register data makes it impossible to identify ethnic groups in Sweden. He also refers to that under the Council of Europe framework convention for the protection of national minorities only Finns, Finns from Tornedalen, Sami, Romanies and Jews are recognised by Swedish authorities as national minorities. While we agree that the official classifications are relevant for the analyses we would argue that they should be considered as social constructions in need of interpretation and not be taken for granted.
} 


\subsection{Concluding comments}

This chapter has argued that inclusion in the labour market depends on several interrelated processes. Given the complexity of the challenges for the Nordic welfare states we are not likely to be able to identify single solutions that would "solve" the problem. Rather what we can hope for is to achieve a better understanding of the interdependencies between policy measures. At best we might be able to identify general principles that may guide the policy design and implementation.

To answer the main question - under which conditions social regulation is most likely to be effective - the report proceeds as follows: Chapter 2 accounts for the overall analytic framework for the report as a whole. Chapter 3 accounts for the data collection. Chapter 4 identifies main features in Nordic labour market inclusion policy the last two decades. We examine cross-national similarities and differences in the design of the social regulatory and redistributive provisions of relevance for the labour market inclusion of minority ethnic youth and youth with disabilities in the Nordic countries in the early 2000s. Based on time series data Chapters 5 and 6 analyses the statistical evidence available about the outcomes of the labour market inclusion policies in the Nordic countries for youth with disabilities and minority ethnic youth the last decade. In Chapter 7 we consider how young adults and employers respond to the different policy measures and the strategies they adopt to pursue outcomes that they value and have reason to value. Chapter 8 concludes by summarizing the main findings and provides recommendations for future directions in Nordic social protection policy to enhance the labour market participation of vulnerable youth groups. 



\section{Understanding the policy mix}

An analysis of the challenges faced by the Nordic countries in promoting employment among young adults requires a theoretical understanding of the social construction of social protection policy. By social protection policy we have in mind the totality of policy measures with the aims to foster quality of life and opportunities for participation. The report examines such policy measures and their interdependencies or interaction to the extent that they have intended and unintended effects for the labour market participation of young adults.

In Chapter 1 we argued that the inclusion of young adults in the labour market depends on several and interrelated and largely parallel transitions. A number of policy measures influence those transitions in multiple ways. To fully understand whether and under which conditions public policy achieve its goals we examine how countries combine different policy measures and establish under which conditions we are most likely to find synergies between the different policy measures. The overall policy approaches of Nordic countries have been shaped by different national policy traditions, division of responsibilities and sets of actors participating in the design and implementation of the labour market inclusion policies for young adults.

By comparing the system of social protection policies in the Nordic countries, this report clarifies the strengths and weaknesses of existing approaches and the scope for policy learning and improvements. For this purpose we distinguish between three subsystems of social protection policy with intended or unintended consequences for the participation of young adults in paid work.

- The social benefit subsystem aims at providing income security for young adults out of paid work, at redistributing monetary resources, and compensating for higher expenses (e.g. child care, medical treatment, diet, transportation, heating). The subsystem aims to 
ensure that the person is equipped with the necessary resources to achieve or return to paid work, and is able to live a life a according to prevailing standards in the country. By guaranteeing a safety net the policy measures aim to avoid that the person become socially isolated and exposed to deteriorating health conditions and thus larger difficulties in (re)entering the labour market.

- The social services subsystem aims at providing benefits in kind to young adults to compensate for various disadvantages and enable them to participate in the labour market and other sectors of society (e.g. education, training, personal assistance, assistive technology, public child care, health services)

- The social regulation subsystem involves government efforts at influencing the functioning of markets and the behaviour of employers with the aim of promoting labour market participation for young adults (e.g. employment protection, legal protection against discrimination, legal duties and financial incentives for employers to provide reasonable accommodation, affirmative action measures, quotas, wage subsidies for trainees and employees with reduced work capacity, voluntary agreements between employers, trade unions and public authorities with the aim to promote labour market inclusion).

Both the social benefit and services subsystems aim at redistributing resources among differing population groups and equalizing their life chances. The provisions are usually financed by general taxes or contributions from the protected person and employers.

By contrast, social regulation policies aim at remedying market failures. Governments seek to influence the labour market and their functioning as well as the behaviour of employers, e.g. by setting legal standards for health, security and labour protection in the work place (Majone, 1993; Jordana and Levi-Faur, 2004:3; King, 2007: 67, 107). While policy measures for social regulation may take different forms, many of them follow the distinction between legislative means, financial incentives and persuasion through information (Etzioni, 1961; Vedung, 1998). 
Each type of policy measures depends on different assumptions about how one may influence non-governmental actors. Legislation presumes that it is possible to force actors to behave in certain ways, or at least prevent them from behaving in unwanted ways, given the prospects of punishment if they do not comply with the rules. Financial incentives presuppose that it is possible to encourage actors to act in certain ways, even if they do not have to, because such measures are cost-effective or profitable. Persuasion through information presupposes that it is possible to have actors behave in a certain manner by convincing them of the intrinsic benefit derives from compliance, that it is morally and normatively right to do so, and that it would adversely affect their conscience and self-respect if they did not comply with the moral standards of society ("name and shame").

While redistributive provisions mainly address the supply side in the labour market, regulatory provisions address the demand side. Redistributive provisions involve social security during periods outside employment and provisions to improve the employability of persons outside the labour market. To the extent that employers do not recruit, hire, accommodate, promote, and retain disadvantaged young adults, public authorities may respond by providing social security benefits or other resources required to enable the person to participate in the labour market and meet the requirements of potential employers (e.g. through education, vocational training, personal assistance, assistive technology). Alternatively or additionally, governments may seek to increase the employment prospects of groups at risk by changing the behaviour of employers through legislation, financial incentives, and persuasion strategies through information (Bemelmans-Videc et al., 1998).

Of particular interest here are provisions aiming to prevent discrimination and failure to provide accessible work places and appropriate accommodation, on the part of employers. The last decade the Nordic countries have to various extents introduced legislation and voluntary agreements to prevent discrimination on grounds of ethnicity, religion and disability, often influenced by policy developments in the EU and policy learning from the UK and USA. We basically refer to three kinds of provisions aiming to enable persons belonging to ethnic minorities and persons with disabilities to find and retain suitable employment; (i) legal provisions giving employers possibilities and constraints regarding hiring and 
firing, (ii) government-created financial incentive structures for employers, and (iii) voluntary agreements and commitments to an corporate culture promoting recruitment and accommodation of the workplace to promote diversity in the workforce.

Figure 2.1: Social Protection Policy as a System

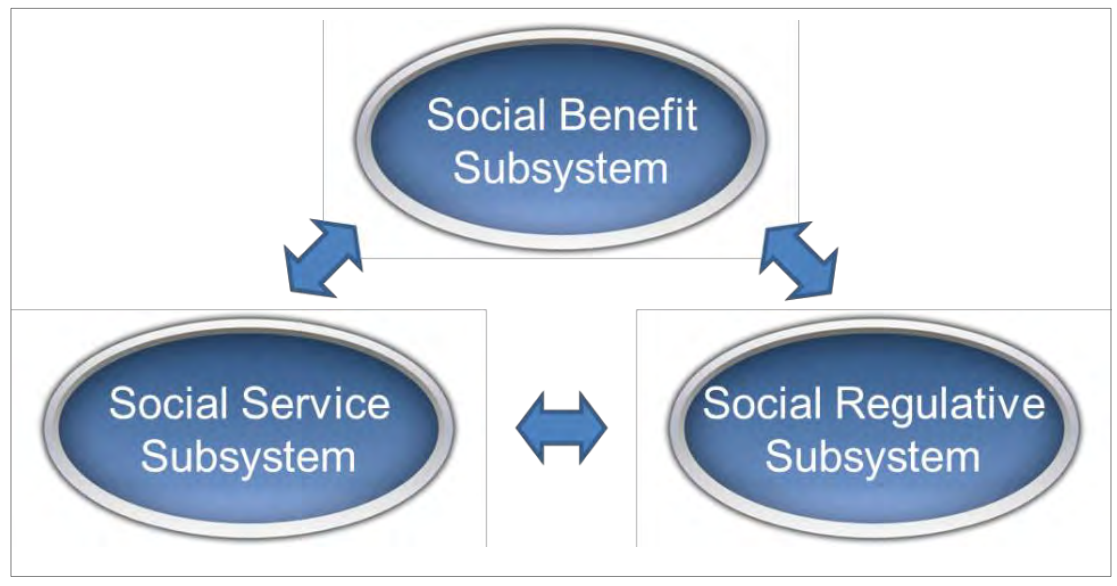

As Figure 2.1 suggests, we regard Social Protection Policy as a "system" in the sense that the three subsystems are interconnected and interdependent with the effect that changes in one part are likely to have consequences in the two others, whether by design (with intent) or default (without intent). Whether policy measures in one subsystem further increases in the labour market participation of young adults depends on the effects of the two other subsystems. The social benefit system may provide economic incentives for social security claimants to seek paid work and cover expenses to services which make it easier and realistic to achieve and retain paid work. The effects of the policy measures in the social benefit subsystem depends, however, on the provision of education and training and other service in kind and whether the regulatory policy measures succeed in influencing employers' behaviour.

This report undertakes a systematic investigation of these connections and dependencies and their implications. Particular attention will be given to whether the Nordic countries have the right balance between the different subsystems to promote labour market participation by young 
adults. While sector specific analyses are numerous and offering important insights, the broader picture has often been missing. The crossnational and comparative literature on the interactions between the three subsystems and their impact is still limited (Halvorsen and Hvinden, 2009). This report aims at rectifying this gap in the current literature.

The distinction between the social benefit system, social services system and social regulation subsystem is analytic. In actual policy making, the three systems are usually combined, and in practice some policy measures do not fall neatly in one of the two categories redistribution or regulation: e.g. wage subsidies to employers (provision on the supply side) may resemble opportunities to combine social security and parttime work (provisions on the demand side). Although they primarily address the demand side of the labour market, wage subsidies may have some of the same effects as individuals' opportunities or obligations to combine social security and part-time work.

Arguably one could see financial schemes aimed at compensating the extra expenses of employers (relating to accommodation of the workplace, training of employees with immigrant background, perceived or actual lower productivity among employees with disabilities) as redistribution of resources among employers. However, we primarily analyse policy instruments on the basis of their primary objective and not their possible unintended side-effects. For the purpose of our analysis, we will regard financial subsidy schemes aimed at changing employers' behaviour as regulatory measures.

\subsection{Social regulation and recognition of diversity}

Recognition of diversity in the labour market and the labour force implies a focus on the relational processes behind the difficulties in achieving and retaining paid work for vulnerable youth groups. Such processes have included denial of worthiness, silencing, assimilation and discriminatory practices. Difficulties in achieving and retaining employment in considered a result of the processes, mechanisms and interaction patterns, coping strategies, reactions and counter reactions of the young adults, co-workers and the employers, or more broadly the interaction 
between the vulnerable youth groups and their social environment. An underlying assumption has been that we find unequal relations of power in the opportunities to define the criteria for being included in the labour market reflected in the dominant assumptions about the work capacity of minority ethnic youth and youth with disabilities and to what extent they fit in at the workplace.

On occasions an individual's characteristics such as sex, religion, belief or disability can result in the inability to perform a particular function of a job unless the difference is accommodated by the employer (Waddington 2007: 631). Minority ethnic youth and youth with disabilities may require accommodation of the work place, working hours or tasks to be able to perform the main functions. In general terms, to accommodate means to take something into consideration and let this consideration influence social arrangements, i.e. the workplace. The term reflects a claim for the need to move beyond tolerating and respecting difference to actually accommodating and taking into consideration the difference. The argument is that simply being treated in the same way as others may result in exclusion from the workplace, whereas different treatment could be essential to achieving equal opportunities in occupation and employment. The emergence of accommodation as a legal duty means that duty bearers need - within reasonable limits - to treat relevant individuals differently from the way in which they treat others to promote parity of participation (Lawson 2008).

The trend towards recognition of diversity in the labour market in Europe implies that employers are expected not only to be difference-blind, neutral and non-discriminatory in their recruitment, training, promotion and retaining of employees. Employers are also expected to take the difference into account and accommodate that difference; i.e. to adopt a differential treatment which takes into account and recognises that the employees have different legitimate needs ("diversity management"). Recognition policy in the workplace or the human resource policy of the employer differs from affirmative action, such as quota programs to compensate for a disadvantaged position in a transition phase before one can return to difference-blindness. Rather recognition policy refers to a sustained policy to protect and foster differences in cultural tradition, belief, religion and/or organize the workplace in a way that appreciates the diversity in human abilities. 
In order to understand the role of social regulation in the on-going reforms in labour market inclusion policy to promote the participation of Nordic youth we need to appreciate the legitimacy of the target group intended to benefit from the non-discrimination policy. We argue that in a Nordic context accommodation of ethnic diversity in the workplace has proved to be more controversial than accommodation of disability. While disability has been conceived as a result of biology, sickness, or accidents ("destiny") and the person cannot be blamed for his or her own situation (particularly when it comes to clear-cut medical diagnosis), many people tend to assume that ethnicity is a "chosen" status; i.e. that the person in question could just choose not to identify with an ethnic minority. According to this perception, people of indigenous, national minority or immigrant background could choose to assimilate to the majority by abandoning their own language and culture ("become Norwegian",), regardless of their different background and visible traits like colour of skin and hair (Kymlicka 2002: 339-40).

First, such regulatory policy measures have aimed at difference blindness to ensure meritocracy based on individual achievements in the labour market and prevent employers from less favourable treatment of job-seekers and employees despite identical productive characteristics ("a taste for discrimination") (Becker 1957). Second, such policy measures have aimed at compensating for a disadvantaged position in a transition phase before one can return to difference-blindness; notably different affirmative action programs (quotas, positive discrimination) to promote the inclusion of underrepresented and vulnerable population groups in the labour market. Third, such policy measures have aimed at accommodating different forms of diversity in lifestyle, self-identity and abilities.

Several observers have noted that while we have seen a relative shift towards recognition in many Western countries, "justice today requires both redistribution and recognition" (Fraser, 1995:2). The labour market has cultural dimensions, expressed in norms and beliefs. Cultural norms and images have been institutionalized (routinized and come to be taken for granted assumptions) in the organization of the labour market, and tend to be biased against some individuals and groups. To ensure that the labour market is inclusive governments need to combine redistributive and regulatory policy measures. As a relative shift towards recognition, 
the field of labour market inclusion policy has become wider and more complex (Williams 1995: 129).

The increasing salience of diversity in public labour market inclusion policy assumes that we not only recognise what makes us all alike but also what makes us different. This diverts from the idea of equality to the law, as some categories of people will be attributed rights not conferred to others, e.g., religious holidays, the use of self-expressive clothing or accessible offices. At the same time, this is based on the principle of universal equality; that we are different but of equal worth (Taylor 1992).

In Europe today we find the clearest and most straightforward practical meaning of accommodation to diversity in the workplace for persons with disabilities. For instance, in order for a person with a physical impairment to be able to perform a work task practical changes in the workplace or other premises may be required. In other cases, persons with impairments may need flexible working hours, the modification of equipment, an assistant or supervisor, or reassessing of non-essential tasks to other employees.

Such accommodation are issues of public policy, as there is usually a need for legislation, voluntary agreements, financial support schemes and/or awareness raising campaigns and guidance of a social regulatory nature to ensure their provision. A common and immediate reaction of many employers is, however, that accommodations are costly and represent a disproportional financial burden for the enterprise. Given that employers have a legal duty to provide "reasonable accommodation" for jobseekers or employees with impairments, this employer has to document or justify that the costs of accommodation are disproportionate. To the extent that public provisions can offer capital grants, subsidies, tax credits or other tax reductions, technical equipment, advice or assistance the employer has less opportunity to plead "disproportionate burden" (Quinn 2010: 267).

The principle of "reasonable accommodation" is embedded in Article 5 of the Employment Framework Directive (EC/78/2000). With the transposition of the directive in Denmark (2005), Finland (2004) and Sweden (1999), the principle has been incorporated in their national legislation, while Norway (2001/2004) has adopted shadow legislation of similar nature. Furthermore, the UN Convention on the Rights of Persons with Disabilities (UN, 2006) establishes denial of reasonable accommodation as a form of discrimination in itself. All the Nordic countries have signed it, 
and Denmark, Norway and Sweden have ratified it. Altogether this means that reasonable accommodation for jobseekers and employees with impairments is not left to the discretion of Nordic employers.

Compared to accommodation of disability, accommodation to ethnic diversity has different and distinct meanings. Accommodation to ethnic diversity may include public recognition of ethnic minorities' observance of religious and cultural practices, and the granting of possibilities for exercising such practices (e.g. rituals like prayers during working hours and time off to celebrate religious holidays), exemption from dress codes (e.g. allowing the wearing of kippa, turban or headscarf at work) and respecting rules for appropriate food (e.g. providing kosher or halal food in the work canteens).

Other forms of accommodation are primarily related to being an immigrant from a faraway country (e.g. adding unpaid leave from work or taking children out of school for some extra weeks in connection to visits to the immigrant's country of origin during the host society's holiday seasons), but many people belonging to the majority population probably perceive such accommodations as "ethnic" and an undue privilege.

While the principle of reasonable accommodation is not explicitly mentioned in the Racial Equality Directive (2000/43/EC), the directive allows for positive action measures "to prevent or compensate for disadvantages linked to racial or ethnic origin". With the transposition of the directive in Denmark (2004), Finland (2003) and Sweden (1999), the principle is incorporated in their national legislation, while Norway (2005) has adopted shadow legislation of similar nature. Furthermore, the UN Convention on the Elimination of All Forms of Racial Discrimination (1965) Article 2(2) contains a certain obligation to protect the equal enjoyment of human rights through the establishment of special measures when the circumstances so warrant. Special measures are defined in article 1(4) as measures taken for the sole purpose of securing adequate advancement of certain racial or ethnic groups or individuals to ensure their equal enjoyment or exercise of human rights and fundamental freedoms. The recommendations of the Committee on the Elimination of All Forms of Racial Discrimination provide practical guidance on the meaning of special measures and more specifically on the scope of the state party obligation to establish such measures (UN 2009). All Nordic countries have ratified the convention. 


\subsection{Labour Market Inclusion as the result of social interaction}

In structuration theory a social system is defined as a set of reproduced social practices and relations between actors. Social systems are relatively bounded social practices that link persons across time and space (Giddens, 1984:25). In line with this perspective we regard "the social protection system" as relatively bounded practices that link actors together across time and space with the aims to foster quality of life, social security and opportunities for participation; we are not only focusing on the rules and resources which frame practices but also the relevant actors and the relations between them. In other words, social systems can be regarded as reproduced social interaction patterns.

The focus on the systemeness of social practices allows examinations of the relations between different loosely coupled practices. When analysing the "systemeness" of Nordic social protection we are interested in how social entities as wholes, comprised of interacting components, are operating in and co-evolving with their environment; i.e. to what extent the policy measures and actors are coordinated, support or contradict each other, and how they evolve within their environment.

While a system perspective may provide a view of the relations between the policies and practices which by design or default influence the quality of life and employment opportunities of young adults, we need a focus on agency to examine how interaction between actors in the labour market (employers, jobseekers) and staff in social services influence the outcome of the policy measures.

If we viewed the social protection policy only from a system perspective (without a view of how the bounded practices are produced and reproduced by social actors) we would risk ignoring how reasoning and purposeful actors influence the social protection policy and its outcomes. Not only do actors have different and sometimes conflicting interests and values. They also have unequal access to symbolic, social and economic resources to pursue their interests.

Efforts to explain the labour market inclusion of young adults solely in terms of relations between policy subsystems would miss out how actors' choices and interaction influence the extent to which young adults man- 
age to achieve and retain paid work. Only by examining the experiences of the employers and vulnerable youth will we be able to achieve a complete picture of the practical impact of the policy measures.

\subsection{Concluding comment}

This chapter has argued that social protection policy can be viewed both from a system perspective and an interactionist perspective. We distinguish between three subsystems of social protection policy which by design or default influence the participation of young adults in paid work; the social benefit, the social services subsystem and the social regulation subsystem. To better understand the policy outcomes we complement the system view of the policy measures by an interactionist perspective on the reactions to the official policy objectives and measures by employers and vulnerable youth. 



\section{Data collection}

Based on combined analyses of new statistical data, policy documents and interview data, the report examines the mechanisms influencing the role of social regulation in Nordic policies to enhance the employment opportunities for minority ethnic youth and youth with disabilities in the Nordic countries (Denmark, Finland, Iceland, Norway and Sweden).

First, we have collected aggregated time series data (surveys and register data) enabling analyses of changes in the rates of education, training, employment, school drop-out and NEET (neither in employment, nor in education nor training) for vulnerable youth groups in the Nordic countries. The data provide descriptive statistics about the development and insight in the factors that influence the activity and in-activity rates. Second, we have collected qualitative interview data which provide insights in the social mechanisms and processes that may account for the development trends and systematic differences we identify in the statistical data. Third, we have collected policy documents and available figures on priorities in Nordic welfare policy.

\subsection{Time series data and outcome measures}

Our collection of time series data has enabled analyses of changes in the rates of education and training, employment and NEET (Not in Employment, Education or Training) for minority ethnic youth and youth with disabilities in Denmark, Finland, Norway and Sweden. Unfortunately, relevant data have not been available from the Icelandic statistics bureau. However, for young adults with disabilities we have achieved time series data from Iceland via EU-SILC.

Time series data have allowed us to examine whether we find changes in the activity rates for young adults that can be related to significant changes in public policy and not only the business cycle. We have examined whether 
we find breaks in the time series which can be related to changes in the social redistribution (income maintenance, active labour market measures) and/or social regulation (employment protection, non-discrimination, quotas). Because such reforms are specific for each country we have looked for any results of the national reforms separately for each country.

In the study we report from, we have been particularly interested in whether we find any evidence of changes in the employment rates. Additionally we have examined participation rates in education and training, and also the inactivity rates among young adults. While regular employment has been a main objective of the social policies in the Nordic countries, participation in education and training and NEET rates provides supplementary information about the activities of the two target groups, and to what extent Nordic social policy reforms have succeeded in enhancing the employment opportunities and preventing social exclusion of the two target groups.

Arguably, for young adults the NEET rate (neither in employment, nor in education nor training) is more relevant than the unemployment rate. The share of young adults who are registered as "unemployed" is not reflecting the average youth population but only those seeking paid work. Because many young adults are studying full-time and are therefore neither working nor looking for a job, the group of unemployed persons aged 15-24 is not necessarily particularly large. In some countries (including Sweden) the unemployment rate includes students who are seeking part time work in addition to their full time studies. Whereas the number of young adults who want paid work is interesting (also while they are completing their education) the most critical is whether students achieve regular paid work after completing their education or dropping out from school (Statistics Sweden, 2013).

Because the categorisation of "education" and "employment" varies between the countries the opportunities for direct cross-country comparisons of the two activities are limited. Different from the other Nordic countries, in Denmark apprenticeships are classified as employment. This means that especially in the age groups 15-18 and 19-23 the employment rates are higher in Denmark than in the other Nordic countries. 


\subsection{Data on ethnicity in the Nordic countries}

In the case of minority ethnic youth we have collected time series data derived from national register data. The data provide descriptive statistics about the development and insight in the factors that influence the activity and in-activity rates in 1997-2011. While individual level data would have been preferable only aggregate data has been possible to purchase from the national statistics bureaus (due to national data protection legislation).

For all countries a division is made in five groups: 1) Native born with native born parents, 2) native born with parents born in Australia, New Zealand, North America, and EU/EEA countries except the Nordic countries, 3) native born with parents born in Africa, Asia (including Turkey), Latin America, Oceania (except Australia and New Zealand) and Europe (except EU/EEA countries), 4) born in Australia, New Zealand, North America, and EU/EEA countries except the Nordic countries, and 5) born in Africa, Asia (including Turkey), Latin America, Oceania (except Australia and New Zealand) and Europe (except EU/EEA countries). We show the mean values for the group each year. For the year 2010 the information has been broken down according to three age groups 15-18(16-19; 18-19), 19-23 (20-24), and 24-28 (25-29) and gender (all, men and women).

As a note of caution the composition of the group changes over time due to immigration and emigration (Swedish Government 2013:35-37, 41). In some cases the NEET-rates in national registers might be too high because persons emigrating from the country do not report to the public authorities. In such cases the person will be registered as NEET while they in fact have emigrated.

Especially in Finland - the Nordic country with the smallest number of immigrants and shortest story of immigration - some of the subcategories of young adults are too small to provide statistically significant data (especially for native born with two immigrant parents) as Finland historically have been more a country of emigration than immigration) (Korkiasaari and Söderling, 1998, Swedish Government 2013:27). 


\subsection{Data on disability in the Nordic countries}

We are at much more disadvantaged situation data wise in relation to disability than to ethnicity.

Although the Nordic countries have put a great emphasis on strengthening the social and labour market inclusion of persons with disabilities, there is little statistical data of employment rates of persons with disabilities. This kind of data has not been gathered systematically and all together there is little information about the number of persons with disabilities. Therefore, the key question whether recent reforms have achieved their tended effect has remained inadequately answered.

For Norway, Sweden and Denmark, some information is available. Statistics Norway has collected data for the disability module to the national labour force surveys from 2002-2012 (Bø and Håland, 2013). Statistics Sweden produced consistent time-series of disability surveys every second year from the 1990s until 2008(Statistics Sweden, 2009). Denmark - through SFI in Copenhagen - has produced consistent time series but at irregular intervals (Kjeldsen et al., 2013b). In Finland no such information is available.

The importance of improving disability data and statistics has been stressed by many (e.g. UN, WHO and EU). Wim van Oorscot et al. (2009) who carried out a comprehensive analysis of European comparative data on the situation of persons with disabilities conclude that although the efforts to collect disability statistics have increased significantly over the past decades, there is a great need for EU comparative data on the situation of persons with disabilities. They also point out that with a view to monitoring, cross-nationally, developments in the situation of persons with disabilities it is imperative to have longitudinal data.

There are several reasons for the lack of statistical data on disability. One reason is the lack of international standards to guide the production and compilation of statistics in the field of disability. A second reason is that in many countries disability or health information is deemed as sensitive personal data and collecting such data is prohibited under the law. Therefore national registers of persons with disabilities are rare. As a result, data about the employment rates for persons with disabilities are almost non-existing. 
One way to obtain data on disability and to estimate the prevalence of disability among population is to use data collected in an administrative recording and registration systems on services for persons with disability. This kind of data is available in the Nordic countries, as they provide services and income transfers for persons with disabilities. The differences in disability definition between countries and organisations constitute however a serious problem (Ward and Grammenos 2007). The number of disability pensioners of working age varies sharply across countries as a result of different eligibility criteria.

Administrative data seldom covers information on participation rates of persons with disabilities. Prevalence data on disability is often collected through censuses and surveys. Survey-data enable to have information on the activities and well-being of persons with disabilities. In surveys disability is identified through questions such as, "Do you have any chronic or mental health problem, a (longstanding) illness?" and "Do you have any long-standing illness/disability/health problem/handicap that limits your work/daily activities in any way?". There is quite some variation in identification questions between the surveys (Oorschot et al. 2009). Thereby, the findings are uncertain due to different definitions of "disability" in the surveys and small subsamples of persons with disabilities (Blekesaune 2007, Molden and Tøssebro 2011).

With few exceptions available surveys have not provided the opportunity to compare time series across different European countries. Often the samples have been too small to allow statistical inferences for young adults with disabilities. Consequently it has so far been difficult to determine whether reforms in the social protection policy have increased the employment prospects for young adults with disabilities in the Nordic countries and how they have fared compared to other countries.

One exception to the general situation is the data sets from the disability ad hoc module to the Eurostat Labour Force Survey in 2002 and 2011. The two data sets provide the opportunity to compare the employment prospects for young adults with disabilities in Europe with a ten year interval. In the same decade the Nordic countries adopted a number of new social regulations to improve the employment prospects of young adults with disabilities. Given that all other factors were equal during the same period we should be able to evaluate the result of the policy reforms. 
The team collected data from the disability ad hoc module to the Eurostat Labour Force Survey in 2002 and 2011 from the national statistics bureaus in Demark, Finland, Norway and Sweden. Because individual level data could not be provided between the Nordic countries we purchased aggregate data in cross-tables we sent to the national statistics bureaus. While Iceland did participate in the disability ad hoc module to the Eurostat Labour Force Survey in 2011 their capacity to provide the aggregate data appears to have been limited.

This report utilizes the two ad hoc modules on employment of persons with disabilities. Data allow for an adequate distinction between persons with and without disabilities.

As usually the case in population surveys based on interviews, disability was defined on the basis of self-assessment. In 2002 the respondents were asked whether they had a longstanding health problem or a disability. In 2011 the respondents were asked what kind of longstanding health condition or disease they have. If a respondent had at least one of the listed long-standing health problems the person was regarded as disabled. Both in 2002 and 2011 the respondents were asked if they were limited by health problems with regard to the amount of hours they could work, the type of work they could perform, and in their opportunities to travel to and from the workplace but the questions were structured differently. As a result of the differences, there are uncertainties of comparability. Only Norway posed the same initial question both in 2002 and $2011 .^{2}$

The reasons for the change in wording in 2011 was to investigate in more details health problems and difficulties in basic activities (separately and by listing diseases and basic activities) so that respondents did not forget to mention any problems. Contrary to the 2002 module, health problems and difficulties in basic activities are asked separately. ${ }^{3}$ Then, for pragmatic reasons, restrictions in participation in the labour market

\footnotetext{
2 See descriptions of the surveys available at http://epp.eurostat.ec.europa.eu/statistics_explained/ index.php/EU_labour_force_survey_-_ad_hoc_modules and Bø, T. P., Håland, I. 2013. Funksjonshemma på arbeidsmarknaden i 2013. Oslo-Kongsvinger, Statistics Norway SSB.

3 "Do you have a longstanding health problem or sickness/disability?" and "Do you have any longstanding or permanent difficulties in the following activities?".
} 
(limitations in work) are linked to health or difficulties in basic activities by asking the respondent about his or her subjective view of the most important reason for the restrictions. To reflect the interaction between limitations in work and the environment of the person, a question on other reasons for limitations in work is added.

The idea was to implement as far as possible the concept of disability as defined by the International Classification of Functioning, Disability and Health (WHO, 2001). According to this model limitations to work should be viewed in the context of interaction between the environment and the person; i.e. a relational model or "gap" model of disability. In practice, the 2011 data set is closer to a medical model of disability.

Table 3.1: Prevalence of long-standing health problem in four Nordic countries. 2002 and 2011. Both sexes. Percent

\begin{tabular}{lcccr} 
& DK & FIN & SE & NO \\
$\mathbf{2 0 0 2}$ & & & & \\
$16-64$ & 19.9 & 32.2 & 19.9 & 16.4 \\
$16-29$ & 12.0 & 17.2 & 11.6 & 9.3 \\
$\mathbf{2 0 1 1}$ & & & & \\
$16-64$ & 23.8 & 57 & 41.1 & 16 \\
$16-29$ & 14.5 & 39 & 31.3 & 8 \\
\hline
\end{tabular}

Source: Eurostat LFS, Disability ad hoc module. Reported by the National statistical offices.

For all countries except Norway we find an increase in the rate of selfreported health problem, sickness, illness or disability (Table 3.1). Of those aged 16-29 years who reported a health problem or disability, the share of respondents with mild disabilities increased significantly in Sweden (from 53 to $72.9 \%$ ) and Finland (from 47 to 78\%). In Denmark the share of mild self-reported disabilities decreased (from 46.1. to 35.3\%) and remained unchanged in Norway (34\%) according to this survey.

The national questionnaires suggest that the national statistics bureaus have asked different questions, despite the effort to collect comparable data. This may in part account for some of the national differences. While Sweden and Finland asked whether the health problem or sickness had existed or would exist for at least six months, Denmark and Norway asked for "long standing problems". While Sweden referred to "health problem or sickness" and Finland to "illness and health problems", Norway and Denmark referred to "health problem or disability". Different 
from the other countries, the Finish interviewers emphasised that the problem did not need to have been diagnosed by a doctor. Such differences in the questions may have given different associations and may account for some of the differences between the countries.

In the data we have purchased from the Nordic statistics offices we only have access to the self-reported health problem, not self-reported problems in basic activities. A recent publication of the first results from the disability ad hoc module 2011 suggest that "problems in basic activities" could have been equally relevant (Table 3.2). Discrepancy between the data we have received from the national statistical offices (Table 3.1) and the data reported by Eurostat (Table 3.2) give reason to caution. Obviously, uncertainty about which population groups the data covers may influence the rates of participation in employment and education, and the rates of inactive persons (NEET).

Table 3.2: People aged 15-64 reporting a longstanding health condition or a basic activity difficulty in 2011. By age. Both sexes. Percent

\begin{tabular}{lrrrr} 
Country & Age & $\begin{array}{r}\text { Only a basic } \\
\text { activity difficulty }\end{array}$ & $\begin{array}{r}\text { Only a longstanding } \\
\text { health condition }\end{array}$ & $\begin{array}{r}\text { Both health problem } \\
\text { and activity difficulty }\end{array}$ \\
Denmark & $15-64$ years & 2.2 & 9.5 & 12.9 \\
& $15-24$ years & 2.3 & 7.1 & 4.9 \\
Finland & $15-64$ years & 1.3 & 33.5 & 20.9 \\
& $15-24$ years & 1.3 & 27.3 & 6.5 \\
Iceland & $15-64$ years & & & 17.2 \\
& $15-24$ years & 2.0 & 29.4 & 15.0 \\
Sweden & 2.8 & 26.3 & 14.7 \\
& $15-64$ years & 1.3 & 26.4 & 8.3 \\
\hline
\end{tabular}

Source: Eurostat LFS, Disability ad hoc module 2011. Reported by Eurostat. ${ }^{4}$

Table 3.2 suggests that of the Nordic countries, Finland had the highest share of persons with a longstanding health condition and also the highest share of persons with both a health and activity difficulty in the general adult population (15-64 years). Of the Nordic countries, Iceland had the 
highest share of persons with a longstanding health condition and also the highest share of persons with both a health and activity difficulty in the youth population (15-24 years). Figures for Norway was not available. Although the age groups are different in Table 3.1 and 3.2, figures about the general adult population suggest that we get significantly smaller percentages if we only focus on those with both a health problem and activity difficulty. Arguably this later population group is more relevant in our examinations of "disability policy" than the broader category of all persons with a self-reported health problem.

Another dataset that enables some analyses on the employment of disabled youth is the EU-Statistics on Income and Living Conditions (EU-SILC) which has annual data for the European Union countries and for several other countries, including Iceland and Norway. Although the sample size is large, the number of cases belonging to a more specific population group remains low. This is also the case for youth with disabilities.

In EU-SILC disability is defined on the basis of self-assessment of health. Respondents are asked whether they suffer from any a chronic (longstanding) illness or condition. Answer alternatives are yes and no. A further question concerns the limitations in activities owing to health problems. Answer alternatives are yes, strongly limited, yes, limited, and no, not limited.

For our purpose we have constructed three groups to make a difference between those whose health problems which limit daily activities from those whose health-problems which do not limit their activities. The three groups we compare are thus 1) young people with no long-standing health problems, 2) young people who have long-standing health problems, but their daily activities are notlimited owing to these problems and 3) young people with long-standing health problems whose daily activities are strongly or to some extent limited.

Due to a small number of respondents, in some parts of the analyses, only two groups can be separated; young people without long-standing health problems (i.e. young people without disability) and young people with disability (having some long-standing health problems). The number of youth with long-standing health problems vary from 104 to 409. The number of youth with more severe disability (whose daily activities are strongly limited because of health problems) is very low. Because of the small number of cases, it is in most cases impossible to draw reliable anal- 
yses for this sub-category. In Chapter 5 on disability, following the guidelines of the EU-SILC, we use an asterisk $\left({ }^{*}\right)$ if the unweighted number of cases is smaller than 20 .

Table 3.3: Percentage of young people with long-standing health problem as a share of age group and those with activity limitations (some or strong) as a share of those having longstanding health problems (number of unweighted cases)

\begin{tabular}{|c|c|c|c|c|}
\hline & & 2005 & 2008 & 2011 \\
\hline \multirow{2}{*}{ Denmark } & Young with long-standing health problems & $13.7 \%(130)$ & $13.5 \%(123)$ & $15.3 \%(109)$ \\
\hline & - of which those with activity limitations & $48.4 \%(68)$ & $60.5 \%(73)$ & $50.3 \%(61)$ \\
\hline \multirow[t]{2}{*}{ Finland } & Young with long-standing health problems & $20.3 \%(409)$ & $17.3 \%(311)$ & $19.3 \%(290)$ \\
\hline & - of which those with activity limitations & $58.2 \%(229)$ & $40.3 \%(141)$ & $45.2 \%(141)$ \\
\hline \multirow[t]{2}{*}{ Iceland } & Young with long-standing health problems & $16.3 \%(111)$ & $16.4 \%(104)$ & $20.6 \%(139)$ \\
\hline & - of which those with activity limitations & $72.0 \%(81)$ & $48.8 \%(57)$ & $58.7 \%(83)$ \\
\hline \multirow[t]{2}{*}{ Norway } & Young with long-standing health problems & $18.6 \%(221)$ & $22.6 \%(234)$ & $26.4 \%(209)$ \\
\hline & - of which those with activity limitations & $46.9 \%(105)$ & $33.2 \%(75)$ & $61.0 \%(127)$ \\
\hline \multirow[t]{2}{*}{ Sweden } & Young with long-standing health problems & $22.9 \%(288)$ & $20.8 \%(291)$ & $17.0 \%(198)$ \\
\hline & - of which those with activity limitations & $43.1 \%(124)$ & $35.7 \%(100)$ & $40.4 \%(80)$ \\
\hline
\end{tabular}

Source: EU-Statistics on Income and Living Conditions.

Table 3.3 suggests that there a no clear trends in the rate of youth with longstanding health problems and activity limitations between 2005 and 2011. The share of young people with long-standing health problems varies between 13 to 26\%. Denmark displays the lowest shares, and has a rather stable development. Finland is another country with a rather stable development, but the share of young people with long-standing health problem is higher than in Denmark. In Norway and Iceland the share of young people with long-standing health problem has increased over the period of examination, whereas the share has declined in Sweden.

The share of young people whose long-standing health problem limit their daily activities either to some or strong extent varies also across countries and time. A rough approximation is that half of those with a long-standing health problem has some activity limitations.

The Eurostat data (Table 3.1) suggests that a somewhat larger proportion of young people see themselves as having a disability now than a decade ago, but first of all in Finland and Sweden. The EU-SILC data supports that a higher share of young people in Finland report to have a 
health problem (Table 3.3). According to national labour force surveys the rate of young adults with self-reported disability has been unchanged in Norway since 2002 (8 to 9\%) (Bø and Håland, 2013). Mykletun and Knudsen (2009) find that the prevalence of psycho-social disabilities has been stable in Norway between 1992 and 2003.

The surprising intra-Nordic differences in reported disability are probably due to different operationalizations of disability. In an examination of how disability definitions affect research results Molden and Tøssebro (2012) reported that the employment rate among Norwegians with disabilities varied with as much as $26 \%$ in the same data set depending on the definition of disability. Overall, these provisional findings emphasise the need to see employment or NEETs rates in the light of how large proportion of the group who report having a disability in each of the Nordic countries.

\subsection{Interview data}

Based on a common topic guide employers (four in Iceland, eight in Norway), professional service providers (eight in Iceland) and vulnerable youth were interviewed (sixteen in Iceland, twelve in Norway). The interview data provide insights in how relational factors further or hamper the transition from education to employment for vulnerable or stigmatized young adults.

The employers were invited to participate because of their reputation to be more active promotion of diversity in the workforce compared to many other enterprises. The sample of employers include enterprises where the leaders have committed themselves to inclusion of ethnic minorities or persons with disabilities, i.e. employers who are known to have an active policy to recruitment and promote the inclusion of ethnic minorities and/or persons with disabilities in the workforce. The employers represented public and private enterprises with more than 400 employees.

The interviews with the employers documented the perception and experience of employers with social regulation policy measures, their working relationship with public employment agencies and support services for employers, and to what extent they assumed any social responsibility in recruiting vulnerable youth (ethnic minorities or persons with 
disabilities) in their workforce. By asking for real examples we achieved data beyond general and official statements (the espoused values), and achieved data about the employers' actions and initiatives.

Additionally we have interviewed minority ethnic youth and youth with disabilities who have succeeded in achieving paid work. The sample of interviewees has provided new insight in the conditions for success and practical solutions. To be able to identify conditions for success we were interested in recruiting interviewees who had work experience.

The semi-structured interviews with the youth documented their trajectories into the labour market and how they achieved paid work. Of particular interest were their experiences with social regulation measures aiming to prevent discrimination and/or failure to provide accessible work places and appropriate accommodation, on the part of employers. In addition we were interested in their experiences with redistributive policy measures (social services in cash and in kind: compulsory education and training, active labour market training programmes, employment services, placement services, apprenticeship schemes, income maintenance).

In recruiting young adults who had achieve employment and did have work experience we relied on snowball sampling (Iceland) - including assistance from municipal activation specialists - and the assistance of organisations of ethnic minority youth and youth with disabilities (Norway).The majority of the interviews were conducted face-to-face in the setting of the participants' choosing. Two interviews in Iceland and one in Norway were conducted by telephone, and one conducted with the assistance of a family member at the participant's request (Iceland). Important insights were gained through comparing and contrasting the categories of youth with disabilities and youth with ethnic minority backgrounds, as well as considering differences internal to these categories. 
The interviews provided data about the social mechanisms and processes which determines the practical impact of regulatory policy measures aiming to enable vulnerable youth to find and retain suitable employment. The main aim of the interviews was to gain in-depth insights into the social mechanisms and processes which determine the impact of innovative measures designed to facilitate entry and sustainability within the labour market for minority ethnic youth and youth with disabilities. The central aim of the interviews was to gain a deeper understanding of processes underpinning adjustment strategies of vulnerable youth and employers.

\subsection{Policy documents and legal data}

With the assistance of the other team members we have collected data about the labour market inclusion policy system (social benefits, services, regulation) in the Nordic countries. In particular we have benefited from comparative statistics from Eurostat and the OECD database. Additionally we have reanalysed existing research literature and policy documents from the Nordic countries.

\subsection{Concluding comment}

Altogether, the three main types of new data (statistics, interviews data and law and policy documents) provide a fuller picture ofunder which conditions social regulation is most likely to be effective. Until now longitudinal data enabling examinations of changes over time have been scarce. This chapter has explained why the statistical data should be interpreted with caution. Small samples and differences in definitions of the populations and the dependent variables (employment, education, NEET) make it difficult to draw definitive conclusions. However, the analysis of our primary data allows for tentative suggestions (or hypotheses) which should be examined in more detailed in future research. In the concluding chapter (Chapter 8) we identify how the Nordic governments may facility higher quality (improved reliability and validity) in cross-national research between the Nordic countries in the future. 



\section{Changing balances in Nordic social protection systems}

To fully understand whether and under which conditions social regulation policies is most likely to promote labour market participation among young adults we want to examine how the Nordic countries combine different policy measures and opportunities for synergies between the different policy subsystems; social benefits, services and social regulation.

A key concern is the relative weight of and interaction between the three subsystems within the overall national system. Different countries do not only use different policy instruments; their efforts to enhance employment for persons with disabilities do also have distinct overall profiles. The policy profile or approaches in the countries have been influenced by or framed within different national policy traditions, distribution of roles and influence between different actors participating in the design and implementation of the labour market inclusion policy (Halvorsen and Hvinden, 2009, Hvinden, 2010, Halvorsen and Hvinden, 2011).

\subsection{Nordic labour market inclusion policy and vulnerable youth}

In general, the Nordic model of welfare has stood for public responsibility for guaranteeing cash benefits and social services to citizens through publicly funded provisions that cater to all needs and the whole population, financed largely through tax revenues. The Nordic income maintenance (social benefit) systems have been comparatively generous, with the official aim of providing benefits enabling people to maintain about the same standard of living during periods of unemployment. To fund these systems, the Nordic countries have promoted as high labour market participation as possible. Public authorities have taken an active role vis-à-vis 
other main social institutions, especially through regulation of the labour market, stimulating tripartite collaboration and encouraging renewal and innovation in the economy in general (Barth et al., 2003, Moene and Wallerstein, 2001).

\subsection{Social benefit subsystem: health and residence as criteria}

In the Nordic countries redistributive policy measures have aimed at being "universal" and not limited to specific business sectors (or population groups. Generally entitlement to income maintenance during periods out of paid work has been restricted by the country's rules for legal residence. Hardly any provisions have been dependent on becoming naturalized and being granted a formal citizenship in a Nordic country. However, we find a number of differentiations of the entitlements.

Entitlement to rights-based social security benefits has been conditional on a minimum duration of legal residence in the country and the amount of earnings and tax contributions made as an employee in the labour market. Young adults immigrating to the Nordic countries have been excluded from rights-based social security until they have a sufficient record of labour market participation and legal residence in the country. For instance a single mother immigrating to Norway has not been entitled to single parent allowance the first three years she lives in the country (Hatland, 2011). While newly arrived migrants with legal residence have been eligible for means-tested financial assistance, the payments have in some programmes been lower than the regular social assistance payments. This has been the case with the Danish Start Help and Introduction Allowance (Leibig, 2007).

The distinction between rights-based social security benefits and means-tested social assistance implies a two-track system for income maintenance in the Nordic welfare states: Young adults have qualified for social insurance benefits if they have a previous record of labour market experience. Those with no or a poor record of labour market participation have been deferred to means-tested social assistance. The scope for local discretion in defining the benefit level has been greatest in Norway and 
most restricted in Denmark and Finland, with Sweden in an intermediate position (Kuivalainen and Nelson, 2012).

From a costs perspective many today argue that the level of Nordic social benefits - in interaction with relative compressed earnings in the labour market -create disincentives for young adults with little or no formal education to find paid work (OECD and Canadian Policy Research Networks, 2005, OECD, 2013). Since the 1990s Nordic governments have adjusted their income maintenance systems on grounds of the changing demographic and economic conditions to strengthen the sustainability of social benefit systems. The Nordic countries have introduced stricter qualifying criteria and/or reduced the benefit levels to avoid disincentives in the income maintenance system and reinforced their orientation towards employment-promoting measures - particularly in connection with young adults (Bonoli, 2010, Nelson, 2013).

While the level and duration of participation in the labour market have been important criteria for being entitled to social security benefits, poor health and impairments have been important justifications for being granted rights-based social security benefits. To be classified as sick, impaired or having a reduced working capacity provide more legitimacy than being "unemployed". If the person out of paid work does not have a diagnosis the person has more easily been blamed for his or her own situation.

In the Nordic countries health-related reasons have been important justifications for claiming social benefits in cash and in kind. The last two decades the Nordic countries did not differ much from other Northern European countries with regard to total expenditures on social protection. However, the Nordic countries gave higher priority to disability issues: during the last two decades they individually spent more on income maintenance for persons with disabilities than most other European countries, except for Iceland which historically has been closer to the average for EU15 (Table 4.1). 
Table 4.1: Public social expenditures on disability related benefits. Year 2011. In percent of GDP

\begin{tabular}{lcc} 
Country & Disability related benefits in cash and kind & Non-means tested disability cash benefits \\
Denmark & 4.1 & 3.9 \\
Finland & 3.5 & 3.5 \\
Iceland & 3.5 & 1.6 \\
Norway & 4.3 & 4.2 \\
Sweden & 3.9 & 3.9 \\
EU15 & 2.1 & 1.6 \\
\hline
\end{tabular}

Source: Eurostat, Database for Social Protection Expenditure and Receipts, 2014.

For newly arrived immigrants and young adults without a previous record of labour market experience and earnings (or contributions) means-tested social assistance has been the most relevant income maintenance scheme (Hatland, 2011). Nelson finds that Nordic social assistance programmes were among the European programmes with the highest adequacy level for alleviating poverty in the 2000s (Nelson, 2013:392-93). Yet the benefit level remained below $60 \%$ of the median income in the Nordic countries. In the general youth population aged 18-24 the risk of poverty was higher in Denmark, Sweden and Norway and to lesser extent in Finland than in other European countries (Eurostat, 2009 :42). This may reflect the work or contribution requirement in the Nordic social protection schemes other than means-tested social assistance.

Altogether, in the Nordic countries young adults with disabilities have benefited from higher degree of legitimacy than young adults with short legal residence in the country and no diagnosis to justify receipt of social security provisions.

\subsection{Social services subsystem: education and on- the-job training}

Expenditures: Generally, the Nordic countries have spent more on active labour market measures (ALMM) than other EU countries (except the Netherlands). In 2010 ALMM expenditures ranged from $0.51 \%$ of GDP in Norway to $1.40 \%$ in Denmark, with Finland $(0.86 \%)$ and Sweden $(0.8 \%)$ in the middle, compared to the $0.49 \%$ average for the OECD countries (OECD, 2012). Although the expenditure on ALMM will drain the public purse in the 
short run, the assumption has been that improved skills and competencies in the labour force will benefit the national economy over time.

We find large differences in how the Nordic countries allocated the resources to ALMM in general in the 2000s Among the Nordic countries Finland and Norway spent a larger share of total public expenditures on active labour market programs on income maintenance for persons without paid work while they were participating in qualifying measures, often education. Sweden and Denmark gave higher priority to providing employers with financial incentives (cash benefits and tax reductions) for offering employment opportunities to persons at risk of exclusion from the labour market; on-the-job experience through support schemes for employers and wage subvention (OECD 2012, Table A and K). Although some of these differences undoubtedly are related to differing and inconsistent classifications of expenses across the countries, the broad pattern agrees with past research (Marin et al., 2004, Prinz, 2003).

Number of participants in ALMM: Consistent with the priorities of public expenditures, all Nordic countries except Sweden had the largest share of ALMM participants in training. Finland (52.5\%) had the highest percentage of ALMM participants in training, followed by Norway (42.4\%) and Denmark (41.3\%), and with Sweden (8.4\%) as the clear exception. Sweden $(62.2 \%)$ had the largest share of participants in employment incentives, followed by Denmark (24.0\%), Norway (22.4\%) and Finland (19.5\%). Denmark (34.7\%) had the largest and Finland (7.7\%) the smallest share of participants in supported employment with Sweden (26.5) and Norway (25.8) in intermediary positions.

In addition to the general labour market inclusion policies Nordic governments have introduced targeted policy measures for young adults to enhance their inclusion in the work force. In particular the Nordic countries have since 2008 - in response to the international economic turbulence - expanded education and training programmes targeted at young adults under age 25 to adjust their individual skills and increase their professional attractiveness for employers. Finland, Norway Sweden and have introduced a social right ("the youth guarantee") to education, training or work for youth aged 16-24 years, while Denmark has introduced several "youth-packets". Iceland has, among others, invested in early intervention, counselling and education for young adults ("ungt folk til 
athafna"). Norway has introduced the Qualification Programme which is an offer of training and vocational training for persons (often young adults) who have received means-tested social assistance for a long time (Halvorsen et al., 2012).

In Iceland supported employment programmes (AMS - atvinna med stuđningi) has offered support to anyone with intellectual or physical disabilities in regard to assistance with job search and placement, direct support within the work place if needed and acted as a liaison between the employee and employer. While the staff in the supported employment programmes generally do not work directly alongside individuals, they do liaison with employers if any issues arise. During the time of our research there were 332 individuals employed with supported employment programmes in Reykjavik. Of those, 58 received daily visits by support staff at the workplace. A further 108 received support visits once or twice a month and another 100 seldom required such support. The programme has not intended, nor likely funded, to have a support worker assist the employee throughout the work day. As such, the programme functioned more as an employment finding resource through the contacts the AMS staff had with local employers, as well as acting as a counselling service for employers.

A prominent feature of Nordic labour market inclusion policy has been that policy measures should not be designed for immigrants specifically or targeted at immigrants or their native born children. With the exception of Denmark (some job-centres have started initiatives specially targeted at minority ethnic youth in the age 15-17 years old) we find no specific strategies for minority ethnic youth. Rather they are supposed to be covered by the general labour market inclusion policy and general youth policy. One argument has been that targeted measures would be stigmatizing. All countries have, however, adopted measures for newly arrived immigrants; the underlying assumption has been that only if they are newly arrived they have special needs that are derived from their immigration. The programmes and requirements differ between the countries. Several of the countries have emphasized language training for immigrants.

On-the-job experience through support schemes for employers and wage subvention have been used to a lesser extent among immigrants 
than in the general population of out paid work (Leibig, 2007, Leibig, 2009, Hardoy and Zhang, 2010). More often than for the general youth population education appears to have been preferred to on-the-job training on grounds that it has been more "difficult to find suitable training opportunities" for immigrants than others (Djuve and Tronstad, 2011).

\subsection{Social regulation subsystem}

To encourage employers to hire young adults Sweden and Denmark have reduced the tax for employers who hire young adults, while Finland has introduced wage subsidies to temporary positions for graduates below 25 years(NOSOSCO, 2011, Ramböll Management Consulting, 2010).

In the Nordic countries disability has justified more entitlements to reasonable accommodation and positive action measures than ethnicity. While the prohibition against discrimination on grounds on ethnicity was introduced earlier than for disability, Nordic policies to promote employment prospects of disability have to a much larger extent included the adoption of reasonable accommodation and positive action measures.

\subsubsection{Disability}

In the Nordic countries, early regulatory measures included legal provisions giving employers duties in relation to employees with disabilities, such as strengthened job security through the general labour code. For a long time Sweden has had one of the strongest frameworks of labour protection legislation (OECD, 1994). Of the Nordic countries Sweden continued to have the strongest and Denmark the weakest employment protection provisions for employees on permanent contract in the 2000s, with Norway and Finland in the middle and Iceland closer to Denmark(Venn, 2009, OECD, 2013).

Of the Nordic countries, Sweden has practiced a stricter enforcement of employer obligations for workplace accommodation on the grounds of disability than the other Nordic countries. By contrast Denmark has been among the OECD countries with the weakest job security protection and obligations for employers, and - of the Nordic countries - the weakest 
protection against workplace discrimination on grounds of disability(Inghammar, 2006, Liisberg, 2011).

Again this policy shift was embraced earlier and more clearly in Sweden than in the other Nordic countries. Sweden adopted non-discrimination legislation in working life in 1999. From 2006 the duty of employers to accommodate the workplace also includes new employees. The other Nordic countries have partly followed up by introducing legal provisions against discrimination in employment and occupation: Inspired by Sweden, Norway first adopted legal protection against discrimination in 2001 and later amended the non-discrimination provisions in 2004 to ensure the same level of legal protection as in the EU Employment Framework Directive (2000/78/EC). Additionally Norwegian state enterprises have the opportunity to give priority to job applicants with disabilities but in practice the use of the opportunity has been left to the discretion of employers and used to a little extent(Bull and Andreassen, 2007). Finland transposed the employment framework directive in 2004 and Denmark in 2005. Iceland has not adopted non-discrimination legislation to protect youth with disabilities from discrimination and ensure the right to reasonable accommodation in the work place (Icelandic Human Rights Centre, 2011). However, in Iceland the law provides for affirmative action: disabled persons shall have preference for government employment over other applicants if equally qualified (Icelandic Human Rights Centre, 2008).

There is no systematic information about the extent to which Nordic authorities have provided financial support or actually reimbursing employers' expenses related to on-the-job adjustments or accommodations for persons with disabilities.

Of the Nordic countries Norway gave the largest priority to voluntary social regulation to enhance the employment prospects of young adults; a Memorandum of Understanding to promote an inclusive working life was first adopted in 2001. Employers have entered into a collaborative agreement with the NAV Inclusive Workplace Support Centre and committed themselves to work towards the objectives of the Memorandum of Understanding. In return the enterprises have been eligible for financial support to reasonable accommodation, but recruiting persons with disabilities has been given lower priority than reducing sick-leave absence and early exist from working life (Ose et al., 2013). Denmark and Sweden channelled 
more resources in the form of subsidies for employers (wage subventions) to achieve work experience (Eurostat, 2013).

In Iceland wage subvention has been adopted to foster the employment opportunities for youth with disabilities. The employment contract for disabled pensioners (Vinnusamningur öryrkja) provides the opportunity for the Social Insurance Administration (Tryggingastofnun) to negotiate with employers in the private sector to hire individuals with reduced working capacity and whose main source of income is typically a disability or rehabilitation pension. The initial contract typically beings with a three month trial period, which is then re-negotiated on a yearly basis (Regulation on the employment of disability pensioners 159/1995). The Social Insurance Administration will subsidies the wages of the employee for a maximum of $75 \%$ but no less than $25 \%$, with the intent that the subsidy will decrease each year until the $25 \%$ minimum rate is met. Thus the intent appears to be that the subsidy is to act as a hiring incentive for employers, and if successful the employees are to be gradually shifted toward employment with little or no state subsidy.

In 2011 there were 461 wage subsidy contracts made. The figure may not appear to be significant considering that in 2011 there were 15,197 registered disability pensioners in Iceland (Social Insurance Administration, 2011). However, more than 400 such contracts is still an indicator that they are a draw for employers and all of the Icelandic employers the team interviewed used this wage subsidy programme. Interviews the team conducted with employers - both in Iceland and Norway - revealed overt references to employing persons with disabilities in reference to social responsibility or "the right thing to do", rather than the financial compensation for doing so, but one could make inferences about the financial incentives in the subsidy programme for employers.

Thus far none of the Nordic countries has required public employers to anticipate the needs of employees with disabilities to ensure workplace accessibility (anticipatory accommodation). Neither has any of the countries required that a party contracting with a public authority for the procurement of goods or services take affirmative action to employ and promote qualified individuals with disabilities. However, the Norwegian government has adopted legislation to the effect that from 2009 public employers, private employers who regularly have more than 50 employ- 
ees, and the social partners have a legal duty to work "actively", in a "goaloriented" way, and "systematically" to promote equal opportunities and prevent discrimination against persons with disabilities. As is also the case for the other new social regulation instruments adopted by Nordic countries since the late 1990s, it is still an open questions how systematically and thoroughly the government ensures that relevant actors are aware of the rights and duties involved and puts in place appropriate arrangements for supervision and enforcement, e.g. simple and accessible channels for filing complaints.

\subsubsection{Ethnicity}

International human rights conventions prohibiting discrimination on grounds of race, religion and ethnicity were ratified by the Nordic countries in the 1960s but the commitment was limited to ensure difference blindness and not accommodate that difference. Since the 1990s the Nordic countries have to an increasing extent incorporated international human rights in national legislation, notably prohibition against discrimination on grounds of inter alia religion, belief and ethnicity in the Constitution and/or the Penal code.

Sweden adopted a law against ethnic discrimination in 1993 and later amended it in 1998 with a special law against discrimination in working life (Proposition 1997/98). Inspired by Sweden, Norway first introduced legislation against discrimination on grounds of race, colour, national or ethnic origin in 1998 and adopted shadow legislation to the race directive in 2005. Denmark transposed the Race Equality Directive in 2003 and Finland in 2004.

Non-discrimination legislation in Iceland has fallen short of the minimum requirements set out in the Directive. Currently, there are no substantive policies concerning the promotion of the hiring, recruitment or inclusion of ethnic minority youth in Iceland. Arguably an underlying tendency has been to view persons of immigrant origin as an economic resource rather than as full members who are entitled to corresponding rights in Iceland(Icelandic Human Rights Centre, 2009).

Of the Nordic countries Sweden has adopted the most and Denmark and Iceland the fewest positive action measures to improve the employ- 
ment prospects of minority ethnic youth. Different from the other Nordic countries Swedish social regulation requires employers to carry out actions so as to ensure that recruitment methods reach an ethnically diverse pool of potential applicants. Whereas Sweden and Norway do not impose specific obligations on employers regarding the identification of barriers to equality, both countries mention in their administrative guidelines certain techniques that an employer may carry out so as to identify barriers to equality (Craig, 2013).

Since 2007 all Norwegian state enterprises have been encouraged to adopt recruitment plans to ensure the inclusion of immigrants and children of immigrants, In 2008 Norway adopted a moderate quota for persons with two foreign-born parents. In 2008-2012 public employers could choose to hire applicants with a minority background even if the applicant was ranked behind the most qualified candidate (Orupabo et al., 2009). From 2012 public employers have to choose the applicant with a non-Western background if the person has approximately the same qualifications.

In Finland (2004) "persons with an immigrant background" can be favoured in recruitment when the candidate's qualifications otherwise are equal. Additionally public employers must develop an equality action plan, identifying measures to foster equality and prevent discrimination. ${ }^{5}$

There are currently no substantive policies concerning the promotion of the hiring, recruitment or inclusion of minority ethnic youth in Iceland. The emphasis has been on the conditions upon which foreign workers may seek to enter Iceland for the purpose of work and the grounds on which permits can be extended and terminated. This is suggestive that foreign labour is mainly conceived of by Icelandic authorities as a temporary resource. This is echoed in a report by the Icelandic Human Rights Commission: "In general, there still appears to be an underlying tendency to view persons of immigrant origin as an economic resource rather than as full members of Icelandic society, who are entitled to the corresponding rights" (Icelandic Human Rights Centre, 2009).

${ }^{5}$ Act on the Promotion of Integration of Immigrants 1386/2010, Finland. 
While Denmark has adopted the European Council Racial Equality Directive (EC/2000/43), the Danish government has been reluctant to provide the opportunity to favour employees with an immigrant background in employment and occupation in a transition period "and only in exceptional cases [made] juridical and political allowance for minority rights and cultural claims based on minority status" (Hedetoft, 2006:403).

\subsection{Summary of priorities in Nordic labour market inclusion policy for vulnerable youth groups}

This chapter has reviewed the overall balance between social benefits, services and social regulation in the Nordic countries. Arguably the Nordic countries are witnessing a shifting balance between redistributive and regulatory policy measures to promote employment among young adults in general and minority ethnic youth and youth with disabilities in particular: While Nordic welfare states have a tradition of encompassing redistributive or transfer-oriented arrangements to enhance employability and provide income security during periods outside employment, regulatory provisions to accomplish welfare policy objectives have been relatively less developed. Since the late 1990s, however, the labour market inclusion policy of the Nordic countries has shifted in composition and balance between policy measures.

The Nordic have to various extents introduced reforms to enhance the financial incentives to seek and retain paid work (i.e. reforms in the social benefit and services subsystems). At the same time, the Nordic countries have introduced new legal provisions, financial incentives and voluntary agreements to prevent discrimination, positive action duties and/or failure to provide reasonable accommodation on the part of employers (i.e. reforms in the social regulation subsystem).

Altogether the increasing salience of diversity has furthered a more complex mix of policy measures combining redistributive and regulatory policy instruments in Nordic labour market inclusion policy. Often the new policy mixes have transcended the public-private divide and required coordination between public authorities and employers. This transformation has in part been a response to demands for voice, visibility and 
equal worth on the part of ethnic minorities and persons with disabilities (Hobson, 2003). However, Nordic public policies have also been influenced by broader international changes such as the emergence of an international human rights regime and the emerging EU policy mix of market integration and social regulation to correct for market deficits (Halvorsen and Hvinden, 2009, Whittle and Halvorsen, 2007).

Of the Nordic countries Sweden adopted the broadest set of policy measures within all three subsystems of labour market inclusion policy in the 2000s. Finland and Norway allocated relatively more resources to income maintenance for persons participating in ALMM (labour market training, education in regular schools), while Denmark and Sweden channelled more resources in the form of subsidies for employers (wage subsidies) and programmes to achieve work experience (Eurostat, 2013). Denmark introduced the "flexjobs" program in 2003 (Brix Pedersen 2010). Sweden has invested more in sheltered work (Halvorsen and Hvinden, 2011). Still, redistributive or transfer-oriented arrangements to enhance employability and provide income security during periods outside employment are more developed than regulatory provisions as means to accomplish welfare policy objectives.

Regulatory provisions as means to accomplish welfare policy objectives have been relatively less developed although with not insignificant differences between population groups. The last 15 years the meaning of accommodation to disability have been codified in legal documents. In a Nordic context, accommodation of ethnic diversity in the workplace has proved to be more controversial. While the Nordic countries have adopted a number of positive action measures to improve the employment prospects of young adults with disabilities the parallel policy measures targeting minority ethnic youth have been more limited.

In the last decade Danish policy has been more dominated by scepticism towards ethno-cultural diversity than the other Nordic countries. While all Nordic countries have attributed importance to cultural "sameness" as a precondition for societal cohesion Danish welfare policy has become more influenced by scepticism to ethno-cultural diversity than the other Nordic countries (Kymlicka, 2012:14, 26). 
Arguably the relatively low public legitimacy of ethno-cultural diversity has been reflected in the reluctance among Nordic politicians to adopt regulatory policy measures and innovative strategies to ensure the accommodation of ethnic diversity in the workplace and increase the participation of minority ethnic youth in employment (Halvorsen and Hvinden, 2014). 


\section{The employment opportunities and prospects of youth with disabilities in the Nordic countries}

Have reforms in the labour inclusion policy improved the employment prospects for young adults with disabilities in the Nordic countries? Chapter 5 examines whether we find any evidence of changes in the participation rates that can be connected to the introduction of new policy instruments in the Nordic countries in the last decade and not only fluctuations in the business cycle. Based on time series data Chapter 5 examines the NEET (not in education, employment or training) rates and participation rates in education, training or employment for youth in general and youth with disabilities.

\subsection{Disability in the Nordic labour markets}

Several national studies provide indicators on the employment and employability of persons with disabilities (Linnenkangas et al., 2006, Holm and Happonen, 2007, Laiho et al., 2010 , Gould and Kaliva, 2010 , Hannesdóttir, 2010, Hannesdóttir et al., 2010, Andersen et al., 2011, Kjeldsen et al., 2013a). These studies show that persons with disabilities have much lower employment rate than those without disabilities. Although employment rates are relatively high in the Nordic countries in general, this has not been the case for persons with disabilities nor for young adults with disabilities. Surveys among persons with disabilities suggest that a large proportion of Nordic citizens with disabilities have been practically excluded from gainful employment (Halvorsen and 
Hvinden, 2009 ). To the extent that they were employed, they more often had marginal positions, e.g. as part-time or temporary workers.

OECD (2009) aimed to collect comparative data on the disability benefit recipiency rates. Although figuresfor the rates of disability benefit recipiency were incomplete or uncertain, available data suggest that the Nordic countries were among the European countries with the highest proportion of recipients of disability related income transfers in the working age population (20-64 years) in the 2000s.

Despite attempts at making the eligibility criteria more restrictive, the share of the working age population receiving disability benefits increased between 2000 and 2008 in Norway (from 9.1 to 10.3\%) and Sweden (from 8.6 to $10.3 \%$, with a peak at $11.3 \%$ in 2005 ) and remained almost unchanged in Denmark (7.0-7.2\%). Only Finland witnessed a decrease in the disability recipiency rate for the working age population as a whole (from 8.8 to $8.5 \%$ ) (OECD, 2009 ).

The general picture is reflected in the disability recipiency rates for young adults aged 20-34. In the 2000s the Nordic countries were among the European countries with the highest disability recipiency rates among young adults (together with UK, the Netherlands, Ireland and Poland). Moreover, during the last decade all Nordic countries witnessed an increase in the disability recipiency rate for this age group, with Sweden (1.7 to $2.6 \%$ ) and Norway (1.7 to $2.0 \%$ ) having the highest disability takeup rate. Denmark (1.4 to $1.8 \%$ ) and Finland (1.6 to $1.8 \%$ ) had a relatively lower disability take-up rate for this age group (Figure 3). ${ }^{6}$

\footnotetext{
${ }^{6}$ To improve comparability across countries, persons receiving sickness benefits for more than two years are counted towards disability benefit recipiency (which matters for Sweden). The same pattern has been reported in NOSOSCO 2012, Figure 2.8 (Norway), Figure 3.9 (Sweden) and Figure 6.9 (Finland).
} 
Figure 5.1: Disability benefit recipiency rates. Percent of all aged 20-34. (OECD, 2009)

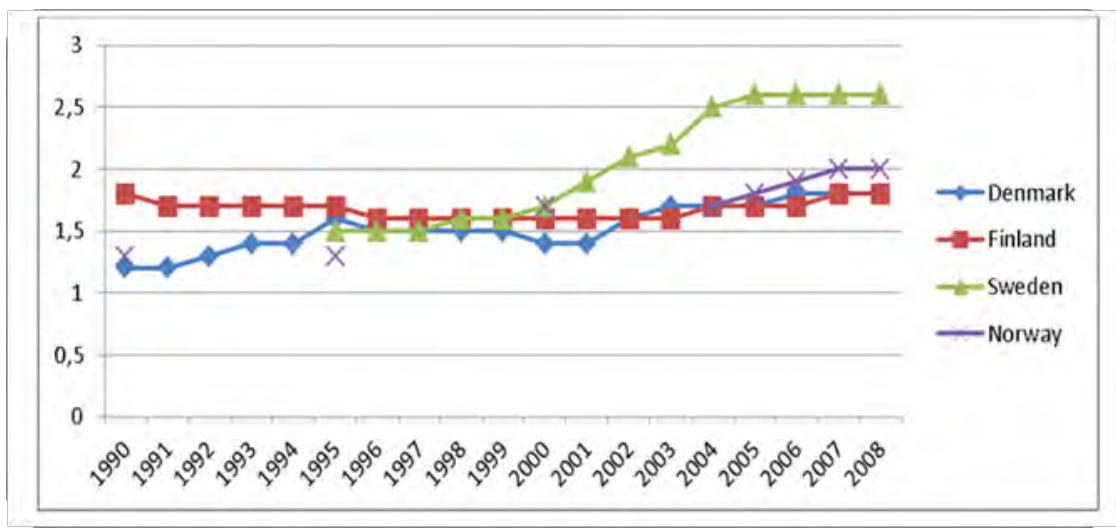

More recent figures about a slightly younger age group (16/18-29 years old) demonstrates that of the Nordic countries Iceland had the highest proportion of young adults in receipt of disability benefit (nearly 3\%), followed by Norway and Sweden (between 2 and 3\%): During 1998-2011 Norway and Sweden has had a similar development with a constant increase of young adults in receipt of disability benefits, although the ratio has been higher in Norway than in Sweden. Denmark and Finland has remained at a lower proportion of young disability benefit recipients (about 1.5\%) than Iceland, Norway and Sweden (Bernitz et al., 2013: 40). ${ }^{7}$

According to Bernitz et al. (2013:41) the number of young males claiming disability benefits was slightly higher than the number of women in Finland and Denmark. In Norway and Sweden, the distribution was relatively even between the sexes, while Iceland had a slightly higher number of women with disability benefits. In all the Nordic countries, mental and behavioural disorders was the most common diagnostic group among young adults on disability benefits

\footnotetext{
${ }^{7}$ For an overview of the social benefit schemes included in the figures, see Bernitz, B. K., et al. 2013. Unga förtidspensionärer. Studie av sju europeiska länder (Young Adults on Disability Benefits). Stockholm, Swedish Social Insurance Inspectorate (Inspektionen för socialforsäkringen) , page 37.
} 
National data from the Finnish centre for pensions show that the number of young people (16-29 years) receiving disability pensions has slightly increased in the 2000s. At the end of 2010, there were nearly 13,000 young people on disability pension, which equals $1.4 \%$ of those aged $16-$ 29 years. According to Raitasalo and Maaniemi (2011) five young people under the age of 30 retire each day due to mental health problems. From 2004 to 2009, the amount of depression-caused retirement in young men increased $60 \%$ and the amount of women increased as much as $42 \%$ in Finland (ibid.).

\subsection{Employment rates among youth with disabilities}

During the first decade of the 2000s young adults have lower employment rates than the working age population as a whole. According to Eurostat Labour Force Survey their employment has also developed less favourably. Apart from Sweden, the employment rates among the young decreased in all Nordic countries. The decrease in youth employment was most remarkable in Denmark (down 8\%). In Denmark and Norway, where employment rates for those aged 16-64 decreased, the employment rates for young adults decreased even more. In Sweden and Finland where employment rates increased in the general working age population, the employment increased less among the young in Sweden and decreased in Finland (Table 5.1).

Due to the methodological problems accounted for Chapter 3 (change in definition of disability and small $\mathrm{N}$ ) the findings should interpreted with caution. 
Table 5.1: Employment rates $^{8}$ in 2002 and 2011, percent. All and self-reported health problem.16-64 years (all) and 16-29 years ${ }^{9}$

\begin{tabular}{|c|c|c|c|c|}
\hline Employment rate & Denmark & Finland & Norway & Sweden \\
\hline \multicolumn{5}{|l|}{$16-64$ all } \\
\hline 2002 & 77 & 70 & 78 & 70 \\
\hline 2011 & $74(-3)$ & $71(+1)$ & $76(-2)$ & $75(+5)$ \\
\hline \multicolumn{5}{|l|}{ Youth all } \\
\hline 2002 & 73 & 59 & 66 & 51 \\
\hline 2011 & $65(-8)$ & $56(-3)$ & $63(-3)$ & $54(+3)$ \\
\hline \multicolumn{5}{|c|}{ Youth without disabilities } \\
\hline 2002 & 73 & 59 & 67 & 52 \\
\hline 2011 & $68(-5)$ & $56(-3)$ & $64(-3)$ & $54(+2)$ \\
\hline \multicolumn{5}{|c|}{ Youth with disabilities } \\
\hline 2002 & 63 & 58 & 54 & 55 \\
\hline 2011 & $50(-13)$ & $57(-1)$ & $48(-6)$ & $55(0)$ \\
\hline \multicolumn{5}{|c|}{ Absolute difference in employment rate between youth with and without disabilities } \\
\hline 2002 & -10 & -1 & -13 & +3 \\
\hline 2011 & -18 & +1 & -16 & +1 \\
\hline
\end{tabular}

Source: Eurostat LFS disability ad hoc module 2002 and 2011.

Regarding the development in employment rates among youth with disabilities we find two groups of countries: In Denmark and Norway the employment rates decreased, while in Sweden and Finland the employment rates remained unchanged (Table 5.1).

When compared to young adults without disabilities we find again the same two groups of countries: In Denmark and Norway youth with disabilities have lower employment rates than youth without disabilities. The difference between young adults with and without disabilities has increased the last decade and more so in Denmark than Norway. In Sweden

\footnotetext{
${ }^{8}$ Employed was defined as those who during the reference week performed work, even for just one hour a week, for pay, profit or family gain, or who were not at work but had a job or business from which they were temporarily absent because of, e.g., illness, holidays, industrial dispute or education and training. ${ }^{9}$ For Finland the age groups follow the national statistical definitions. From 2005 the employment statistics only cover adults (18 years and older); i.e. the age group for the Finish 2011 data are 18-74 years and 18-29 years.
} 
and Finland the employment rates do not differ, nor do we witness any significant improvement.

Unsurprisingly the employment rate was highest among young adults with mild disabilities and declined with increasing degree of severity. Of the Nordic countries Denmark and Norway had the highest employment rate for youth with mild disabilities both in 2002 and 2011. In all Nordic countries the employment rate decreased for youth with mild disabilities between 2002 and 2011, except Norway where the rate increased. For youth with severe and very severe disabilities the employment rate decreased in Denmark (from 57 to 30\%), Finland (from 56 to 51\%) and Norway (from 39 to 37\%), but increased in Sweden (from 39 to 49\%) (Figure 5.2).

Figure 5.2: Youth employment rates in 2002 and 2011 (\%). Eurostat LFS disability ad hoc modules

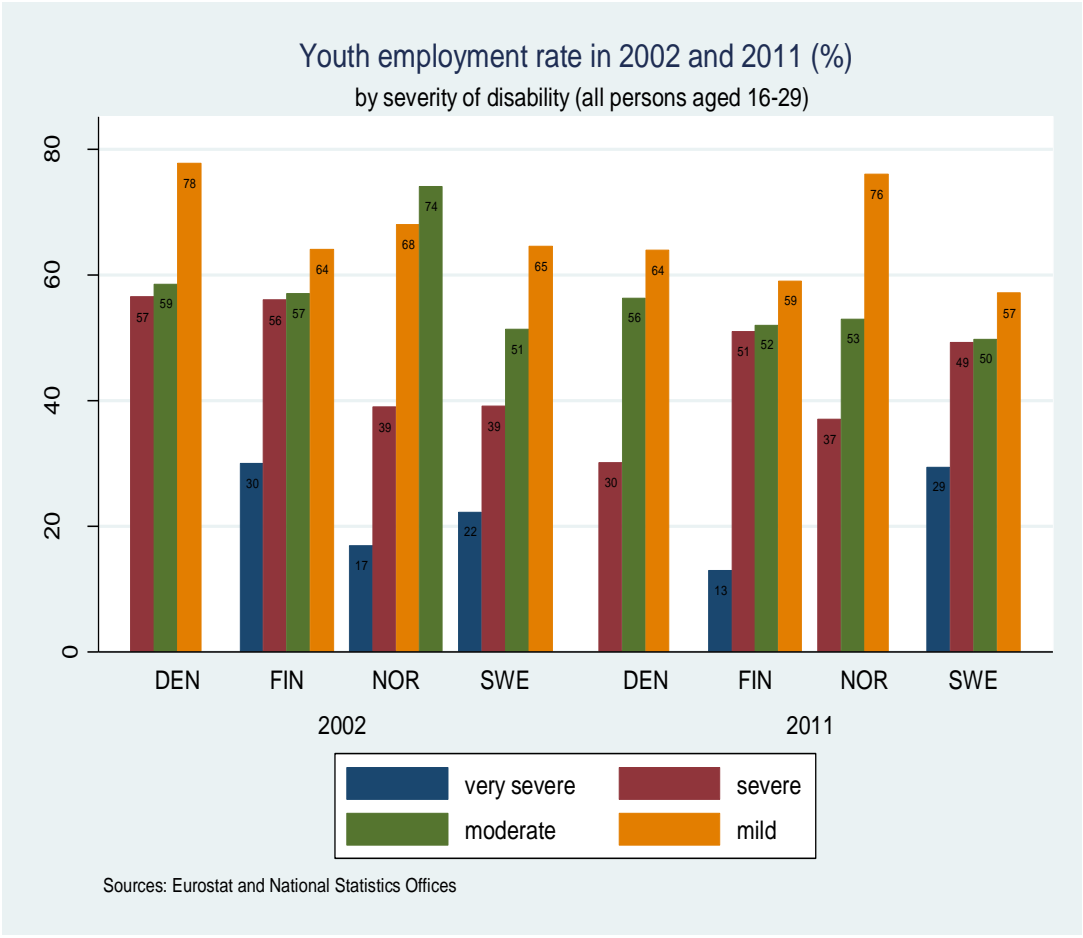


In Norway the decline in employment rate was most significant for young adults with disabilities in the age group 15-19 years and 20-24 years. More detailed data from Norway suggests that for this country the difference between persons with and without disabilities in employment was small for the youngest age cohort (age 15-19) but was larger for the older age groups. The employment gap increased with increasing age. This suggests that while youth without disabilities achieved paid work when they had finished their studies youth with disabilities did so to a lesser extent.

In the age group 15-19 years the employment rate declined from $43 \%$ in 2002 to $39 \%$ in the general population and from 42 to 30 among youth with disabilities. In the age group 20-24 years the employment rate remained unchanged at $67-68 \%$ for the general population and declined from 56 to $47 \%$ for youth with disabilities. In the age group 25-29 the employment rate remained unchanged at $80-81 \%$ in the general population and $59-57 \%$ for youth with disabilities. In the age group 30-34 the employment rate declined from 90 to $84 \%$ in the general population and from 57 to $40 \%$ among adults with disabilities (Statistics Norway 2013, LFS disability ad hoc modules 2002, 2007 and 2012)(Bø and Håland, 2013).

The Eurostat LFS ad hoc modules suggest that the employment gap has increased between young adults with and without disabilities, notably in Denmark and Norway. Do we find the same trend in the EU-SILC panel data? 
Table 5.2: Employment rate among young without disability, young with disability (i.e. long standing health problem) and young with severe disability (some or strong limitations) ${ }^{10} 16-29$ years. Both sexes

\begin{tabular}{|c|c|c|c|c|}
\hline & & 2005 & 2008 & 2011 \\
\hline \multirow[t]{3}{*}{ Denmark } & Young adults without disability & $52 \%$ & $42 \%$ & $32 \%$ \\
\hline & Young adults with disability & $49 \%$ & $51 \%$ & $18 \% *$ \\
\hline & Young adults with severe disability & $50 \%$ & $40 \%$ & $26 \% *$ \\
\hline \multirow[t]{3}{*}{ Finland } & Young adults without disability & $49 \%$ & $50 \%$ & $42 \%$ \\
\hline & Young adults with disability & $46 \%$ & $48 \%$ & $45 \%$ \\
\hline & Young adults with severe disability & $45 \%$ & $40 \%$ & $35 \%$ \\
\hline \multirow[t]{3}{*}{ Iceland } & Young adults without disability & $67 \%$ & $54 \%$ & $38 \%$ \\
\hline & Young adults with disability & $75 \%$ & $58 \%$ & $35 \%$ \\
\hline & Young adults with severe disability & $68 \%$ & $36 \%$ & $25 \%$ \\
\hline \multirow[t]{3}{*}{ Norway } & Young adults without disability & $46 \%$ & $54 \%$ & $43 \%$ \\
\hline & Young adults with disability & $50 \%$ & $46 \%$ & $42 \%$ \\
\hline & Young adults with severe disability & $40 \%$ & $43 \%$ & $34 \%$ \\
\hline \multirow[t]{3}{*}{ Sweden } & Young adults without disability & $44 \%$ & $49 \%$ & $48 \%$ \\
\hline & Young adults with disability & $48 \%$ & $50 \%$ & $51 \%$ \\
\hline & Young adults with severe disability & $36 \%$ & $40 \%$ & $49 \%$ \\
\hline
\end{tabular}

Source: European Union Statistics on Income and Living Conditions (EU-SILC)

In Denmark, Finland and Iceland the development is rather similar over the period of examination: the employment rates among young adults has declined between 2005 and 2011. In Iceland and Denmark, the drop is more notable among those young people with disability and especially among those young adults whose long-standing health problem limits their daily activities. The difference in employment rates between young adults without disability and those with severe disability was approximately $10 \%$ in 2011, while in 2005 the difference was much smaller.

The development in Norway resembles that of the Danish, Finish and Icelandic: the trend is similar, yet more modest. Employment rates have declined both among young people without disability and young people with disability. In Norway, the difference between young people without disability and young people with severe disability has, however, remained stable over the period.

$10 *$ If un-weighted number of cases if smaller than 20. 
Sweden differs from other Nordic countries as the employment rates have increased rather than decreased over the period of examination. The increase is particularly noticeable among young adults with severe disability, and there is no difference in employment rates in 2011.

Overall, available employment data provide a mixed picture of the Nordic countries. While some of the findings clearly are related to methodological problem, the general trend is that the difference in employment rate between young adults with and without disabilities has increased or remained unchanged the last decade (Sweden being the exception). More detailed Norwegian data suggest that the difference increases when the young adults have finished their tertiary education, i.e. after they have turned 20 years old.

\subsection{Education rates among youth with disabilities}

Employment rates and incomes are strongly correlated with educational level and qualifications(OECD, 2012 ).A regression analysis of EU-SILC data from 2010 found that on average in Europe having a tertiary education increases the employment probability of males by $7 \%$ in comparison to people with (at most) lower secondary education. The equivalent for females was about 11\% (Grammenos, 2013:285).The returns of education for persons with disabilities were significantly higher compared to persons without disabilities (ibid. 287-88).

In Norway, persons with higher education are more likely to be employed among all population groups, but among persons with disabilities this impact was twice that of non-disabled persons (Molden et al., 2009).Survey data from 2007 found that $23 \%$ of Norwegians with disabilities had higher education, compared to $37 \%$ of persons without disabilities. More women than men have higher education, and the same is the case for disabled people (26 and 18\% for women and men respectively) (ibid.). When controlling for a range of other factors (including gender) and adopting different operational definitions of disability, the most significant factors for predicting employment participation among Norwegians with disabilities were educational level, and next, severity of disability and age (Molden and Tøssebro, 2012). 
In Denmark,Kjeldsen et al. (2013a) found that among Danes with disabilities (16-64 years old), 15\% had reading and writing problems, while this was the case for $6 \%$ among Danes without disabilities. Among Danes with disabilities and reading and writing problems, $28 \%$ were employed, while this was the case for $47 \%$ among Danes with disabilities but without reading and writing problems. The corresponding figures for Danes without disabilities were $69 \%$ and $78 \%$. The findings regarding reading and writing problems demonstrate that not only health issues impact on the employment prospects of persons with disabilities but also depends on the design and inclusiveness of the national education system. For these reasons, a critical question is to what extent Nordic education systems are able to furnish youth with disabilities with the qualifications they need to find suitable jobs.

For such reasons, a critical question is to what extent the educational systems in the Nordic countries are able to furnish youth with disabilities with the qualifications they need to find suitable jobs. In the previous section we demonstrated that the employment rate has declined or remained unchanged among youth with disabilities. We may ask if this is because young adults with disabilities take more or longer education than 10-15 years ago.

The LFS disability ad hoc module data demonstrates that the development in education rates ${ }^{11}$ differed between the Nordic countries. Among youth without disabilities the education rates increased in Sweden between 2002 and 2011, whereas in the other countries it remained at the same level. Among youth with disabilities education participation rates declined in Denmark and Finland, whereas it increased in Sweden and Norway. When looking at the absolute difference in education rates, we see that in Finland and Denmark the difference in education rates between youth with and without disabilities increased. In Norway the difference remained unchanged. In Sweden, however, the difference between

\footnotetext{
${ }^{11}$ Education covered students and apprentices in regular education during the last four weeks, and participation in any courses, seminars, conferences, private lessons or instructions outside the regular education system within the last four weeks.
} 
youth with and without disabilities decreased, and in 2011 we find no difference between the two youth groups (Table 5.3).

Table 5.3: Youth (aged 16-29) in education in 2002 and 2011. Percent

\begin{tabular}{|c|c|c|c|c|}
\hline & Denmark & Finland & Sweden & Norway \\
\hline \multicolumn{5}{|c|}{ All aged $16-29$} \\
\hline 2002 & 55 & 56 & 52 & 41 \\
\hline 2011 & $55(0)$ & $52(-4)$ & $61(+9)$ & $43(+2)$ \\
\hline \multicolumn{5}{|c|}{ Young without disability } \\
\hline 2002 & 56 & 57 & 54 & 42 \\
\hline 2011 & $56(0)$ & $55(-2)$ & $61(+7)$ & $44(+2)$ \\
\hline \multicolumn{5}{|c|}{ Young with disability } \\
\hline 2002 & 54 & 54 & 48 & 33 \\
\hline 2011 & $45(-9)$ & $48(-6)$ & $60(+12)$ & $36(+3)$ \\
\hline \multicolumn{5}{|c|}{ Absolute difference in education rate between youth with and without disabilities } \\
\hline 2002 & $(-2)$ & $(-3)$ & $(-8)$ & $(-9)$ \\
\hline 2011 & $(-11)$ & $(-7)$ & $(-1)$ & $(-8)$ \\
\hline
\end{tabular}

Sources: Eurostat LFS disability ad hoc modules 2002 and 2011.

We find two contrasting development trends in educational attainment in the Nordic countries: declining participation rates and increasing differences in Denmark and Finland versus increasing participation and decreasing differences in Sweden. Norway has remained unchanged.

More detailed data from Norway suggests that for this country the education rate remained unchanged between 2002 and 2012 for men and women in general but with an increase in educational participation for women aged 20-24. We find a more mixed picture among men and women with disabilities. Some of the variations are probably due to the smaller samples for young adults with disabilities. We might, however, observe an increase in the share of young men with disabilities in education (aged 20-24) (Table 5.4 and 5.5). 
Table 5.4: Men. Youth in education. All and disabled (self-reported). Percent. Norway

\begin{tabular}{lrrrrrr} 
All men & \multicolumn{5}{c}{ Men with disabilities } \\
Age/year & $\mathbf{2 0 0 2}$ & $\mathbf{2 0 0 7}$ & $\mathbf{2 0 1 2}$ & $\mathbf{2 0 0 2}$ & $\mathbf{2 0 0 7}$ & $\mathbf{2 0 1 2}$ \\
$15-19$ & 83.6 & 79.8 & 82.6 & 77.8 & 87.5 & 78.5 \\
$20-24$ & 33.1 & 31.7 & 32.7 & 20.0 & 23.1 & 38.5 \\
$25-29$ & 13.1 & 9.5 & 13.8 & 20.0 & 8.3 & 6.3 \\
\hline
\end{tabular}

Source: Statistics Norway, LFS disability ad hoc modules (AKU)

Table 5.5: Women. Youth in education. All and disabled (self-reported). Percent. Norway

\begin{tabular}{lrrrrrr} 
All women & \multicolumn{5}{c}{ Women with disabilities } \\
Age/year & $\mathbf{2 0 0 2}$ & $\mathbf{2 0 0 7}$ & $\mathbf{2 0 1 2}$ & $\mathbf{2 0 0 2}$ & $\mathbf{2 0 0 7}$ & $\mathbf{2 0 1 2}$ \\
$15-19$ & 88.5 & 85.4 & 87.3 & 87.5 & 83.3 & 62.5 \\
$20-24$ & 40.3 & 40.6 & 45.9 & 27.3 & 33.3 & 31.3 \\
$25-29$ & 17.3 & 14.7 & 16.3 & 14.3 & 20.0 & 13.3
\end{tabular}

Source: Statistics Norway, LFS disability ad hoc modules (AKU).

EU-SILC data suggest that there is a link between employment rates and education participation rates. In countries where employment rates have decreased over the period of examination, education rates have increased and vice versa. Denmark and Finland had an increase in education participation rates, while Sweden had a decrease. In Iceland and Norway the development was more mixed or the education participation rates remained unchanged (Table 5.6). 
Table 5.6: A share of those in education (education rate) among young without disability, young with disability (i.e. long-standing health problem) and young with severe disability (some or strong limitations)

\begin{tabular}{|c|c|c|c|c|}
\hline & & 2005 & 2008 & 2011 \\
\hline \multirow[t]{3}{*}{ Denmark } & Young adults without disability & $51 \%$ & $60 \%$ & $66 \%$ \\
\hline & Young adults with disability & $52 \%$ & $39 \%$ & $62 \%$ \\
\hline & Young adults with severe disability & $47 \%$ & $54 \%$ & $66 \%$ \\
\hline \multirow[t]{3}{*}{ Finland } & Young adults without disability & $53 \%$ & $54 \%$ & $55 \%$ \\
\hline & Young adults with disability & $59 \%$ & $56 \%$ & $58 \%$ \\
\hline & Young adults with severe disability & $40 \%$ & $46 \%$ & $48 \%$ \\
\hline \multirow[t]{3}{*}{ Iceland } & Young adults without disability & $56 \%$ & $53 \%$ & $61 \%$ \\
\hline & Young adults with disability & $49 \%$ & $45 \%$ & $59 \%$ \\
\hline & Young adults with severe disability & $51 \%$ & $33 \%$ & $53 \%$ \\
\hline \multirow[t]{3}{*}{ Norway } & Young adults without disability & $57 \%$ & $46 \%$ & $52 \%$ \\
\hline & Young adults with disability & $54 \%$ & $49 \%$ & $56 \%$ \\
\hline & Young adults with severe disability & $50 \%$ & $46 \%$ & $55 \%$ \\
\hline \multirow[t]{3}{*}{ Sweden } & Young adults without disability & $47 \%$ & $46 \%$ & $42 \%$ \\
\hline & Young adults with disability & $46 \%$ & $42 \%$ & $42 \%$ \\
\hline & Young adults with severe disability & $46 \%$ & $38 \%$ & $33 \%$ \\
\hline
\end{tabular}

Source: European Union Statistics on Income and Living Conditions (EU-SILC)

During the period of study the changes in education rates are more modest than in employment rates. The most notable changes have taken place in Denmark, where education rates among severely disabled young adults have increased significantly and in Sweden where it has on contrary declined (but on the other hand their employment rate has increased over the period of examination).

Not only Eurostat LFS disability ad hoc modules and Norwegian survey data but also EU-SILC data demonstrate that the difference between young adults with and without disability is smaller in education than in employment rates (Sweden being an exception) (Table 5.6).

\subsection{NEET-rates among youth with disabilities}

NEET rates has a an additional value to that of unemployment rates as it eliminates those still in school and identify those who are disengaged from labour market, education or training, and who potentially may be mobilised to participate in the labour market. The denominator of the 
NEET rates is the total population of young adults while the unemployment rates only refers to the economically active members of the population. This is why NEET rates tend to be lower than unemployment rates(Eurofound, 2012: 23).

NEETs covers a heterogeneous population, including young carers and young adults with family responsibilities not available to the labour market. Included in the NEET figures are also the conventional short-term and long-term unemployed who are actively seeking employment as well as discouraged workers (ibid., p. 24). The NEET population covers early school leavers and drop-outs who lack formal qualifications, persons who have a diploma but nevertheless experience difficulties in achieving paid work, as well as persons not available to the labour market (including care givers) (OECD, 2010).

Earlier research suggest that the NEET population fluctuates during the course of the year (Quintini and Martin, 2006). Short time spells as NEET is likely to reflect frictional unemployment; i.e. short transition periods between education and employment. As argued by Bäckman and Nilsson (2013) the young adults most at riskare those in NEET for longer time spells. To get a more accurate picture of the temporal dimension of the transitions in and out of the labour market we would need individual level data - which has not been available. While available aggregate data do not provide information about the duration of the NEET status, change in the NEET rates the last 10-15 years is nevertheless an indicator of the changes in difficulties in converting education to employment or the friction in the transition from school to work.

In the general youth population, NEET rates in the Nordic countries are larger in the older age groups. In 2012 gender differences were small except for the oldest age group with a larger NEET among women (Table 5.7).

Table 5.7: NEET rates in the general youth population (\%). 2012. Age/gender difference*

\begin{tabular}{lrrrrrr} 
& \multicolumn{2}{c}{ 15-19 years } & \multicolumn{2}{c}{$\mathbf{1 5 - 2 4}$ years } & \multicolumn{2}{c}{$\mathbf{2 5 - 2 9}$ years } \\
& Total & Gender difference & Total & Gender difference & Total & Gender difference \\
DK & 3.8 & -0.6 & 6.3 & -0.3 & 10.5 & 2.9 \\
FIN & 4.3 & 0.1 & 8.4 & -0.5 & 13.0 & 6.6 \\
SE & 4.2 & $-0-9$ & 7.5 & -0.3 & 8.4 & 3.7 \\
\hline
\end{tabular}

Source: Eurofound (2012: 29). Data from Iceland and Norway were not available.

* female-male difference. 
What is new information in this section is data on development trends in NEET among Nordic youth with disabilities. According to the LFS disability ad hoc module data from 2002 and 2011, the NEET rate remained unchanged for young adults without disabilities in all four Nordic countries. For young adults with disabilities the NEET rate increased in Denmark (from 11 to 19\%) and Norway (from 21 to 24\%) while the rate remained unchanged in Finland (from 15 to 14\%) and decreased in Sweden (from 13 to 8\%). Both young adults with disabilities had significantly higher NEET rates in all Nordic countries, except Sweden in 2011.

Table 5.8: Youth (aged 16-29) Not in in employment, education or training in 2002 and 2011. Percent

\begin{tabular}{|c|c|c|c|c|}
\hline & Denmark & Finland & Sweden & Norway \\
\hline \multicolumn{5}{|c|}{ All aged $16-29$} \\
\hline 2002 & 6 & 11 & 9 & 7 \\
\hline 2011 & $8(+2)$ & $11(0)$ & $7(-2)$ & $7(0)$ \\
\hline \multicolumn{5}{|c|}{ Without disability } \\
\hline 2002 & 5 & 9 & 8 & 6 \\
\hline 2011 & $6(+1)$ & $9(0)$ & $7(-1)$ & $6(0)$ \\
\hline \multicolumn{5}{|c|}{ With disability } \\
\hline 2002 & 11 & 15 & 13 & 21 \\
\hline 2011 & $19(+8)$ & $14(-1)$ & $8(-5)$ & $24(-3)$ \\
\hline \multicolumn{5}{|c|}{ Absolute difference in NEET rate between young with and without disabilities } \\
\hline 2002 & $(-6)$ & $(-6)$ & $(-5)$ & $(-15)$ \\
\hline 2011 & $(-13)$ & $(-5)$ & $(-1)$ & $(-18)$ \\
\hline
\end{tabular}

Source: Eurostat LFS disability ad hoc module 2002 and 2011.

More detailed data from Norway suggests that for this country the NEET rate was higher for persons with disabilities in all age groups but particularly from the age of 20 and older. Between 2002 and 2012 the NEET rate decreased among men and women with disabilities aged 15-19 and men with disabilities aged 20-24 but increased for all other age groups. ${ }^{12}$

We find the same basic trend reflected in the EU-SILC data. For this data set we have available two alternative NEET measures: those not in em-

${ }_{12}^{12}$ LFS disability ad hoc modules, Statistics Norway 2002, 2007, 2012. Because we do not have the NEET figures for this particular Norwegian data set we use the figures for those not in employment or education as a proxy for NEET. The figures may include persons participating in active labour market training courses. 
ployment, education or training (NEET RATE 1) and those not in employment, education or training or not taking care child or in military service (NEET RATE 2). The trends and picture is rather similar with the two alternative measures of NEET rate but for obvious reason the rates are lower in the second alternative (Table 5.9).

Table 5.9: Share of those not in employment, education or training (NEETRATE 1) among young adults with and without disability (long-standing health problem) and share of those not in employment, education or training or not taking care child or in military service (NEETRATE 2, in brackets).Percent. Weighted

\begin{tabular}{|c|c|c|c|c|}
\hline & & 2005 & 2008 & 2011 \\
\hline \multirow[t]{4}{*}{ Denmark } & Young people without disability & 8.4 & 9.8 & 13.2 \\
\hline & & (3.9) & (4.5) & $(5.2)$ \\
\hline & Young with disability & $12.7^{*}$ & $18^{*}$ & 16.5 \\
\hline & & $\left(9.4^{*}\right)$ & $\left(11.0^{*}\right)$ & $\left(8.4^{*}\right)$ \\
\hline \multirow[t]{4}{*}{ Finland } & Young people without disability & 13.3 & 12.6 & 16.5 \\
\hline & & (5.9) & (3.7) & (6.5) \\
\hline & Young with disability & 21.4 & 20.4 & 20.7 \\
\hline & & $(14.7)$ & $(11.7)$ & (13.1) \\
\hline \multirow[t]{4}{*}{ Iceland } & Young people without disability & 5.0 & 6.5 & 9.5 \\
\hline & & $\left(2.7^{*}\right)$ & $\left(2.2^{*}\right)$ & (5.0) \\
\hline & Young with disability & 9.6 & 21.4 & 22.0 \\
\hline & & $\left(7.3^{*}\right)$ & $\left(14.5^{*}\right)$ & $(18.2)$ \\
\hline \multirow[t]{4}{*}{ Norway } & Young people without disability & 6.4 & 11.3 & 15.7 \\
\hline & & $(0.3 *)$ & (3.2) & $(1.8 *)$ \\
\hline & Young with disability & 10.4 & 16.4 & 16.0 \\
\hline & & $(5.0)$ & $(8.1 *)$ & $\left(6.7^{*}\right)$ \\
\hline \multirow[t]{4}{*}{ Sweden } & Young people without disability & 10.7 & 6.6 & 11.7 \\
\hline & & (8.7) & (5.3) & (9.5) \\
\hline & Young with disability & 14.6 & 13.1 & 12.6 \\
\hline & & $(14.4)$ & (11.6) & (11.7) \\
\hline
\end{tabular}

Source: European Union Statistics on Income and Living Conditions (EU-SILC).

*If un-weighted number of cases if smaller than 20. 
Young adults with disabilities have higher NEET rates than young adults without disabilities. The difference is most visible in Iceland. In Sweden the rates are almost the same for young adults with and without disabilities in 2011. NEET rates have increased over the period of examination apart from Sweden. The increase had been particularly strong in Norway and more modest in Finland. In Denmark, Iceland and Norway NEET rates have increased more among young people with disabilities than among young people without disabilities (ibid.).

\subsection{Concluding comment}

This chapter has examined whether reforms in labour inclusion policy has increased the employment prospects and opportunities for young adults with disabilities in the Nordic countries. In all Nordic countries except Sweden - the employment rates decreased in the first decade of the 2000s. Additionally NEET rates increased in Denmark, Iceland and Norway. To some extent national authorities appear to have succeeded in increasing the rate of students in higher education to maintain a low NEET rate (although the LFS ad hoc module data and EU-SILC data contradict each other at this point). Finally, the rate of young adults in receipt of disability benefits increased in all the Nordic countries during the last decade.

In conclusion, there is little evidence which suggest that the Nordic countries managed to improve the employment prospects for young adults with disabilities in the last decade. In addition to methodological problems associated with varying definitions of "disability" and instability over time in the respondents who report to have a "disability" (Molden and Tøssebro, 2012), lack of individual level data prevents us from drawing conclusions about the duration of time spells outside employment, education or training. Despite the uncertainties related to the reliability and comparability of available figures, there can be no doubt that a large proportion of young adults with disabilities have been practically excluded from gainful employment in the Nordic countries. 
Returning to the question of the impact of regulatory social policies on the employment prospects of young adults with disabilities, we may ask why we do not find any evidence of improvements despite the policy reforms the last decade. Apart from the methodological issues we find at least two alternative interpretations. First, we may ask whether the introduction of new regulatory policy measures has been counterproductive or not properly enforced. Second, the outcomes or policy returns can be due to design and implementation issues in other subsystems of the social policy system (including the education system) during the same period and affecting the employment prospects of young adults with disabilities. We will examine this in more detail in the concluding Chapter 8. 


\section{The employment opportunities and prospects of minority ethnic youth in the Nordic countries}

Have reforms in the labour inclusion policy improved the employment prospects for minority ethnic youth in the Nordic countries? Chapter 6 examines whether we find any evidence of changes in the participation rates that can be connected to the introduction of new policy instruments in the Nordic countries in the last decade and not only fluctuations in the business cycle. Based on time series data Chapter 6 examines the employment, education and NEET rates for minority ethnic youth and compares with youth in general. The emphasis in this chapter is a comparison after country of origin - natives with native born parents and persons born in different categories of other countries and their children.

\subsection{Ethnic stratification in the Nordic labour markets}

The study of ethnic stratification - the construction of social boundaries based on race or ethnicity - in working life is expanding in sociological research. Due to an increase in cross-national mobility and ethnic diversity the Nordic countries have seen a growing concern that ethnic diversity is accompanied by ethnic stratification, with white majority ethnic groups at the top of the hierarchy and visible minority ethnic groups with origin in developing countries at the bottom(Bevelander et al., 2013, Heath et al., 2008).

The notion of "equal opportunities" in the labour market is attributed different meanings. The notion initially referred to absence of legal barriers 
which prevent certain ethnic groups from obtaining employment. Sociologists have used the notion more broadly to include the absence of the de facto barriers to participation, e.g. recognition of education credentials and work experience from other countries, access to training in the language of the majority population, reasonable accommodation, and absence of discrimination and harassment in working life. ${ }^{13}$

Their disadvantages in the labour market are, however, not necessarily indicative of inequality of opportunity per se but rather differences in aspirations or investment in education or socialization into the cultural codes in national educational systems. Such alternative interpretations have emphasised the impact of socio-economic background and parental involvement on educational attainment(Boudon, 1974 , Lauglo, 2000).

Several national studies provide indicators on the employment and employability of minority ethnic groups in the Nordic countries. These studies show lower employment rates for first generation minorities than for the native born population, especially for persons immigrating from developing countries. The employment gap has been particularly high between women who have immigrated from developing countries and native born women (Bevelander et al., 2013, Jonsson, 2007, Schröder, 2007).

This is balanced by two facts: first, a number of studies find that the labour-market attainment of first generation minorities increases with years of residence in the host country (Brekke and Mastekaasa, 2008, Jonsson, 2007). Second, second generation minorities tend to perform better than their parents in the labour market (Jonsson, 2007). Several studies find that some minorities outperform majority ethnic students in higher education (Fangen and Frønes, 2013).

After controlling for educational attainment and the resources of the family of origin some studies find no or insignificant differences in activity level (continued education or employment)among 20-29 years old in the Scandinavian countries (Olsen, 2012). Activity level was only marginally affected by gender and immigration status. However, Olsen (2012) found that an im-

\footnotetext{
13 Other sociologists have used the notion to refer to equality in outcome. In this context we retain the use to a focus on the conditions for participation.
} 
portant reason for differences in activity level between the population groups was that first generation minorities, and to some extent second generation minorities, have larger shares with only compulsory education.

Other studies find "a gradient in the disadvantages faced by secondgeneration [minorities] suggesting that the more visible the ethnic origin, the lower the probability of being employed" (Jonsson, 2007:452). Especially non-European (notably African) minority ethnic groups experience difficulties in achieving paid work. In Norway, Brekke (2007:1299) found that transition from education to employment takes longer time for those with a minority ethnic background (especially for persons with background from Africa) compared to the majority ethnic group. Insofar as ethnic stratification is reproduced between first and second generation minorities in Norway, this appears "not to happen via differential allocation to occupational positions, but primarily within the educational system and at the entrance to the labour market" (Hermansen, 2013:517).

Below we examine new and updated data on the labour-market attainment of ethnic majority and minority youth in the Nordic countries. We focus particularly on those who according to earlier research experience the largest difficulties in achieving employment e.g. minorities with background from Africa and Asia (Jonsson, 2007). As these minority groups have been most at risk of experiencing discrimination in the labour market, regulatory social policy measures have potentially the largest impact for these minority groups. Recent labour immigration from EU/EEA countries to the Nordic countries, especially from Poland, Lithuania and other Central and Eastern European countries, make these population groups interesting comparators (Friberg and Eldring, 2013).As employment rates vary considerably dependent on the country of origin we want to avoid generalisation about entire immigrant populations. The data we have available are, however, limited to broad categories of countries and may hide important differences within the categories. 


\subsection{Employment rates among minority ethnic youth}

On the one hand, we expect smaller ethnic penalty for younger age cohorts than for the older age cohorts, especially for first generation minorities. Younger age cohorts are more likely to acquire the majority language and complete education in the new host country. On the other, first and second generation minority ethnic youth experience other and additional problems in transition from education to employment than majority ethnic youth (cf. Chapter 2).

Norwegian register data indicate that we find the largest ethnic penalty among those expected to be at their peak working age (born 19551975).We find the clearest gap in employment rates between all men of working age and men born in Africa, except for the earliest (born before 1935) and latest (born after 1985) cohorts. Likewise, we find a tendency to growing gaps in employment of all men of working age and men born in Asia, especially for cohorts that are now in late middle age (born before 1965). The differences in employment rates are much smaller between all men of working age and men born in new EU member states (independent of age cohort).These cross-sectional data suggest that the employment gap increases when most people have finished their education and decreases when people get closer to retirement age, especially for first generation minorities from Africa and Asia (Figure 6.1-6.3, also Table1-3 in the Annex). 
Figure 6.1: Cohort specific employment rate. Age. Total men (TM) (upper curve) and men born in Africa (AFM) (lower curve).Percent. Norway. 2000-2010

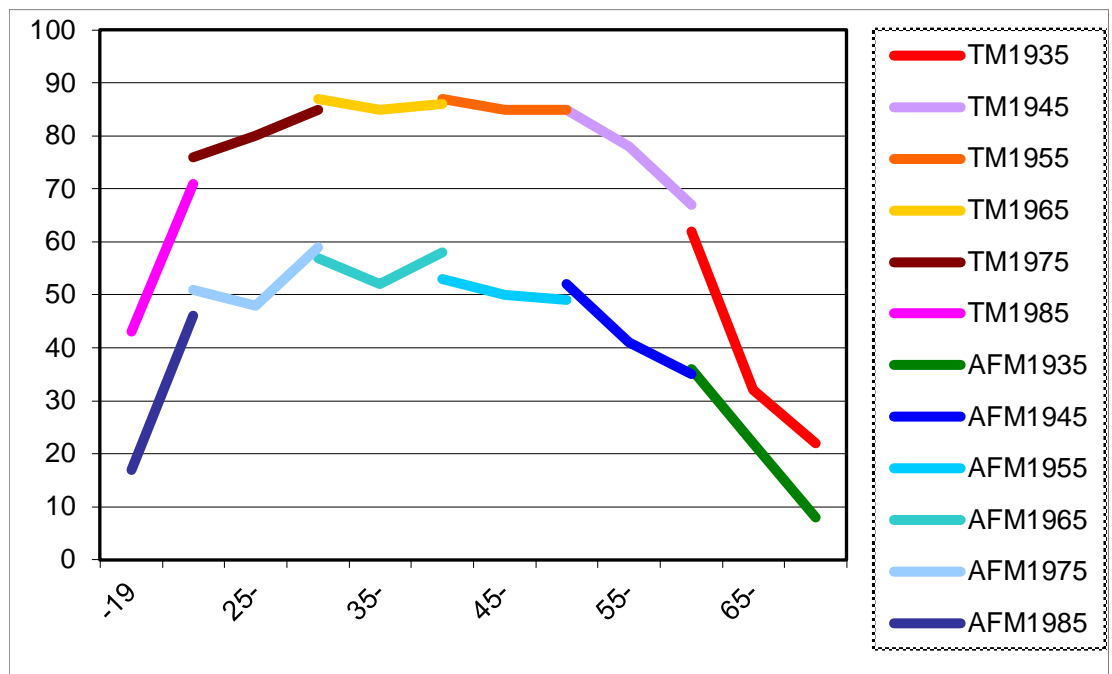

Source: Register data, Statistics Norway 2001, 2004, 2009.

Figure 6.2: Cohort specific employment rate. Age. Total men (TM) (upper curve) and men born in Asia (ASM) (lower curve). Percent. Norway. 2000-2010

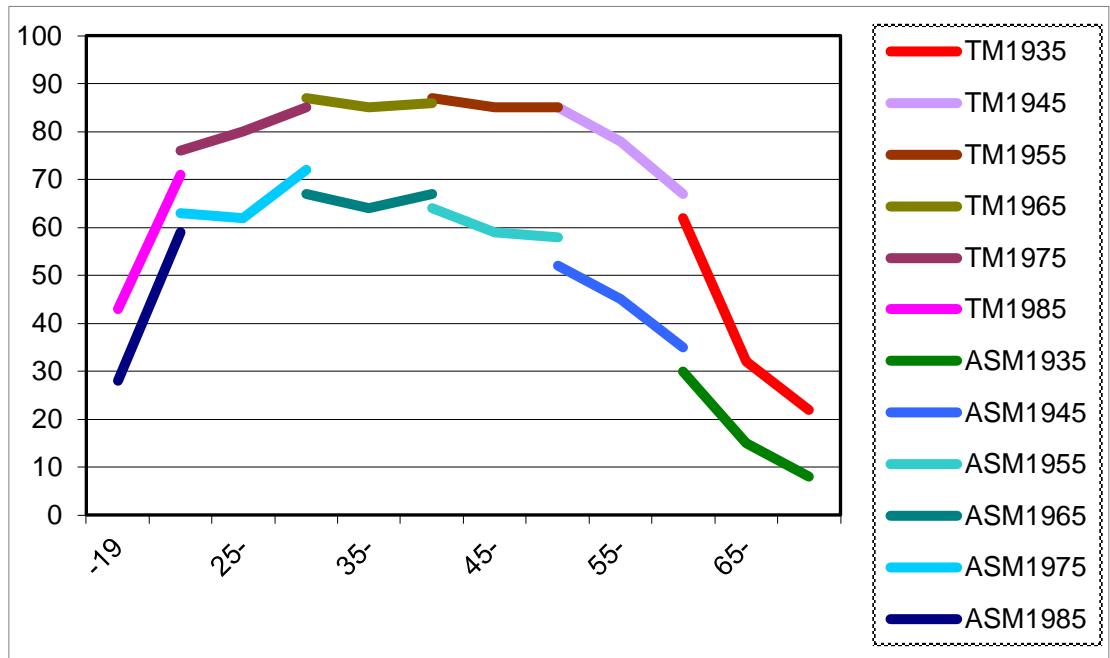

Source: Register data, Statistics Norway 2001, 2004, 2009. 
Figure 6.3: Cohort specific employment rate. Age. Total men (TM) (upper curve) and men born in new EU member states (NEU) (lower curve). Percent. Norway. 2000-2010

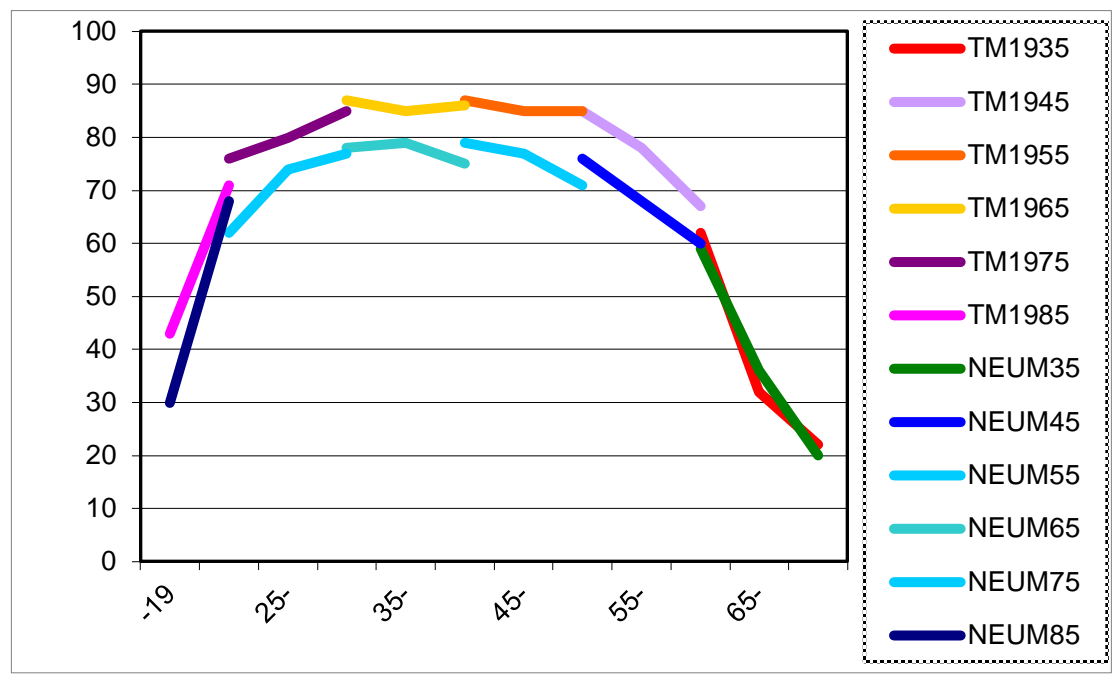

Source: Register data, Statistics Norway 2001, 2004, 2009.

This gives reasons to concern about the opportunities for new generations minority youth to enter the labour market. To what extent has the labour market situation of minority ethnic youth changed the last decade? The general picture is that when looking at young adults aged 16-29, all ethno-cultural groups follow the same changes in the business cycle (Figures 1-4 in the Annex). We find, however, some variations:

- In Denmark the difference between native born with native born parents (down from 74.7 to 63.8\%) and persons born in Africa or Asia (up from 36.3\% to 43.7\%) decreased between 1997 and 2011.

- In Finland the increase in employment rate among young adults was larger among those born Africa or Asia (from $22.65 \%$ to $43.62 \%$ ) than among native born with parents native born (from 48.5 to 60.08 ).

- In Norway the employment rate for native born with native born parents remained at 67.1-71.5\% while persons born in Africa or Asia remained at $46.7-51.9 \%$. 
- In Sweden minority ethnic youth were more affected by changes in the business cycle. On the positive side persons born in Africa or Asia had a larger increase in employment than other groups between 19972000 (from 22.4 to $36.0 \%$ ). On the negative side persons born in Sweden with parents born in Africa or Asia had a persistent decline in employment rate after 2000 (from 42.3 to $33.9 \%$ ) while the employment rate for native born with native born parents fluctuated between 50.8 and $58.2 \%$.

Overall available figures for the Nordic countries provide a mixed picture of developments in the employment rates in the last decade.

The real test is, however, what is happening in the age groups when most people have completed their education. Table 6.1 compares the employment rates for native born with native born parents and immigrants from Africa etc. in the oldest age group (25-29 years). Between 1997 (2001) and 2010 the employment gap was reduced from 45.5 to $23.5 \%$ in Denmark, from to 41.72 to $24.68 \%$ in Finland and from 42.4 to $31.7 \%$ in Sweden, but remained unchanged in Norway at about $25 \%$.

Table 6.1: Youth aged 25-29 in employment. ${ }^{14} 1997$ (2001) and 2010. Both sexes. Percent

\begin{tabular}{lrrrr}
\multicolumn{2}{c}{1997 (NO: 2001) } & \multicolumn{2}{c}{$\mathbf{2 0 1 0}$} \\
DK & Native & Born in Africa, Asia & Native & Born in Africa, Asia \\
FIN & 80.6 & 35.1 & 75.5 & 52.0 \\
NO & 66.85 & 25.23 & 74.68 & 50.0 \\
SE & 83.0 & 57.9 & 82.0 & 57.2 \\
& 73.7 & 31.3 & 78.5 & 46.8 \\
\hline
\end{tabular}

Sources: National statistical bureaus in the Nordic countries, register data.

${ }^{14}$ As the definition of employment varies between the countries the figures are not directly comparable between the countries. 
To complete the picture we compare the same five groups broken down for men and women and three different age groups separately for the year 2010. The more detailed data demonstrate that we find the largest ethnic penalty in the oldest youth group (25-29 years old) and larger differences among women than men. The difference was particularly high for women aged 25-29 born in Africa in all Nordic countries except Sweden (Tables 6.2-6.5).

\subsection{Employment rates: more about Denmark}

Denmark has a large share of the young people in apprenticeship training. As earlier mentioned apprentices are classified as employed in the Danish statistics. This is the reason why the employment rate was relatively high for those aged 15-18 and 19-23 in Denmark compared to the corresponding age groups in the other Nordic countries. The employment rate was, however, not higher for those aged 24-28 than in the other Nordic countries. The employment rate was not very much higher for those who were 24-28 compared to the younger age groups in Denmark.

First and second generation minority youth had lower employment rates than the native born with native born parents. This was especially the case for those born in a non-Nordic country. For the youngest age group one reason is likely to be that fewer minority youth being apprentices (which in Denmark are categories as employed). For the older ones the lower employment rate probably reflects that minority youth have larger difficulties in achieving gainful employment. 
Table 6.2: Share of youths in employment in Denmark in 2010. Percent

\begin{tabular}{|c|c|c|c|}
\hline & All & Men & Women \\
\hline \multicolumn{4}{|c|}{ Native born with both parents native born $(\mathrm{N}=700.405)$} \\
\hline Age $15-18$ & 50.8 & 47.8 & 54.0 \\
\hline Age $19-23$ & 66.1 & 65.2 & 67.0 \\
\hline Age $24-28$ & 74.3 & 76.3 & 72.4 \\
\hline \multicolumn{4}{|c|}{ Native born with both parents born in Australia, etc. ( $N=3.176$ ) } \\
\hline Age $15-18$ & 47.9 & 42.2 & 53.8 \\
\hline Age $19-23$ & 59.8 & 57.8 & 62.1 \\
\hline Age $24-28$ & 66.1 & 63.5 & 68.7 \\
\hline \multicolumn{4}{|c|}{ Native born with both parents born in Africa, Asia, etc. ( $N=25.782$ ) } \\
\hline Age $15-18$ & 43.0 & 40.5 & 45.6 \\
\hline Age $19-23$ & 54.9 & 55.1 & 54.8 \\
\hline Age $24-28$ & 62.0 & 64.0 & 60.0 \\
\hline \multicolumn{4}{|c|}{ Born in Australia etc. $(\mathrm{N}=38.462)$} \\
\hline Age $15-18$ & 31.4 & 30.1 & 32.7 \\
\hline Age $19-23$ & 36.3 & 38.6 & 34.2 \\
\hline Age $24-28$ & 54.1 & 57.2 & 50.6 \\
\hline \multicolumn{4}{|c|}{ Born in Africa, etc. $(\mathrm{N}=76.838)$} \\
\hline Age $15-18$ & 33.3 & 32.5 & 34.2 \\
\hline Age $19-23$ & 46.3 & 50.2 & 42.4 \\
\hline Age $24-28$ & 49.8 & 58.6 & 42.3 \\
\hline
\end{tabular}

$\mathrm{N}=$ total population

\subsection{Employment rates: more about Finland}

Finland has had a vocational school system. This means that few of the teenagers were counted as employed. Consequently, the employment rate of teenagers was rather low in Finland compared to Denmark. If we, however, compare those who were of an age when most have left the educational system, we find more or less the same share in employment as in Denmark among the native born. The employment rate for those in the older age group was more or less the same for men and women. Young adults born in a non-Nordic country had lower employment rates in most age groups and for both sexes. 
Table 6.3: Share of youths in employment in Finland in 2010. Percent

\begin{tabular}{llll} 
& All & Men & Women \\
Native born with both parents native born (N= 723.040) & & & \\
$\quad$ Age $18-19$ & 32.2 & 26.0 & 38.7 \\
Age $20-24$ & 56.5 & 53.1 & 60.2 \\
Age $25-29$ & 74.7 & 75.5 & 73.8 \\
Native born with both parents born in Australia, etc. (N=144) & & \\
Age $18-19$ & 37.2 & $32.6 *$ & $43.8^{*}$ \\
Age $20-24$ & $42.2^{*}$ & $35.1^{*}$ & $48.0^{*}$ \\
Age $25-29$ & $57.1^{*}$ & $78.6 *$ & \\
Native born with both parents born in Africa, etc. (N=806) & & & 32.0 \\
Age $18-19$ & 26.2 & 21.5 & 62.1 \\
Age $20-24$ & 55.5 & 49.6 & 76.5 \\
Age $25-29$ & 73.1 & 69.7 & \\
Born in Australia, etc.(N=13.690) & & & 32.6 \\
Age $18-19$ & 29.1 & 25.4 & 47.3 \\
Age $20-24$ & 47.7 & 48.1 & 54.7 \\
Age $25-29$ & 58.3 & 61.4 & \\
Born in Africa, Asia etc. (N=39.813) & & & 22.8 \\
Age $18-19$ & 19.8 & 17.1 & 38.5 \\
Age $20-24$ & 41.8 & 44.8 & 41.4 \\
Age $25-29$ & 50.0 & 57.8 & \\
\hline
\end{tabular}

*Below 20 observations.

$\mathrm{N}=$ total population.

\subsection{Employment rates: more about Norway}

Like Denmark, Norway has had an extensive apprenticeship system, but in Norway the first two of the four years have been school based. This may explain why Norway had a slightly lower employment rate among teenagers than Denmark but a higher rate than Finland. For all three age groups and for both sexes the employment rate was higher for the native born with native born parents than the four groups of minority youth. The employment rate in the oldest age group was especially low among women born in Africa etc. 
Table 6.4: Share of youths in employment in Norway in 2010. Percent

\begin{tabular}{|c|c|c|c|}
\hline & All & Men & Women \\
\hline \multicolumn{4}{|c|}{ Native born with both parents native born ( $N=460.833$ ) } \\
\hline Age $16-19$ & 47.1 & 44.8 & 49.6 \\
\hline Age $20-24$ & 71.7 & 71.8 & 71.5 \\
\hline Age $25-29$ & 82.0 & 82.9 & 81.0 \\
\hline \multicolumn{4}{|c|}{ Native born with mother born in Australia, etc. $* *(N=678)$} \\
\hline Age $16-19$ & 33.7 & 27.8 & 39.6 \\
\hline Age $20-24$ & 58.3 & 55.6 & 61.1 \\
\hline Age $25-29$ & 74.3 & 78.1 & 69.9 \\
\hline \multicolumn{4}{|c|}{ Native born with mother born in Africa, etc.** ( $N=9871$ ) } \\
\hline Age $16-19$ & 34.3 & 33.3 & 35.4 \\
\hline Age $20-24$ & 64.8 & 62.7 & 67.0 \\
\hline Age $25-29$ & 72.2 & 74.6 & 69.6 \\
\hline \multicolumn{4}{|c|}{ Born in Australia, etc. $(N=25.784)$} \\
\hline Age $16-19$ & 29.7 & 29.0 & 30.3 \\
\hline Age $20-24$ & 57.3 & 61.2 & 53.2 \\
\hline Age $25-29$ & 73.4 & 77.1 & 68.8 \\
\hline \multicolumn{4}{|c|}{ Born in Africa, Asia etc. $(\mathrm{N}=40.980)$} \\
\hline Age $16-19$ & 28.1 & 25.6 & 31.2 \\
\hline Age $20-24$ & 51.7 & 56.0 & 48.0 \\
\hline Age $25-29$ & 57.2 & 66.0 & 50.3 \\
\hline
\end{tabular}

** In cases where the country of origin of the mother was unknown, the country of the origin of the father has been used.

$\mathrm{N}=$ total population.

\subsection{Employment rates: more about Sweden}

In Sweden almost all young people have continued to secondary school. This meant that few teenagers were in the labour force. It has, however, not been uncommon to have a part-time job besides studies (classified as employed) or to be looking for a part-time job (classified as unemployed). In 2010 the employment rates were low for all young adults irrespective of origin. It was low for both majority (natives) and minority ethnic youth. The differences were, however, larger between the older age groups; i.e. the ethnic penalty increased with increasing age. The employment rates were lower for the minority youth. This indicates that first and second generation minority youth had larger difficulties in establishing themselves in the labour market than the native born with native born parents. 
Among those who were in their late twenties in Sweden, the employment rates were higher than in Denmark and Finland but at about the same level as in Norway.

Table 6.5: Share of youths in employment in Sweden in 2010. Percent

\begin{tabular}{|c|c|c|c|}
\hline & All & Men & Women \\
\hline \multicolumn{4}{|c|}{ Native born with both parents native born ( $\mathrm{N}=1.181 .216$ ) } \\
\hline Age $16-19$ & 20.4 & 19.1 & 21.7 \\
\hline Age $20-24$ & 62.2 & 62.7 & 61.7 \\
\hline Age $25-29$ & 78.3 & 79.4 & 77.0 \\
\hline \multicolumn{4}{|c|}{ Native born with both parents born in Australia etc. $(\mathrm{N}=8.951)$} \\
\hline Age 16-19 & 18.5 & 16.1 & 20.9 \\
\hline Age $20-24$ & 47.4 & 48.6 & 46.2 \\
\hline Age $25-29$ & 63.4 & 65.7 & 60.9 \\
\hline \multicolumn{4}{|c|}{ Native born with both parents born in Africa, etc. ( $N=65.446$ ) } \\
\hline Age $16-19$ & 11.7 & 10.5 & 12.9 \\
\hline Age $20-24$ & 46.6 & 46.6 & 46.6 \\
\hline Age $25-29$ & 68.3 & 69.6 & 66.8 \\
\hline \multicolumn{4}{|c|}{ Born in Australia, etc. $(\mathrm{N}=40.909)$} \\
\hline Age $16-19$ & 10.1 & 8.5 & 11.9 \\
\hline Age $20-24$ & 37.7 & 37.1 & 38.4 \\
\hline Age 25-29 & 60.6 & 62.3 & 58.7 \\
\hline \multicolumn{4}{|c|}{ Born in Africa etc. $(N=211.774)$} \\
\hline Age $16-19$ & 11.9 & 11.5 & 12.3 \\
\hline Age $20-24$ & 44.0 & 44.9 & 43.0 \\
\hline Age $25-29$ & 63.6 & 65.1 & 61.9 \\
\hline
\end{tabular}

$\mathrm{N}=$ total population.

\subsection{Education rates among minority ethnic youth}

In all Nordic countries native born with parents born in a non-Nordic country had the highest share of young adults in education (Figure 9-12 in the Annex, also Swedish Government 2013:51). This probably reflects the emphasis on redistributive measures to increase the employability of minority ethnic youth in the Nordic countries. Partly, second generation minorities may invest more in education to increase their likelihood of achieving paid work. Partly, prolonged participation in education may have become a substitute for lack of employment opportunities.

In Denmark the share of young adults in education has increased in all ethno-cultural groups, especially since the financial crisis in 2007. Native born with parents born in Africa etc. (up from 19.6 to 27.7\%) and native born with 
parents born in Australia etc. (up from 14.1 to 21.7\%) had the highest share of young adults in education, followed by native born with native born parents (up from 13.2 to 20.2\%). Immigrants born in Africa etc. (up from 10.9 to 15.4\%) or Australia etc. (up from 8.4 to $14.1 \%$ ) had the lowest rates of young adults in education.

In Norway the share of young adults in education has changed in different directions for different ethno-cultural youth groups. The rate of persons in education increased the most among native born with mother from Africa etc. (from 23.6 to $33.9 \%$ ) or Australia etc. (from 24.6 to $30.6 \%$ ). The rate for native born with native born parents increased marginally (from 17.5 to $22.3 \%$ ) and remained unchanged for immigrants from Africa etc. (at 15.3-19.8\%). The number of immigrants from Australia etc. in education declined, which reflects the labour immigration from those countries (including the EU member states).

In Sweden the share of young adults in education has changed in different directions for different ethno-cultural youth groups. While the rate for native born with native born parents remained unchanged (46-49\%), the rate increased for native born with both parents born in Africa etc. (from 53 to $62 \%$ ) and declined for immigrants from Australia etc. (from 42.5 to $34.1 \%$ ) and Africa etc. (from 47.0 to $42.5 \%$ ).

In Finland the share of young adults in education remained unchanged during 1997-2010. 


\subsection{Education: More about Denmark}

In Table 6.6 we see that only $37 \%$ of the native born with native born parents teenagers were classified as being in education in spite of the fact that the group we have information on in Denmark was slightly younger than the corresponding groups in the other three countries. The reason is that many were employed as apprentices (and received payment for that).

Table 6.6: Share of youths in education in Denmark in 2010. Percent

\begin{tabular}{|c|c|c|c|}
\hline & All & Men & Women \\
\hline \multicolumn{4}{|c|}{ Native born with both parents native born $(\mathrm{N}=700.405)$} \\
\hline Age $15-18$ & 36.8 & 39.4 & 34.0 \\
\hline Age $19-23$ & 16.1 & 16.2 & 16.0 \\
\hline Age $24-28$ & 8.1 & 7.5 & 8.8 \\
\hline \multicolumn{4}{|c|}{ Native born with both parents born in Australia, etc. $(\mathrm{N}=3.176)$} \\
\hline Age $15-18$ & 34.8 & 39.4 & 29.9 \\
\hline Age $19-23$ & 17.4 & 17.5 & 17.2 \\
\hline Age $24-28$ & 6.4 & 5.2 & 7.5 \\
\hline \multicolumn{4}{|c|}{ Native born with both parents born in Africa etc. ( $N=25.782)$} \\
\hline Age $15-18$ & 40.6 & 41.1 & 40.0 \\
\hline Age $19-23$ & 20.1 & 17.7 & 22.6 \\
\hline Age $24-28$ & 7.5 & 6.6 & 8.3 \\
\hline \multicolumn{4}{|c|}{ Born in Australia etc. ( $N=38.462)$} \\
\hline Age $15-18$ & 40.8 & 43.6 & 37.9 \\
\hline Age $19-23$ & 14.2 & 14.4 & 14.0 \\
\hline Age $24-28$ & 5.9 & 5.4 & 6.5 \\
\hline \multicolumn{4}{|c|}{ Born in Africa etc. $(\mathrm{N}=76.838)$} \\
\hline Age $15-18$ & 42.3 & 42.7 & 41.8 \\
\hline Age $19-23$ & 15.0 & 14.9 & 15.1 \\
\hline Age $24-28$ & 6.3 & 5.6 & 6.9 \\
\hline
\end{tabular}

$\mathrm{N}=$ total population.

The pattern of the share in education was more or less the same for the five groups with different origin. The share was slightly higher for three of the four groups with minority background. One reason may be that they experienced more difficulties in achieving apprenticeship places and partly related to this difficulty - they more often chose theoretical studies in secondary education. 


\subsection{Education: More about Finland}

In 2010 the share in education was higher in Finland than in Denmark. For the teenagers the difference can be explained by the differences between the two educational systems. For those in their twenties the pattern and the share in education was more or less the same in the two countries.

Table 6.7: Share of youths in education in Finland in 2010. Percent

\begin{tabular}{|c|c|c|c|}
\hline & All & Men & Women \\
\hline \multicolumn{4}{|c|}{ Native born with both parents native born $(\mathrm{N}=723.040)$} \\
\hline Age $18-19$ & 49.6 & 50.4 & 48.7 \\
\hline Age $20-24$ & 24.4 & 24.3 & 24.5 \\
\hline Age $25-29$ & 9.8 & 9.7 & 10.0 \\
\hline \multicolumn{4}{|c|}{ Native born with both parents born in Australia, etc. $(N=144)$} \\
\hline Age $18-19$ & 41.0 & $37.0^{*}$ & $46.9 *$ \\
\hline Age $20-24$ & $26.7^{*}$ & $25.0^{*}$ & $28.0^{*}$ \\
\hline Age $25-29$ & $14.3^{*}$ & $0.0^{*}$ & $42.9 *$ \\
\hline \multicolumn{4}{|c|}{ Native born with both parents born in Africa, Asia etc. ( $N=806)$} \\
\hline Age $18-19$ & 51.2 & 53.0 & 49.1 \\
\hline Age $20-24$ & 16.6 & 16.0 & 17.2 \\
\hline Age $25-29$ & $4.5^{*}$ & $6.1^{*}$ & $2.9^{*}$ \\
\hline \multicolumn{4}{|c|}{ Born in Australia, etc ( $N=13.690)$} \\
\hline Age $18-19$ & 40.6 & 42.2 & 39.1 \\
\hline Age $20-24$ & 14.9 & 14.6 & 15.3 \\
\hline Age $25-29$ & 7.8 & 7.1 & 8.6 \\
\hline \multicolumn{4}{|c|}{ Born in Africa etc. ( $N=39.813)$} \\
\hline Age $18-19$ & 40.5 & 39.8 & 41.3 \\
\hline Age $20-24$ & 19.9 & 19.7 & 20.2 \\
\hline Age $25-29$ & 9.5 & 9.0 & 10.0 \\
\hline
\end{tabular}

*Below 20 respondents.

$\mathrm{N}=$ total population.

For those with foreign background the pattern and level was more or less the same as for those with native background with a few exceptions. The low number of native born with foreign born parents in Finland may explain why the results are a bit surprising for some of the groups. 


\subsection{Education: More about Norway}

Norway has a partly school-based, partly work-place based apprenticeship system. It explains that the share of the teenagers classified as being in education is higher than in Denmark but a bit lower than in Finland. Note that fewer aged 25-29 years are in education in Norway compared to those in the other three countries.

Table 6.8: Share of youths in education in Norway in 2010. Percent

\begin{tabular}{|c|c|c|c|}
\hline & All & Men & Women \\
\hline \multicolumn{4}{|c|}{ Native born with both parents native born ( $\mathrm{N}=460.833$ ) } \\
\hline Age $16-19$ & 46.8 & 48.4 & 45.0 \\
\hline Age $20-24$ & 16.6 & 15.6 & 17.7 \\
\hline Age $25-29$ & 5.8 & 5.3 & 6.4 \\
\hline \multicolumn{4}{|c|}{ Native born with mother born in Australia** $(\mathrm{N}=678)$} \\
\hline Age $16-19$ & 50.5 & 57.5 & 43.4 \\
\hline Age $20-24$ & 25.2 & 27.2 & 23.0 \\
\hline Age $25-29$ & $5.4^{*}$ & $5.6^{*}$ & $5.2^{*}$ \\
\hline \multicolumn{4}{|c|}{ Native born with mother born in Africa etc. $* *(N=9.871)$} \\
\hline Age $16-19$ & 56.0 & 56.3 & 55.6 \\
\hline Age $20-24$ & 18.0 & 17.9 & 18.1 \\
\hline Age $25-29$ & 6.3 & 6.3 & 6.3 \\
\hline \multicolumn{4}{|c|}{ Born in Australia etc. $(\mathrm{N}=\mathbf{2 5 . 7 8 4})$} \\
\hline Age $16-19$ & 46.2 & 47.4 & 45.0 \\
\hline Age $20-24$ & 9.8 & 9.1 & 10.5 \\
\hline Age $25-29$ & 2.1 & 1.5 & 2.9 \\
\hline \multicolumn{4}{|c|}{ Born in Africa, etc. ( $N=40.980)$} \\
\hline Age $16-19$ & 44.1 & 42.5 & 46.0 \\
\hline Age $20-24$ & 15.7 & 16.3 & 15.1 \\
\hline Age $25-29$ & 7.0 & 6.7 & 7.2 \\
\hline
\end{tabular}

*Below 20 respondents.

$\mathrm{N}=$ total population

** $=$ in cases where the country of origin of the mother was unknown, the country of origin of the father has been used.

The share being in education was more or less the same irrespective of native or foreign origin. An exception was that the native born with foreign born parents were more often in education than the natives with native born parents. 


\subsection{Education: More about Sweden}

Sweden was an outlier regarding the share in education compared to the other three countries. The reason is that secondary education has been school-based but also that many have continued to higher education. The share of teenagers in education was much higher in Sweden than in the other Nordic countries and the shares were also higher in the older age groups.

Table 6.9: Share of youths in education in Sweden in 2010. Percent

\begin{tabular}{|c|c|c|c|}
\hline & All & Men & Women \\
\hline \multicolumn{4}{|c|}{ Native born with both parents native born ( $\mathrm{N}=1.181 .216$ ) } \\
\hline Age $16-19$ & 70.4 & 71.1 & 69.7 \\
\hline Age $20-24$ & 23.0 & 21.4 & 24.6 \\
\hline Age $25-29$ & 10.8 & 9.6 & 12.0 \\
\hline \multicolumn{4}{|c|}{ Native born with both parents born in Australia etc. $(\mathrm{N}=8.951)$} \\
\hline Age $16-19$ & 65.4 & 68.1 & 62.8 \\
\hline Age $20-24$ & 31.7 & 28.0 & 35.5 \\
\hline Age $25-29$ & 10.2 & 10.1 & 10.3 \\
\hline \multicolumn{4}{|c|}{ Native born with both parents born in Africa etc. ( $N=65.446)$} \\
\hline Age $16-19$ & 77.7 & 77.7 & 77.6 \\
\hline Age $20-24$ & 33.2 & 30.3 & 36.4 \\
\hline Age $25-29$ & 12.1 & 11.2 & 13.0 \\
\hline \multicolumn{4}{|c|}{ Born in Australia etc. $(\mathrm{N}=40.909)$} \\
\hline Age $16-19$ & 73.7 & 76.2 & 70.9 \\
\hline Age $20-24$ & 39.7 & 39.8 & 39.4 \\
\hline Age $25-29$ & 15.8 & 13.9 & 17.9 \\
\hline \multicolumn{4}{|c|}{ Born in Africa etc. $(\mathrm{N}=\mathbf{2 1 1 . 7 7 4 )}$} \\
\hline Age $16-19$ & 70.9 & 70.9 & 71.0 \\
\hline Age $20-24$ & 33.1 & 29.8 & 36.7 \\
\hline Age $25-29$ & 13.3 & 11.3 & 15.5 \\
\hline
\end{tabular}

$\mathrm{N}=$ total population

The pattern was mainly the same for the five ethnic groups. The main exception was that native born youth with parents from Africa etc. to a higher extent than the other four groups of teenagers were in education. For those aged 20-24 first and second generation minority youth were to a higher extent in education than native born with native born parents. 


\subsection{NEET rates among minority ethnic youth}

Between 1997 and 2010 Denmark (down from 53.2 to 38.8\%) and Finland (down from 62.99 to 38.48\%) witnessed a decrease in the NEET rates for young adults born in Africa etc., while the NEET rates remained unchanged in Norway (varying between 28.6 and 33.6\%) and Sweden (varying between 30.5 and $40.0 \%$ ) for young adults born in Africa etc. (Figure 1-4 in the Annex).

During the entire time period 1997-2010 (2011) the NEET rates were higher for young adults born in Africa etc. than for those who were native born in all Nordic countries except Sweden where native born youth with parents born in Australia etc. had the highest NEET rate. One reason could be that labour immigrants from Australia etc. do not report to Swedish authorities when they leave the country and remain registered as NEET (while persons born in Africa etc. immigrate for different reasons and often on a more permanent basis); i.e. the NEET rate might de facto be lower for this category of youth.

In all the Nordic countries the NEET rates were the highest in the oldest age group. With increasing age the difference increased between the native born with native born parents and youth born in Africa etc. I.e. the ethnic penaltywas larger in the older age cohorts. In Denmark (50.8\%), Finland (48.2\%) and Norway (43\%) women born in Africa etc. and aged 24-28 (25-29) had a higher NEET rate than any other youth groups. Again Sweden was the exception with the highest NEET rate among native born women aged 25-29 with parents born in Australia etc. (28.6\%).

\subsection{NEET rates: more about age and gender}

Table 6.10 compares the situation in Denmark for the five groups in 2010 with information for men and women and three different age groups. The pattern was more or less the same for men and women. For all other groups than native born with native born parents the situation differed much between different age groups. The NEET rate was higher for the older age groups and the differences were larger for first and second generation ethnic minorities. The teenagers were to a high extent in school. 
Note that the NEET rate was highest for women aged 24-28 years born in Africa etc.; just over 50\%.

Table 6.10: Share of youths not in education or employment in Denmark in 2010. Percent

\begin{tabular}{|c|c|c|c|}
\hline & All & Men & Women \\
\hline \multicolumn{4}{|c|}{ Native born with both parents native born $(\mathrm{N}=700.405)$} \\
\hline Age $15-18$ & 12.4 & 12.9 & 12.0 \\
\hline Age $19-23$ & 17.8 & 18.6 & 17.0 \\
\hline Age $24-28$ & 17.5 & 16.2 & 18.9 \\
\hline \multicolumn{4}{|c|}{ Native born with both parents born in Australia, etc. ( $N=3.176$ ) } \\
\hline Age $15-18$ & 17.3 & 18.3 & 16.3 \\
\hline Age $19-23$ & 22.8 & 24.8 & 20.6 \\
\hline Age $24-28$ & 27.5 & 31.3 & 23.8 \\
\hline \multicolumn{4}{|c|}{ Native born with both parents born in Africa etc. $(\mathrm{N}=25.782)$} \\
\hline Age $15-18$ & 16.4 & 18.4 & 14.4 \\
\hline Age $19-23$ & 25.0 & 27.2 & 22.6 \\
\hline Age $24-28$ & 30.5 & 29.4 & 31.7 \\
\hline \multicolumn{4}{|c|}{ Born in Australia etc. ( $N=38.462)$} \\
\hline Age $15-18$ & 27.8 & 26.2 & 29.4 \\
\hline Age $19-23$ & 49.5 & 47.0 & 51.9 \\
\hline Age $24-28$ & 40.0 & 37.3 & 42.9 \\
\hline \multicolumn{4}{|c|}{ Born in Africa etc. ( $N=76.838$ ) } \\
\hline Age $15-18$ & 24.4 & 24.8 & 24.0 \\
\hline Age $19-23$ & 38.7 & 4.9 & 42.6 \\
\hline Age $24-28$ & 43.9 & 34.9 & 50.8 \\
\hline
\end{tabular}

$\mathrm{N}=$ total population

Table 6.11 shows the situation for the five groups in 2010 with information separately for men and women and for three different age groups in Finland. The pattern differed between men and women. For the four groups - other than the native born with native born parents - the situation differed much between the age groups. The NEET rate was higher for the older age groups. The NEET rate was highest for women aged 25-29 years born in Africa etc.; almost 50\%. 
Table 6.11: Share of youth not in education or employment or in military service in Finland in 2010. Percent

\begin{tabular}{|c|c|c|c|}
\hline & All & Men & Women \\
\hline \multicolumn{4}{|c|}{ Native born with both parents native born $(N=723.040)$} \\
\hline Age $18-19$ & 11.7 & 12.1 & 11.7 \\
\hline Age $20-24$ & 14.9 & 15.9 & 14.1 \\
\hline Age $25-29$ & 14.9 & 14.3 & 15.6 \\
\hline \multicolumn{4}{|c|}{ Native born with both parents born in Australia, etc. ( $N=144)$} \\
\hline Age $18-19$ & $16.7^{*}$ & $21.7^{*}$ & $9.4^{*}$ \\
\hline Age $20-24$ & $22.2^{*}$ & $25.0^{*}$ & $20.0^{*}$ \\
\hline Age $25-29$ & $28.7^{*}$ & $21.4^{*}$ & $42.9 *$ \\
\hline \multicolumn{4}{|c|}{ Native born with both parents born in Africa etc. $(\mathrm{N}=806)$} \\
\hline Age $18-19$ & 20.5 & 21.8 & 18.9 \\
\hline Age $20-24$ & 23.1 & 25.2 & 20.7 \\
\hline Age $25-29$ & 22.4 & $24.2^{*}$ & $20.6^{*}$ \\
\hline \multicolumn{4}{|c|}{ Born in Australia etc. $(\mathrm{N}=13.690)$} \\
\hline Age $18-19$ & 27.9 & 28.1 & 27.6 \\
\hline Age $20-24$ & 35.9 & 35.3 & 36.5 \\
\hline Age $25-29$ & 33.5 & 31.2 & 36.2 \\
\hline \multicolumn{4}{|c|}{ Born in Africa etc. $(N=39.813)$} \\
\hline Age $18-19$ & 38.3 & 40.8 & 35.5 \\
\hline Age $20-24$ & 36.5 & 32.8 & 40.5 \\
\hline Age $25-29$ & 40.1 & 32.8 & 48.2 \\
\hline
\end{tabular}

$\mathrm{N}=$ total population.

* Below 20 respondents.

Table 6.12 compares the situation for the same five groups for 2010 with information for men and women and for three different age groups in Norway. The pattern was similar for men and women. For the four groups other than native born with native born parents the situation differed much between different age groups. The NEET rate was higher for the older age groups than for teenagers, but less so for the native born with native born parents. The NEET rate was highest for women aged 25-29 years who were born in Africa etc.; almost 45 percent. 
Table 6.12: Share of youths not in education or employment in Norway in 2010. Percent

\begin{tabular}{|c|c|c|c|}
\hline & All & Men & Women \\
\hline \multicolumn{4}{|c|}{ Native born with both parents native born ( $N=460.833$ ) } \\
\hline Age $16-19$ & 6.1 & 6.8 & 5.4 \\
\hline Age $20-24$ & 11.7 & 12.5 & 10.8 \\
\hline Age $25-29$ & 12.2 & 11.8 & 12.7 \\
\hline \multicolumn{4}{|c|}{ Native born with mother born in Australia, etc.* $(N=678)$} \\
\hline Age $16-19$ & 15.8 & 14.6 & 17.0 \\
\hline Age $20-24$ & 16.5 & 17.1 & 15.9 \\
\hline Age $25-29$ & 20.2 & 16.3 & 24.8 \\
\hline \multicolumn{4}{|c|}{ Native born with mother born in Africa, etc.* ( $N=9.871)$} \\
\hline Age $16-19$ & 9.7 & 10.4 & 9.0 \\
\hline Age $20-24$ & 17.2 & 19.4 & 15.0 \\
\hline Age $25-29$ & 21.5 & 19.1 & 24.1 \\
\hline \multicolumn{4}{|c|}{ Born in Australia etc. ( $N=25.784)$} \\
\hline Age $16-19$ & 24.1 & 23.6 & 27.7 \\
\hline Age $20-24$ & 32.9 & 29.6 & 36.3 \\
\hline Age $25-29$ & 24.5 & 21.5 & 28.2 \\
\hline \multicolumn{4}{|c|}{ Born in Africa etc. $(N=40.980)$} \\
\hline Age $16-19$ & 27.8 & 31.9 & 22.8 \\
\hline Age $20-24$ & 32.6 & 27.7 & 36.9 \\
\hline Age $25-29$ & 35.5 & 27.3 & 43.5 \\
\hline
\end{tabular}

$\mathrm{N}=$ total population.

* $=$ in cases where the country of origin of the mother is unknown, the country of the origin of the father is used.

Table 6.13 compares the situation for the same five ethnic groups in 2010 with information for men and women and three different age groups in Sweden. The pattern was more or less the same for men and women. The NEET rate was low for the teenagers, especially for native born with native born parents. The teenagers were most likely in school. For all groups the situation differed much between different age groups. The NEET rate was higher for the older age groups. The NEET rate was highest for native born women aged 25-29 years with parents who were born in Australia etc.; almost 30\%. The later counter-intuitive finding might reflect shortcomings in the register data rather than the actual situation in Sweden. 
Table 6.13: Share of youths not in education or employment in Sweden in 2010. Percent

\begin{tabular}{|c|c|c|c|}
\hline & All & Men & Women \\
\hline \multicolumn{4}{|c|}{ Native born with both parents native born ( $\mathrm{N}=1.181 .216)$} \\
\hline Age $16-19$ & 3.6 & 3.9 & 2.7 \\
\hline Age $20-24$ & 12.4 & 13.4 & 11.4 \\
\hline Age $25-29$ & 10.4 & 10.5 & 10.3 \\
\hline \multicolumn{4}{|c|}{ Native born with both parents born in Australia, etc. ( $N=8.951)$} \\
\hline Age $16-19$ & 8.0 & 8.2 & 7.8 \\
\hline Age $20-24$ & 18.5 & 20.5 & 16.5 \\
\hline Age $25-29$ & 25.9 & 23.4 & 28.6 \\
\hline \multicolumn{4}{|c|}{ Native born with both parents born in Africa, etc. $(N=65.446)$} \\
\hline Age $16-19$ & 6.0 & 6.9 & 5.1 \\
\hline Age $20-24$ & 16.2 & 18.9 & 13.5 \\
\hline Age $25-29$ & 18.7 & 18.3 & 19.1 \\
\hline \multicolumn{4}{|c|}{ Born in Australia etc. $(\mathrm{N}=40.909)$} \\
\hline Age $16-19$ & 9.8 & 9.4 & 10.3 \\
\hline Age $20-24$ & 19.1 & 19.6 & 18.5 \\
\hline Age $25-29$ & 22.6 & 22.6 & 22.6 \\
\hline \multicolumn{4}{|c|}{ Born in Africa etc. $(\mathrm{N}=\mathbf{2 1 1 . 7 7 4 )}$} \\
\hline Age $16-19$ & 12.0 & 12.0 & 12.0 \\
\hline Age $20-24$ & 18.3 & 20.4 & 15.9 \\
\hline Age $25-29$ & 21.9 & 22.4 & 21.2 \\
\hline
\end{tabular}

$\mathrm{N}=$ total population. 


\subsection{Concluding comment}

The results demonstrate a mixed picture. Some categories of minority ethnic youth are clearly more at risk of social exclusion from the labour market than native born youth with native born parents (and some subcategories of minority ethnic youth). The situation has been particularly disadvantaged for youth who have immigrated from Africa. Our data demonstrate that especially young women born in Africa etc. aged 25-29 had a high NEET rate. There are reasons to believe that women in this category to larger extent have had unpaid housework and have relied on a male breadwinner model.

As data have been missing it is not entirely clear the extent to which minority ethnic youth are excluded from the labour market in Iceland. A report from the Icelandic Red Cross (2010) suggests that the children of immigrants are at risk of isolation and marginalisation due to difficulties in coping with language and cultural barriers, though there has been no data regarding employment, education and NEET figures available for young adults from this country.

Earlier research has found that while completion of secondary and tertiary education have increased the chances of achieving gainful employment, fewer persons immigrated from non-Nordic countries have completed higher education (Olsen, 2012). This give reasons to ask if the Nordic educational systems and training opportunities are sufficiently accommodated to the needs of first and second generation minority youth. Danish and Norwegian data suggest that minority youth experience larger difficulties in achieving apprenticeship than majority ethnic youth. With the exception of language training for newly arrived immigrants, the Nordic countries have emphasised inclusion through to general education and training programmes on grounds of avoiding stigmatizing solutions.

The last decade the Nordic countries have increased the conditionality for receiving means-tested benefits and expanded the education and training programmes targeted at young adults under age 25, much in line with their tradition for investments on the supply side of the labour market to increase the "employability" of individuals at risk of exclusion. During the same period the adoption of new regulatory policy measures have 
increased but are still moderate and with not insignificant differences between the Nordic countries.

During the last decade we find some evidence of increased employment prospects for minority ethnic youth in Denmark, Finland and Sweden (Figure 5-8 in the Annex). Also the NEET rates have declined in Denmark and Finland from a relatively high level compared to Norway and Sweden (Figure 1-2 in the Annex). In Denmark the decline in NEETs may in part be explained by the increasing education rate during the same time period; more young adults may have been transferred to or chosen to follow continued education to We find the smallest signs of improvements in Norway where the ethno-cultural divides in NEET and employment rates remained unchanged. At the same time, in Norway the rate of persons in education increased the most among native born youth with a mother from a non-Nordic country (Australia etc. and Africa etc.). In other words, the Norwegian investment strategy fostered an increase in education rates but has - at least so far - not witnessed any returns in the form of increased employment in the minority youth populations. 


\section{Implementing social regulation - local negotiations}

To understand under which circumstances social regulation of diversity is most likely to be effective we need to appreciate the perceptions and experiences of employers and young adults seeking or aiming to retain employment. Only by documenting the experiences of the employers and vulnerable youth will we be able to achieve a complete picture of the practical impact of the policy measures aiming to enable vulnerable youth to find and retain suitable employment.

The outcome of the social regulation of diversity can be construed as the result of reciprocity between suppliers and demanders of manpower and public officials; i.e. the result of the dynamic interplay between institutionalized expectations (legal and moral duties), the extent to which employers manage to comply with, neutralize or avoid the expectations of conformity from the public officials, and to what extent the youth groups manage to present and justify claims to reasonable accommodation and protection from discrimination. Ultimately the outcomes of Nordic social regulation depend on the adjustments the actors in the labour market make to the situations in which they find themselves.

We may argue that what happens to the social regulation in the end is constructed through a social, rather than entirely policy driven, process. The American sociologist Anselm Strauss (1988) asserted that prior decisions, legislation and customs ("rules") only were sociologically effective if the actors perceived, experienced and defined them as significant in the present. Negotiations occur among individuals as a consequence of their individual strategies for adjustment to norms and values rules. Generally, some rules tend to be broken, stretched or ignored when certain exigencies arise. 
All rules are not enforced with the same determination or in all relevant circumstances. In other cases rules are ignored, forgotten or fall into disuse.

With regard to Nordic regulatory policy instruments their sociological effectiveness depends not only on how they have been designed by the Nordic governments but also to what extent actors in the labour market (employers, employees, public officials) define the regulatory policy instruments as important and relevant to themselves. This is not to say that employers can define the situation just as they please. Employers cannot simply ignore social expectations, legal and moral duties in the labour market but have to relate to the constraints actions and decisions of prior and higher-level actors - policies and rules - set to local "negotiations" or adjustments of official labour market policy in the individual workplace.

Employers need to account for their choices; how they relate to legal and moral obligations and expectations from public officials and employees. Individual employers shape their own actions in conformance with the structures, policies and traditions in the labour market - a social world that is already structured, not one that is self-defined.

In their capacity as job applicants and employees vulnerable youth need to "negotiate" with employers to achieve and retain employment. While the young adults have less power than employers they may adopt several strategies to pursue their interests. Vulnerable youth groups strive to gain access to or keep paid work. Despite their real constraints and sharp power differentials, young job applicants and employees are social actors who have freedom to operate strategically. On the backdrop of the actual and anticipated reactions from employers and greater society, and the resources available to them, young adults aim to pursue their own objectives in life in how they choose to present themselves to employers and co-workers.

Among the resources which structure the capacity for voice and agency on the part of young adults, is the extent to which they have access to - or are dependent on - formal and informal relations which can facilitate actions.

According to Mark Granovetter's strong and weak tie hypothesis the role of a social network depend on the nature of the social ties (Granovetter 1973, 1983). Granovetter noted that information and support gained from strong ties - characterized by frequent and heterogeneous interaction -offer multiple benefits; it is inexpensive, more trustworthy, more 
detailed and accurate. Nevertheless, strong ties have been perceived as redundant information since the actors can be anticipated to move in similar, if not the same, social circles. The value of weak ties - characterized by infrequent and limited interaction - has been in the possibility of connecting to new social systems. The literature on social networks has found that while strong ties may provide support and motivation in finding gainful employment, weak ties can provide access to job opportunities outside one's own close circle.

In negotiations with employers about hiring and retaining employment, a third party (family, friends, acquaintances, trade unions, NGOs or public agencies) may intervene, provide support or information to foster inclusion in the labour market. Compared to direct communication with employers the interference of a third party - or a mediator -may change the nature of the negotiations (Simmel, 1950:145ff.).

In the next sections we first examine the direct negotiations between employers and jobseekers on the basis of the Norwegian data. We then compare the role of a third party in Iceland and Norway before we conclude.

\subsection{Negotiations between employers and vulnerable youth}

In contemporary Nordic countries the norms of equality are so strong employers are likely to feel uncomfortable expressing negative opinions about youth with disabilities or ethnic minority youth. When asked questions about sensitive issues in the workplace, employers may be led by these pressures to present their accounts in ways they perceive to be the most socially acceptable. To the extent that real-world discrimination continues, this has the effect of biasing their accounts in the direction of politically correct, non-prejudicial responses.

Nevertheless earlier studies have found that Nordic employers often are reluctant to hire persons with disabilities and persons born in Africa even if they have higher education (MMI, 2006) but with not insignificant differences between business sectors (Andreassen, 2012).A field experiment among Norwegian employers found that the likelihood of being summoned to a job interview was $25 \%$ less if the applicant has a "foreign 
sounding" name indicating an ethnic minority background compared to a job applicant with the same qualifications but with a name suggesting a majority background (Midtbøen and Rogstad 2012). Similarly, OECD (2013a) has reported how discrimination prevent full inclusion of first and second generation minorities in the labour market.

\subsubsection{Defence of meritocracy and self-regulation}

Nordic employers have largely supported a meritocratic system and focused on formal equality of opportunities in the labour market. While the employers did not necessarily support stereotypes about persons with disabilities as having a reduced working capacity, they have not given priority to adopt more inclusive recruitment processes and accommodation procedures - despite the affirmative action duty covering persons with disabilities in the 2008 Norwegian accessibility and nondiscrimination act (Svalund and Hansen, 2013, Ose et al., 2013).

Several of the interviewees were not aware of or interested in the affirmative action duty adopted in 2008 to promote non-discrimination in recruitment, working conditions, promotion and protection against harassment and to report annually on measures to promote the objectives of the discrimination act. In one case the annual report was presented as of marginal interest and importance ("drudgery"). In a second case the efforts by the staff member to present a more elaborate section on diversity management in the annual report had been cut off by the board of directors. Some of the enterprises did, however, complete annual Health, Safety and Security surveys to map inter alia the job satisfaction and experiences with bullying, harassment and discrimination at the workplace.

While the employers were eager to present their voluntary commitments and self-initiated activities, they knew little or nothing about their legal duty since 2009 to report annually on the work to promote equal opportunities and prevent discrimination against persons with disabilities. When asked about their experiences with employees with disabilities the employers tended to frame their activities as part of their work with the voluntary tripartite agreement on inclusive working life in Norway rather than as a legal duty to comply with existing non-discrimination legislation and promote diversity in the workplace. 


\subsubsection{Barriers and bridges to the recruitment of vulnerable youth}

Both in the case of minority ethnic youth and youth with disabilities employers were concerned whether the job candidates would fit in at the workplace. Earlier research suggests that employers often consider "personal qualifications" or "suitability" as relevant criteria for hiring an employee. In the case of minority ethnic youth the concept is sometimes used as a generic term or euphemism for explaining why ethnic minority candidates do not fit in at the workplace. Employers have referred to assumed co-operation skills, flexibility, adaptability, honesty, punctuality and expectations to participate in social events outside work (e.g. wine lottery, Christmas table). This suggests that employers use their prerogative to construct a difference between "us" and "them", between personal qualifications assumed to be common among the employees at the workplace and others. The underlying assumptions about the community at the workplace may serve to exclude ethnic minority candidates from being considered qualified for the job, even if they have the same professional qualifications as the majority population candidates (Midtbøen and Rogstad 2012, Tronstad 2010:35, Sandal, 2009).

One could have imagined that experience or suspicion of negative discrimination would have given reasons to protests and demands for amendments on the part of employers. Several of the regulatory policy instruments require that individual citizens or citizens groups publicly present claims to benefit from protection against discrimination and harassment, present complaints to the Discrimination and Equality Ombud or even take legal actions in individual cases. However, as the young adults were vulnerable to criticism from the majority population they were concerned to avoid conflicts and embarrassing situation with potential employers.

\footnotetext{
"Some places you just understand they are not interested. You can see it on the environment it wont work. (...) I was earlier at a job interview at [hardware store]. They talked Swedish. It was hard to understand what they said. I felt I said the same all the time. In the end I told "this won't work"."

(Woman 22 years, from Afghanistan, 10 years in Norway, working part time and attending ALMP, October 2012)
} 
"I have never experienced any difficulties with employers - except once. I stopped by [kiosk] to ask for a trainee position. The boss asked about lots of funny things. Can you work without the headscarf? He was going to ask people higher in the system. I just cut and ran from the place."

(Woman 21 years, born in Norway, parents from Somalia, part time positions as interpreter and assistant teacher, October 2012)

In addition to conflict avoidance the interviewees stressed their demonstrative loyalty and fulfilment of societal expectations to achieve higher education and find paid work ("I am very busy. I like to be active", "always looking for something to do"). Several of the minority ethnic youth had presented their CV in grocery stores without success. However, some of them had managed to achieve unskilled work and summer jobs by turning up at the workplace.

In some cases the interviewees had achieved the first job through the social network of their Norwegian boyfriend, through vocational training in secondary education (16-18 years), or - in absence of a relevant social network - by assistance from NGOs of and for ethnic minorities. In other cases the interviewees had received assistance in writing a $\mathrm{CV}$, practicing on jobinterviews and breaking the code for what is required from employment certificates. When applying for jobs the applicant has to master the required format and content of CVs and employment certificates, i.e. they have to adjust to expectations of formal certification and documentation of skills and experiences (job description, period of employment, signature, true copy stamp, enterprise letterhead, copy on white - not coloured - paper). Written applications submitted trough electronic web portals are to be tailor-made and expected to identify how the skills of the applicant meet the call text. Oral communication is not filed or processed in bureaucratic enterprises. Undocumented skills cannot be validated in the system.

In several cases the interviewees stressed their efforts not only to improve individual skills but also to adjust to what was considered realistic employment opportunities ("teacher is a bit difficult, kindergarten teacher is easier", "an apprenticeship certificate is perhaps possible but not higher education."). In this respect the interviewees seemed to echo the recommendations of staff in NAV (the integrated employment and social security agency) and other social services. Additionally the interviewees often downplayed the assistance they had received from NAV. Given that they 
did everything possible to achieve paid work they were in a better position also to criticizing public authorities for not doing enough.

While most interviewees accepted the importance of education and language training they also criticized the system for not achieving its official objectives. Such complaints included barriers to a well-functioning meritocracy; lack of recognition of foreign third level education, insufficient teaching in Norwegian, and barriers in accessing the labour market. The strategies of the interviewees sometimes resembled what Norwegian criminologist Thomas Mathiesen (1972) referred to as "censoriousness": the individual did not present him or herself as part of a subculture of alternative norms but as carrier and defender of dominant norms.

In the case of youth with disabilities Norwegian employers have excused themselves by claiming they never receive any applications from persons who explicitly state that they are disabled (Falkum 2012). The legal opportunity for Norwegian public sector employers to favour job applicants with disabilities requires that the applicant state to have a disability in the first place. However both youth with mobility and sensory impairments and with mental-health problems reported about their efforts to pass as non-disabled; hide the hearing aid, conceal the reason for sick-leaves or their medical record ("have never talked about sickness at work"). Several of the interviewees aimed to reduce the importance of the impairment ("milder mental health problems than many others") or considered it irrelevant for the kind of work they were looking for. While openness about disabilities, impairments or sickness could be seen as desirable the interviewees considered it too risky due to the anticipated level of prejudices and/or stereotypical images among employers ("will never tell anything before people ask"). ${ }^{15}$

15Due to obvious signs of difference (language, physical features and a foreign-sounding name) concealment or detachment did not emerge as an option for the minority ethnic youth. 
Few employers were aware of the affirmation action duty to promote non-discrimination in recruitment, working conditions promotion and protection against harassment under Norwegian law. To the extent that employers did recruit persons with disabilities to temporary vocational training positions they identified candidates through NGOs or NAV. Such initiatives tended to be framed in terms of corporate social responsibility and compliance with the voluntary Inclusive Working life agreement.

\subsubsection{Reasonable accommodation for youth with disabilities}

When asked about their experience with recruiting employees with disabilities the employers sometimes expressed more concern about the interaction between employees with disabilities and co-workers than their performance of the work tasks ("scepticism at the workplace").

"She worked with administrative tasks here for $3 / 4$ year. She was about 30 years, had had a stroke and had difficulties in walking. It was a larger burden. It was more unpopular than popular among the employees. She needed assistance from time to time, for instance to carry the tray in the restaurant. She could not carry a glass of water without spilling it while she was walking." (HR director, public sector enterprise, November 2012)

\footnotetext{
"It was not an easy decision to hire her. She remained a bit longer on temporary contract than usual but it would have been inhuman not to employ her. It would have been easier to say no but you have the human factor. She has a good memory and is bright. She does a good job but it is no always easy to organize the practical issues. Now is it usually the youngest assistant in the office who assists her. Some of the other employees feel uncomfortable. They have to be very careful and are afraid to hurt her. It is not a pleasant task to assist her."

(Section manager, large private sector enterprise, November 2012)
}

In some cases the burdens for co-workers appeared to be of larger concern for the employer than the economic costs to accommodation in the workplace. In other cases the section managers and co-workers found it easier to accept trainees with disabilities if they did not replace employees on ordinary employment contracts and the enterprise section did not have to charge their own budget but received additional allocations for this purpose. 
Several of the employers expressed more willingness and interest in accommodating the workplace for employees who acquired as disability after they had been hired. Some interviewees presented unsolicited accounts for their work to reduce the rate of sick-leave in the workplace and prevent that people were transferred to disability benefit ("skills development strategy"). Others emphasized they were flexible and accommodated the needs of the employees as long as it was compatible with their business strategy and objectives; e.g. flexible working hours, home office, adjustable office table, elevator and barrier-free access ("we often have cases of ankle sprain, tendinitis and so on"). Some employers stated they did not aim at an active recruitment of employees with disabilities but focused on employees being able to perform optimally in their work ("no mercy").

Others did accept trainees with disabilities from NAV but expressed less flexibility towards those candidates than towards employees who had worked in the enterprise for many years ("expect them to deliver"). In one case the enterprise accepted trainees with disabilities (often mental health conditions) from NAV only after consultations with the employees; they would not accept any candidates unless they had the time and resources to follow them up. Both employers and co-workers excused themselves that in some periods they had too much to do and did not have the capacity to accept trainees with disabilities.

Co-workers and trade unions have more easily defended the needs of employees who acquired disabilities. At the same time and vexing with this the co-workers expressed concern that employees with disabilities created additional work or required assistance with tasks which were considered too private, intimate or simply not part of the official and "proper" tasks associated with prestige and awards for the other employees.

\footnotetext{
"We had one employee who became a wheelchair user after a heart-attack and a hemorrhagic stroke. (...) The co-workers tried to help him and some claimed we had not done enough for him. Especially one person was critical but when we tried to involve him he soon discovered how difficult it was." (HR Director, independent research and development organization, November 2012)
} 
While employers were more prepared to take responsibility for employees already hired before they acquired a disability, they considered those on the outside of the labour market have tended to be the responsibility of public authorities and to fall outside the scope of the company's social responsibilities. Through this reasoning, employers created or reinforced an insider/outsider division in the labour market for young adults with disabilities.

The youth with disabilities tended to see employers' concern about their work capacity or possible needs for accommodation as part of the difficulties in achieving and retaining paid work.

"When I attended a second interview for a summer job I was asked whether I was able to use a regular computer. If this had been a problem I would have brought up that issue long time ago. From my CV it was clear that I had had three jobs as executive officer already. I was chocked that people look at you as different. It was almost like asking if you are able to use a computer because you are a woman. Anyway, it is the employer's duty to accommodate. It is something that should be taken care of after you have been employed. If the employer addresses it in the interview this may overshadow the qualifications. It is not a reason for not being offered the job. ... It was insulting but I did not argue about it. You could have contacted the Discrimination Ombud but who does that? To go to court is demanding. In the end I was offered the job but declined it because I got a better offer."

(Woman, 24 years, dexterity impairment, MA student, April 2012)

In another case the interviewee had learned from previous experience and avoided demanding accommodation from employers. Instead she now looked for workplaces with little noise and not so hectic work environment. At the same time she had become more reluctant to have a parttime job in addition to being a student. 
"It was a lot of noise. They gave messages from the loudspeakers at the mall. Constant background noise. I discussed it with the boss but she did not want to do anything. Other employees had complained as well. (The trade union) referred to the duty to reasonable accommodation. But it turned out that they had economic difficulties. ... The boss made a large issue of my hearing impairment. She was nagging about it. She could comment: "hey, I do not think you heared what the customers said." She got very occupied with that. The boss complained she lost profit on me and would not give me more shifts than I had been allocated already. But I was not dismissed before the shop was insolvent."

(Woman, 24 years, hearing impairment, dyslexia and difficulties concentrating, BA-student, April 2012)

In these ways, youth with disabilities experienced difficulties in maintaining and enforcing their legal entitlements to reasonable accommodation in negotiations with employers. Moreover, the employees with disabilities refrained from presenting their needs.; e.g. one interviewee reported she avoided asking for accommodation but brought her own lap-top to work to be able to perform her work to avoid being considered a financial burden ("expenditure item"). Although Norwegian employers in certain cases can be compensated $100 \%$ for costs to accommodation in the workplace, the employee could risk a conflict with the employer and being labelled as a potential social problem at the workplace. However, in some cases the assumed reluctance from employers turned out not to be real. As the external barriers disappeared the internal barriers to present demands for accommodation became more apparent.

While youth with mobility, dexterity and sensory impairments might require assistive technology or accommodation of the working environment, youth with mental health problems sometimes needed flexible working hours or reduced working hours in periods with sickness.

"I got new medicines in September and I told the employer it could make me listless. It was the first time I told the employer about the mental health problems. In the job interview they asked if there was any underlying reason [to my earlier career changes] but I did not answer that. It was none of their business. But then I overslept three days in a row. The boss was not so happy when he learned it. He claimed they had a right to be informed in the job interview. It got worse after that. (...) I talked with the assistant manager but it was not much he could do. I complained to LO [the trade union] and The Norwegian Labour Inspection Authority and received in- 
formation about what I should do. The manager got furious and thought I was doing this behind his back. The Norwegian Labour Inspection Authority visited at the workplace but it was only a conversation with the deputy manager and me. I tried to work together with the assistant manager rather than the manager. It worked for a month. Then it was back to the boss again and after another month I resigned. I do not tolerate this!." (Man, 28 years, mental health problem, previous apprentice in electrician trade)

In this case exit from working life emerged as a self-protective strategy to avoid further negative reactions from the employer.

\subsubsection{Reasonable accommodation for minority ethnic groups}

Prejudice and bias are sometimes openly expressed by employers, often confrontational in form, and carried out with the blessings of society or at the very least condoned and accepted. More subtle forms of negative discrimination are found in a setting where employers and others give ideological expression to equality - where many have internalized that it is social taboo and morally wrong to discriminate("differences is the normal at our workplace"), and in consequence believe in and espouse egalitarian values ("focus on their qualifications not their origin"). And yet in this same setting, organizational practice and culture in work places continues to create and perpetuate positions of relative disadvantage for some groups, and privilege for other groups.

"We do not have special measures for minority groups at the work place. We have had some requests about praying room but the employees have accepted it is not going to happen. We have not wanted much special arrangements. Otherwise we could experience conflicts between the employees. (...) Some individuals have complained that we decorate for Christmas. But the other employees have reacted against that. Of course we do decorate for Christmas."

(HR Manager, public enterprise, 400 employees, October 2012) 
"They can be granted paid leave on Eid and the Prophet's Birthday. But almost all are working in a rotation scheme so there is not guarantee. (...) Eid is a flexible holiday and our directors do not manage to take that into account in their planning. We have told it is not so difficult. Eid moves forward with 10 days each year. But they are not aware of that."

(HR manager, public enterprise, 3800 employees, November 2012)

Because the culture of the majority ethnic group is taken for granted and given privilege the minority employees have been expected to accept the larger and more visible presence of the majority culture in the workplace. In some cases ignorance of minority cultures in the management hampered anticipation and accommodation of special needs in the manpower plan.

In other cases it has been a risk that employers' concern with the language skills or accent of the job applicants would be given undue weight in recruitment, temporary lay-offs and dismissals (Perduco, 2010). However, a couple of the employers had accommodated the different language skills among their staff. In one case the enterprise had purchased voice pickers software in the 13 most common languages for their employees in the logistics department. In another case the HR department had published a glossary with the terminology in their enterprise.

Generally the employers were concerned to treat the employees "equally". Accommodation of special needs of ethnic minority staff was granted on the basis of the same rules as for other employees: Employers tended to be flexible with regard to holiday and unpaid leave to be able to celebrate religious holidays or visit relatives in a faraway country as long as this was possible to combine with the needs of the enterprise. To the extent that the Norwegian employers adopted policy measures to ensure reasonable accommodation of ethnic and religious diversity in the workplace, the accommodation was limited to individual rights and did not included collective (group) rights; e.g. individual opportunities to vacation during religious holidays for religious minorities but not access to prayer rooms at the work place.

A common concern among the employers was that collective rights and separate networks for ethnic minorities would create tensions in relation to the co-workers from the majority population or other minorities. In one of the enterprises the staff of Pakistani origin was usually sitting together at social events ("but at least they have started to attend"). In 
the annual celebration of jubilees among the staff the Muslim men used to attend without their spouses. But after their staff advisor with a particular responsibility for ethnic minority issues had talked with them the men had started bringing their wives to the events - like the staff from the majority population. The employer clearly considered their adjustment to the dominant (majority) norms of gender interaction as an achievement of increased cohesion at the workplace.

Not only gender norms but also language and clothing were potential sources of conflict and tensions among the staff:

\begin{abstract}
"It is not a question whether somebody do not fit in at the workplace. Racism is totally unacceptable. But we require that they talk Norwegian at work. Otherwise there will be misunderstandings. If anything if could become a problem that ethnically Norwegians felt they do not fit in at the workplace but it is not a problem today. In some nursing homes we have clusters of certain ethnic groups, for instance Philippines. They talk Philippine in the staff room. Even though they know they ought to talk Norwegian it is unnatural for them when it only is them."
\end{abstract}

(HR manager, public enterprise, 3800 employees, November 2012)

The expression of concern for the relations between co-workers can be interpreted as a concern for the social construction of otherness in the workplace; i.e. how ethnic groups perceive and interact with each other. An underlying concern was that if ethnical-racial categories (culture, skin colour, language) were mobilised and made relevant as a basis for social interaction in the workplace, conflicts could more easily emerge or have the potential to spark conflict if a triggering event occurred.

From the individual minority employee's point of view, however, lack of recognition of the minority culture or questioning of the legitimacy of the minority culture was sometimes associated with experiences of harassment from co-workers. 
"I am the only Muslim at work. One of the other employees says that "Muslims are terrorists", "How can anyone with a Niqab work at our place? It is not possible for hygienic reasons". Our boss and the others do not say anything against her. I feel she is attacking me. But when I work I only use the headscarf and trousers. (...) When I first read the newspapers and read all the comments about Muslims I was depressed. Does everyone think like that?" (Woman 28 years, from Somalia, in Norway for 4 years, working as home help and nursing assistant, November 2012)

Such conflicts were associated with the risk of early exit from working life to avoid further exposure to negative reactions from colleagues.

\subsubsection{Comparing the negotiation strategies of minority ethnic youth and youth with disabilities}

Several of the regulatory policy instruments require that individual citizens or citizens groups publicly present claims to benefit from entitlements to accommodation or protection against discrimination and harassment; e.g. to the Norwegian Discrimination and Equality Ombud or the trade union. In our cases both minority ethnic youth and youth with disabilities benefited from participation in virtual networks and self-help groups in which they had developed skills and strategies (writing CV, identifying job-opportunities, self-presentation in interviews), shared knowledge and developed their own interpretations which they benefited from in negotiations with (prospective) employers and co-workers. As the interviewees, however, were vulnerable to criticism from the majority population they were generally concerned to avoid conflicts, downplayed their contact with the Norwegian Labour and Welfare Service and expressed demonstrative loyalty to the dominant expectations to achieve a formal education and paid work. This was especially the case among minority ethnic youth.

Youth with mobility and sensory impairments could more easily claim to be victims of negative discrimination (physical, organizational and attitudinal barriers to participation) and tended to frame their self-presentation in line with a social model of disability; i.e. societal conditions were considered the main reason for why persons with atypical attributes (or lack of attributes) experience that their life choices are restricted and prevented from equal opportunities to participate in the market and other arenas of society. 
From a social model perspective, the lack of accommodation and prejudices on the part of employers and co-workers are considered the main barriers to participation in the labour market. As the interviewees had clear-cut diagnoses they could more easily claim that the barriers to participate in the labour market were created by others and they could not be blamed for the disadvantaged situation themselves.

Youth with mental health problems tended to a larger extent to frame their status in line with an medical model of disability ("sick, not disabled"). From a medical model perspective, reduction in life-quality and barriers to participation the individual experience are considered the result of a physical or psychological condition intrinsic to the individual. From this perspective society should invests resources in health care and related services in an attempt to cure the sickness, to expand functionality or improve functioning of the individual to reduce the difficulties experienced in education, vocational training and the labour market. Additionally and in keeping with this the interviewees tended to present the health condition as temporary. Altogether the youth with mental health problems were more concerned about access to social services than "discrimination".

\subsection{The role of a third partyin finding and keeping paid work}

Both in Iceland and Norway the role of third parties emerged as a topic in the interviews. Together the two data set provide insights in processes and mechanisms that affected the role of third parties or mediators in the "negotiations" between employers and the vulnerable youth in their efforts to achieve and retain paid work.

In Iceland Traustadottir, Rice and Jokumsen (forthcoming) found that the formal social regulation played an important role in employment outcomes. However the outcome also depended on a number of informal mechanisms and the nature of employment in question. Both in the case of minority ethnic youth and youth with disabilities social networks appeared to be a key factor. In the case of youth with disabilities these networks more often were formed out of a mixture of personal connections as well as connections made with labour and educational professionals. 
In Norway both minority ethnic youth and youth with disabilities benefited from participation in virtual networks (via social media) and selfhelp groups in which they had developed skills and strategies (writing CV, identifying job-opportunities, self-presentation in interviews), shared knowledge and developed their own interpretations which they benefited from in negotiations with (prospective) employers and co-workers.

\subsubsection{Employers}

In Iceland formal social regulations were quite minimal in the case of minority ethnic youth. The impacts of formal regulations were much more apparent in the case of youth with disabilities. Icelandic employers found the wage subsidy scheme for youth with disabilities to have clear economic benefits and the ability to call upon assistance of case workers in supported employment programmes.

In Norway, employers vexed between stating they had no need of support from the public employment services (NAV) and wanting more support and opportunities for consultations. Often employers' expressed an ambivalent relationship to NAV. On the one hand they would downplay the need for special arrangement and policy measures to support the inclusion of the two groups in the labour market. On the other, inclusion of youth with need for accommodation has represented a potential expense and been considered a responsibility for the public authorities.

As part of their corporate social responsibility strategy most of the Norwegian enterprises we interviewed recruited ethnic minorities for vocational training through NGOs or the Norwegian Labour and Welfare Service (NAV). Some of the enterprises also had separate recruitment and promotion programs to stimulate broader diversity in management level positions. To the extent that the employers actively recruited and hired young adults with disabilities they did so through NAV or a self-help organisation for persons with mental health problems (Clubhouse Norway).

Norwegian employers reported mixed experiences with recruiting candidates through NAV. While some public agencies recommended all their clients to apply other agencies filtered their clients and transferred only those with sufficient language skills. To ensure they received only qualified candidates some of the employers had selected a few NAV offices 
they had managed to achieve a good working relationship with ("have taken time before they understood our needs as employer").

To the extent the employers felt they received help and assistance from the Norwegian Labour and Welfare Service (NAV) the employer had a personal contact person in the agency they could contact when they needed advice and information about reasonable accommodation in the workplace.

\subsubsection{Minority ethnic youth}

Among minority ethnic youth in Iceland the social networks as a method for finding work usually took the form a parent, sibling or friend who alerted the participant of the availability of employment. In a number of cases it appeared that the participant's contact was able, to an extent, to exert some influence behind the scenes to improve the chance of the participant being successful in the application process.

Similar stories emerged in the minority youth in Norway. Additionally in several cases non-governmental organisations working against discrimination compensated for the lack of a relevant social network.

\subsubsection{Youth with disabilities}

The role of social networks was a little more complex for youth with disabilities. Given the more extensive involvement of youth with disabilities in active labour market schemes and other forms of support the networks of the youths with disabilities - both in Iceland and Norway tended to include employment counsellors, former employers and educators along with friends and family. However, interviewees among youth with invisible and less severe disabilities reported experiences of seeking work independently and through formal procedures. 


\subsection{Concluding comments}

While the formal social regulation played an important role in employment outcomes a number of informal mechanisms were also important. This chapter has argued that the legitimacy of the youth groups has influenced on their opportunities to take advantage of the formal social regulation. Several of the regulatory policy instruments require that individual citizens or citizens groups publicly present claims to benefit from entitlements to accommodation or protection against discrimination and harassment; e.g. to the Norwegian Discrimination and Equality Ombud or the trade union.

Some of the difficulties among the minority ethnic youth to find paid work illustrated the complex interaction between redistributive and regulatory policy measures. Because most of them considered they needed to improve their Norwegian language skills and/ or complete more education it was seldom obvious that they have been exposed to discrimination in the cases they had not been hired for a job. More often the interviewees illustrated the need for access to temporary positions in vocational training and financial schemes which would provide incentives for employers to employ minority youth with little or no economic risk.

As the youth were vulnerable to criticism from the majority population they were generally concerned to avoid conflicts, downplayed their contact with the Norwegian Labour and Welfare Service and expressed demonstrative loyalty to the dominant expectations to achieve a formal education and paid work. This was especially the case among minority ethnic youth.

Youth with mobility and sensory impairments could more easily claim to be victims of negative discrimination (physical, organizational and attitudinal barriers to participation) and tended to frame their selfpresentation in line with a social model of disability; i.e. societal conditions were considered the main reason for why persons with atypical attributes (or lack of attributes) experience that their life choices are restricted and prevented from equal opportunities to participate in the market and other arenas of society. From this perspective the lack of accommodation and prejudices on the part of employers and co-workers are considered the main barriers to participation in the labour market. As the interviewees had clear-cut diagnoses they could more easily claim that the 
barriers to participate in the labour market were created by others and they could not be blamed for the disadvantaged situation themselves.

Youth with mental health problems tended to a larger extent to frame their status in line with a medical model of disability ("sick, not disabled"). I.e. the reduction in life-quality and the barriers to participation the individual experience were considered the result of a physical or psychological condition intrinsic to the individual. From this perspective society should invests resources in health care and related services in an attempt to cure the sickness, to expand functionality or improve functioning of the individual to reduce the difficulties experienced in education, vocational training and the labour market. Additionally and in keeping with this the interviewees tended to present the health condition as temporary. Altogether the youth with mental health problems were more concerned about access to social services than "discrimination".

Due to their larger degree of legitimacy youth with clear-cut diagnosis and physical impairments could more easily claim to be discriminated against. Minority ethnic youth and youth with mental health problems were better positioned to negotiate with public agencies about access to redistributive policy measures (education and training) than taking advantage of the regulatory policy measures.

While disability has been conceived as a result of biology, sickness, or accidents ("destiny"), many people tend to assume that ethnicity is a "chosen" status; i.e. that the person in question could just choose not to identify with an ethnic minority. According to this perception, people of indigenous, national minority or immigrant background could choose to assimilate to the majority by abandoning their own language and culture ("adjust to the local culture", e.g. Adresseavisen 21.01.2014), regardless of their different background and visible traits like colour of skin and hair (Kymlicka, 2002:339-40). This perception has often been associated with blaming minority ethnic youth for maintaining their culture and/or claims to accommodate ethno-cultural diversity in the workplace has been considered unreasonable.

Overall the employers were occupied with the social construction of otherness in the workplace: who fit in at the workplace and how to avoid tensions and conflicts at the workplace. To maintain their legitimacy, employers are driven to incorporate prevailing norms and institutionalized 
policies and programmes to foster diversity in the organisation. Vexing with this, the employers need a focus on efficiency to ensure that the organisation achieves its objectives. While the formal organisation have to take into consideration the expectations from their institutional environment and maintain the official image of the enterprise, the actual day-today work activities may reflect quite different priorities. Arguably the emphasis given to Corporate Social Responsibility or diversity management in many organisations reflects the norms and values of their institutional environments instead of the demands of their work activities. Many diversity policies and programmes emerge in response to prevailing norms and expectations in the environment rather than from internal needs in the organisation. Many of the official positions organisations take are enforced if not by law then by public opinion and the views of their important constituents.

Our data suggest that employers individualized the accommodation of ethnicity in the workplace: Partly accommodation of the needs of ethnic minorities was limited to individual rights and did not include collective rights to observe religious rituals during the work day. Partly corporate social responsibility to enhance the recruitment of minority ethnic groups in the management was framed as an individual need for education and training rather than a question of discrimination.

Obviously the strategies adopted by employers and the vulnerable youths have affected the effectiveness of the regulatory measures adopted in the Nordic countries during the last decade. Altogether this suggests increased attention to the implementation stage of the policy process is necessary to be able to assess whether seemingly novel (or innovative) policies represent true changes. 



\section{Concluding discussion: Regulating diversity in the labour market}

Despite reforms in the redistributive policy measures and the adoption of new regulatory policies to enhance the employment prospects of ethnic minority youth, the Nordic countries still witness ethno-cultural divides in the employment prospects for young adults. Similarly there is little evidence that suggest that the Nordic countries managed to improve the employment prospects for young adults with disabilities in the last decade. Despite the uncertainties related to the reliability and comparability of available figures, there can be no doubt that a large proportion of young adults with disabilities have been practically excluded from gainful employment in the Nordic countries. Together ethnicity and disability ads to our understanding of social divisions in the Nordic countries today (in addition to social class and gender) (Williams, 1995).

This report has examined what overall significance social regulation provisions have had on the employment opportunities and prospects of minority ethnic youth and youth with disabilities. In doing so the report has taken into account the role of existing redistributive arrangements and possible interactions or incompatibilities between regulatory and redistributive provisions.

Initially we asked under which conditions social regulation is most likely to have a positive impact on the labour market participation of vulnerable youth groups. However, the team increasingly discussed how the outcomes of the social regulation subsystem needs to considered as interacting with differences between the Nordic countries in the social services subsystem and social benefit subsystem.

This revised focus was partly a general acknowledgement of the difficulty in isolating the impact of social regulation instruments (and controlling for all 
other relevant factors). Partly, the unexpected problems we encountered in seeking access to relevant and comparable longitudinal data about young individuals in the five countries have contributed to this revised focus.

The report has demonstrated the need for better data to examine under which conditions social regulation is most likely to have a positive impact on the labour market participation of vulnerable youth groups. If Nordic governments want a better knowledge-base for policy development, innovation and exchange of best practice, efforts and resources need to be invested in ensuring:

- Longer time series of data and more frequent data points.

- Data that are consistent and truly comparative across time and place (e.g. regarding definitions and categories used).

- Effective use of existing register data across countries.

- Repeated surveys with sufficient size to allow comparisons between subgroups (e.g. different impairments or disabilities, ethnicity, immigration background, length of residency, first or second generation, etc.).

- Panel data making it possible to follow the same individuals over time.

- Well-designed intervention studies and controlled trials.

While available data has not made it possible to determine robust evidence of an effect (positive or negative) of the social regulation policies for the employment of vulnerable youth groups in statistical (numeric) terms, the team has been able to clarify processes and mechanisms through which social regulation policies make a difference.

\subsection{Ethnicity and disability in Nordic social protection policy}

The report has argued that ethnicity and disability represent social categories of high policy relevance for understanding the present challenges to the Nordic welfare states, including their efforts to promote the inclusion of new generations of young adults in the workforce. We have argued that in order to understand the role of the new and emerging regulatory 
policy instruments to promote the participation of Nordic youth we need to take into account the legitimacy of the target group intended to benefit from the policy.

Earlier studies have found that Nordic employers often are reluctant to hire persons with disabilities and persons with minority ethnicbackground even if they have higher education (Andreassen, 2012, Midtbøen and Rogstad 2012, OECD 2013a). Our interview data demonstrate that employers were concerned about otherness in the workplace; i.e. whether minority youth or youth with disabilities would fit in at the workplace, change the work organizational culture or create extra work and concerns for the co-workers. Ignorance and neglect of existing obligations on the part of employers, recurring fears that the costs associated with making workplaces fully accessible and accommodating them to the requirement of workers with disabilities, and efforts among persons with disabilities to pass as non-disabled and reluctance to present demands for reasonable accommodation or protection against harassment and discrimination in the workplace, have prevented social regulation policy measures to be effective (Halvorsen and Hvinden, 2014).

\subsection{Social regulation vs social redistribution in the Nordic countries}

The report has argued that the transitions from education to employment is associated with four interrelated challenges for the labour market inclusion of young adults: school drop-out, lack of employment opportunities, labour market segmentation and early exit and termination of contracts. The complexity of the transitions suggest a multidimensional approach (Table 8.1). 
Table 8.1: Enhancing transitions between education and employment

\begin{tabular}{|c|c|c|c|}
\hline Young people & In general & $\begin{array}{l}\text { With minority } \\
\text { background }\end{array}$ & $\begin{array}{l}\text { With } \\
\text { disability }\end{array}$ \\
\hline $\begin{array}{l}\text { Combat school absence and drop-out, provide follow-up and } \\
\text { support, accommodate diversity, improve educational accom- } \\
\text { plishments }\end{array}$ & $x$ & $x$ & $x$ \\
\hline $\begin{array}{l}\text { Facilitate combined training and real work experience, relevant } \\
\text { work practice and apprenticeships }\end{array}$ & $x$ & $x$ & $x$ \\
\hline $\begin{array}{l}\text { Combat discrimination, prejudice and stereotypes, promote } \\
\text { accessibility, raise awareness through campaigns, disseminate best } \\
\text { practice, lower thresholds for complaints and redress }\end{array}$ & $x$ & $x$ & $x$ \\
\hline $\begin{array}{l}\text { Lower companies costs related to work accommodation, lower } \\
\text { threshold support for diversity management, positive duties for } \\
\text { major public and private employers }\end{array}$ & & $x$ & $x$ \\
\hline $\begin{array}{l}\text { Target flexible wage subsidies, compensate for initial or lasting } \\
\text { diminished productivity }\end{array}$ & $x$ & $x$ & $x$ \\
\hline
\end{tabular}

The report has demonstrated that the Nordic countries have responded differently to the concerns about the public expenditures and financial disincentives for the individual to participate in the labour market, the need for an up-to-date and relevant educational and vocational training services and social regulation of the market to ensure an inclusive labour market. The Nordic countries all have adopted regulatory provisions to enhance the employment prospects and opportunities of young mothers, minority ethnic youth and youth with disabilities. Nevertheless, we find not insignificant differences between the countries both in scope and implementation of the provisions. Of the Nordic countries, Sweden had adopted the broadest repertoire of legal and financial provisions. Denmark was the most reluctant to adopt statutory provisions to ensure nondiscrimination and accommodation for all three population groups.

Altogether the increasing salience of diversity has furthered a more complex mix of policy measures combining redistributive and regulatory policy instruments in Nordic labour market policy. Still redistributive or transfer-oriented arrangements to enhance employability and provide income security during periods outside employment are more developed than regulatory provisions. However, the last 15 years the meaning of accommodation to disability have been codified in legal documents - but to various extent. In a Nordic context, accommodation of ethnic diversity 
in the workplace has proved to be more controversial. Arguably the relatively low public legitimacy of ethno-cultural diversity has been reflected in the reluctance among Nordic politicians to adopt regulatory policy measures and innovative strategies to ensure the accommodation of ethnic diversity in the workplace and increase the participation of minority ethnic youth in employment (Halvorsen and Hvinden, 2014).

To considerable extent Nordic social protection policy has been supply oriented and emphasised efforts to strengthen the individual's qualifications, skills or "human capital" through education and training to improve his or her job chances and employability. Since the early 1990s,a number of reforms have tightened up the eligibility criteria, introduced or reinforced emphasis on the conditionality of participation in ALMP to continue receiving benefits. To hasten the flow of potential workers into or back to employment "passive" income maintenance schemes have become less generous. We also find an increasing emphasis on extending the scope for use of temporary employment contracts ("flexibility"). Altogether, Nordic social protection policies have demonstrated many of the features associated with the "social investment approach" and productivist social policy more generally (Esping-Andersen, 2002 , Hemerijck et al., 2013, Morel et al., 2012, Vandenbroucke et al., 2011).

Given the large investments in education and training for young in the Nordic countries we could have expected larger returns. This may partly be due to the design and implementation of the general education service and the ALMP. The higher number of early school leavers and lower participation rates in education and training suggests that there is scope for better accommodation of the human capital or skills improvement measures to the needs of minority ethnic youth and youth with disabilities and/or learning difficulties (e.g. dyslexia). Unless education and training is physically accessible, provide necessary flexibility in time needed to complete courses due to illness or incapacity, and books and lectures are available in accessible formats, the opportunities to invest in education will be limited (Magnus, 2009).

Earlier studies have questioned whether ALMPs have made the beneficiaries more attractive in the labour market and increased their skills or mainly served to test their willingness to achieve gainful employment (Kluve, 2006, Koning, 2007). Despite the increasing emphasis given to 
"individual action plans" in implementing ALMP we find strategies to standardise the help and assistance provided among local agents and limited scope for "voice", influence on the final choice of education and training programmes or opportunities to decline offers the claimant finds degrading or meaningless (Halvorsen et al., 2007 ). Several studies have demonstrated how limited resources and time constrains in the local agents and managerial requirements to report efficient spending of public resources have structured ALMP. Local agents have favoured selection of the most employable beneficiaries among the disabled. In other cases a narrow conception of "activation" has hampered the opportunities for tailor-made solutions and adopting a broader and more long-time perspective on the investment in persons at risk of social exclusion.

For those at a distance from the labour market strengthening capacities and capabilities may include more long-term investments than is commonly the case. However, if the objective capacity to work is minimal, a reduction in the benefit level and/or activation strategies will not necessarily increase the likelihood of achieving paid work. In such cases benefit cuts and activation requirements will do little to prevent social exclusion and enable agency.

Unless the policy design and implementation are sensitive to the variation in the needs of the population some population groups will not be able to benefit from the services in cash or in kind; e.g. abilities to benefit from education designed for the general population or standardised ALMP unless special needs (related to an immigrant background, impairment, school drop-out) are accommodated. Because people are fundamentally diverse - due to personal, environmental and social conditions - the processes and mechanisms that structure the abilities to benefit from the resources varies between population groups.

The challenges faced by Nordic welfare states to foster social inclusion and participation of persons with outside the labour market are not only related to instrumental coordination or selecting the most effective policy instruments. Making sure that staff in the educational and social services stimulates involvement, initiatives and participation from persons outside the labour market is equally important.

If social and educational services are designed in a strict top-down manner by national authorities and leave little space for manouvering by local 
agents the diversity of needs will be difficult to take properly into account. While this does not necessarily imply unconditional respect of the beneficiaries' point of view, effective possibilities for co-determination (a capability for voice) by the beneficiaries would increase the likelihood of collaborative relations between the service providers and beneficiaries and coproduction of the services they participate in (Bonvin and Orton, 2012).

The issues about the design of the education and training programmes aside, a one-sided focus on investments on the supply side seem insufficient to ensure social inclusion of vulnerable population groups in the labour market. Social regulation (e.g. wage subsidies, reimbursement of costs associated with reasonable accommodation) to influence employers preferences and behaviour are equally important to promote inclusion of such population groups. More generally, we want to consider the context or social environment that the person faces and how changes in these surroundings may be required to achieve active inclusion. For instance, it may be necessary to promote physical accessibility in the social environment of persons with mobility restrictions and to combat discrimination and stereotypes. Altogether this suggests a pluralist and multidimensional approach to social protection policies to enhance the labour market opportunities for vulnerable youth groups. 



\section{References}

Allen, J. \& van der Velden, R. (eds.) (2011). “The Flexible Professional in the Knowledge Society: New Challenges for Higher Education". Higher Education Dynamics, 35, Dordrecht: Springer.

Andersen, T., Hougaard, K. F. \& Ólafsson, S. (2011). "Assessment of the Labour Market in Iceland. Final report". . Policy and Business Analysis. Aarhus, Danish Technological Institute.

Andreassen, T. A. (2012). "Disability as an Asset? Reflections on Employment Patterns in the Health and Social Care Sector ", in Disability Studies Quarterly, Vol. 32, No. 3.

Arrow, K., 1973: "The Theory of Discrimination", in Discrimination in Labor Markets, eds. O. Ashenfelter and A. Rees, 3-33. Princeton NJ: Princeton University Press.

Barth, E., Moene, K. O., \& Wallerstein, M. (2003). Likhet under press: utfordringer for den skandinaviske fordelingsmodellen. Oslo, Gyldendal akademisk.

Becker, G. (1957). The Economics of Discrimination. University of Chicago Press, Chicago.

Bell, D. (1973). The Coming of Post-Industrial Society. A Venture in Social. New York: Basic Books.

Bell, David N. F. \& Blanchflower, David G. (2010). "Youth Unemployment: Déjà Vu?," IZA Discussion Papers, 4705. Institute for the Study of Labor (IZA).

David N. F. Bell \& David G. Blanchflower, 2011. "Young people and the Great Recession". Oxford Review of Economic Policy. Oxford University Press, vol. 27(2), pages 241-267.

Bemelmans-Videc, M.-L. , Rist, R. C., \& Vedung, E. (eds.) (1998). Carrots, sticks and sermons.Transaction Publishers.

Bernitz, B. K., et al. (2013). Unga förtidspensionärer. Studie av sju europeiska länder (Young Adults on Disability Benefits). Stockholm, Swedish Social Insurance Inspectorate (Inspektionen för socialforsäkringen).

Bevelander, P., et al. (2013). Scandinavia's Population Groups Originating from Developing Countries: Change and Integration. Copenhagen, Nordic Council of Ministers.

Bjørnstad, R. (2006). "Learned helplessness, discouraged workers, and multiple unemployment equilibria". The journal of socio-economics. Amsterdam, Elsevier, Vol. 35.2006, 3, p. 458-475

Blekesaune, M. (2007) "Have some European countries been more successful at employing people with disabilities than others?" Working Paper 23. University of Essex. 
Bonoli, G. (2010). "The political economy of active labour market policy". REC-WP Working Papers on the Reconciliation of Work and Welfare in Europe. ChavannesRenens, Swiss Graduate School of Public Administration.

Bonvin, J.-M. \& Orton, M. (2012). "Activation policies and organisational innovation. The added value of the capablity approach", in International Journal of Sociology,Vol. 29, No. 11/12.

Boudon, R. (1974) Education, Opportunity and Social Inequality. Changing Prospects in Western Society. New York, John Wiley.

Bø, T. P., \& Håland, I. (2013). Funksjonshemma på arbeidsmarknaden i 2013. Report 2013/51.

Brekke, I. (2007). "Ethnic background and the transition from vocational education to work: A multilevel analysis of the differences in labour market outcomes ", in Journal of Education and Work,Vol. 20, No. 3.

Brekke, I. \& Mastekaasa, A. (2008). "Highly educated immigrants in the Norwegian labour market: permanent disadvantage? ", in Work, Employment and Society, Vol. 22, No. 3.

Brix Pedersen, K. (2010). "What is Denmark doing to stop people from ending up on disability pension?" in Kautto, M., Bach-Othman, J. (Eds.) Disability and employment - lessons from reforms. Report 2010:4. Finish Centre for Pensions, Helsinki.

Bull, H. \& Andreassen, T. A. (2007). Oppfølgingsundersøkelse om ansettelse av funksjonshemmede i staten. Oslo: Arbeidsforskningsinstituttet. Oslo.

Bäckman, O., Nilsson, A. (2013). "Unga som varken arbetar eller studerar - olika definitioners betydelse för omfattning, sammansättning och konsekvenser" in SOU Unga som varken arbetar eller studerar - statistik, stöd och samverkan. Slutbetänkande av Utredningen om unga som mvarken arbetar eller studerar. Stockholm, Statens Offentliga Utredningar.

Bø, T. P. \& Håland, I. (2013). Funksjonshemma på arbeidsmarknaden i 2013. Report 2013/51. Oslo, Statistics Norway.

Craig, R. (2013). System Discrimination and Positive Duties: REgulating Workplace Equality through enforced Employer-Driven Self-Regulation. Oslo.

Dobbin, F. (2009). Inventing Equal Opportunity. Princeton University Press

Djuve, A. B. \& Tronstad, K. R. (2011). Innvandrere i praksis. Om likeverdig tjenestetilbud i NAV. Oslo, Fafo

Ellingsæter, A. L. \& Leira, A. (eds.) (2006). Politicising parenthood in Scandinavia. Gender relations in welfare states. Policy Press.

Esping-Andersen, G. (1999). Social foundations of postindustrial economies. Oxford: Oxford University Press.

Esping-Andersen, G. (2002). "A Child-Centred Social Investment Strategy". G. Esping-Andersen, D. Gallie, A. Hemerijck, J. Myle (eds.) Why We Need a New Welfare State? Oxford, Oxford University Press.

Etzioni, A. (1961). A Comparative Analysis of Complex Organizations: On Power, Involvement, and Their Correlates. Free Press. 
Eurofound. (2012). Young people not in employment, education or training: Characteristics, costs and policy responses in Europe. Dublin, European Foundation for the Improvement of Living and Working Conditions.

Eurostat. (2009). Youth in Europe - A statistical portrait. Luxembourg, Publications Office of the European Union.

Eurostat. (2013). Public expenditure on labour market policy measures, by type of action.

Fagan, C., (2012).. In T. Knijn. Work, Family Policies and Transitions to Adulthood in Europe. Palgrave Hampshire.

Falkum, Eivind (2012). Risiko og inkludering. Betingelser for funksjonshemmedes og eldres deltakelse $i$ arbeidslivet. Arbeidsforskningsinstitutte Oslo.

Fangen, K. \& Frønes, I. (2013). "Structural barriers and individual agency: A mixedmethods approach to school-work transitions among young adult immigrants and descendants". in G. Gudmundsson, D. Beach, V. Vestel (eds.) Youth and marginalisation: Young people from immigrant families in Scandinavia. Tufnell Press.

Fraser, N. (1995). "From Redistribution to Recognition? Dilemmas of Justice in a 'Post-Socialist' Age". New Left Review I/212, July-August 1995.

Friberg, J. H. \& Eldring, L. (2013). "Labour migrants from Central and Eastern Europe in the Nordic countries. Patterns of migration, working conditions and recruitment practices". TemaNord. Copenhagen, Nordic Council of Ministers.

Giddens, A. (1984). The Constitution of Society. Cambridge Polity Press.

Granovetter, M. (1973) "The Strength of Weak Ties". American Journal of Sociology, Volume 78, Issue 6 (May, 1973), 1360-1380.

Granovetter, M. (1983). "The Strength of Weak Ties: A Network Theory Revisited". Sociological Theory, Vol. 1: 201-233.

Gould, R. \& Kaliva, K. (2010). Työkyvyttömyyseläke ja ansiotyö. Helsinki Eläketurvakeskuks/ Finnish Centre for Pensions.

Grammenos, S. (2013). "European Comparative Data on Europe 2020 and Housing Conditions". Academic Network of European Disability Experts. Leeds, University of Leeds, Centre for European Social and Economic Policy.

Halvorsen, B., Hansen, O. J. \& Tägtström, J. (2012). Unge på kanten. Om inkludering av utsatte ungdommer, in N. C. O. Ministers (ed.) Norden, Copenhagen.

Halvorsen, R. \& Hvinden, B. (2009). "Nordic Disability Protection Meeting Supranational Equal Treatment Policy - A Boost for the Human Rights of Persons With Disabilities?" in H. S. Aasen, R. Halvorsen, A. B. D. Silva (eds.) Human Rights, Dignity and Autonomy in Health Care and Social Services: Nordic Perspektives. Belgium, Intersentia.

Halvorsen, R. \& Hvinden, B. (2011). Andre lands modeller for å fremme sysselsetting blant personer med nedsatt funksjonsevne. Oslo, Norsk institutt for forskning om oppvekst, velferd og aldring.

Halvorsen, R. \& Hvinden, B. (2014). "Nordic reforms to improve labour market participation of vulnerable youth: An effective new approach? ", in International Social Security Review,Vol. 67. 
Halvorsen, R., et al. (2007). "The challenges of decentralized delivery of services" in B. Hvinden, H. Johansson (eds.) Citizenship in Nordic Welfare States. Dynamics of choice, duties and participation in a changing Europe. London. New York Routledge

Hammer, T. \& Hyggen, C. (2006). "Stengte dører? Unge sosialklienters arbeidstilpasning i voksen alder" in T. Hammer, E. Øverbye (eds.) Inkluderende arbeidsliv? Erfaringer og strategier. Oslo Gyldendal Akademiske.

Hammer, T. \& Julkunen, I. (2003). "Surviving unemployment: a question of money or families?" in T. Hammer (ed.) Youth Unemployment and social exclusion in Europe. A Comparative Study. . Bristol, Policy Press

Hannesdóttir, G. (2010). "Lífskjör og hagir öryrkja. Könnun meðal örorku- og endurhæfingarlífeyrispega" [Living conditions and circumstances of disabillity pensioners. A survey of disability and rehabilitation pensioners] Pjóðmálastofnun Öryrkjabandalag Íslands.

Hannesdóttir, G., Thorlacius, S. \& Ólafsson, S. (2010). "Örorka og virk velferðarstefna Könnun meðal örorku- og endurhæfingarlífeyrispega". Reyijavik Social Research Center (Pjóðmálastofnun).

Hardoy, I. \& Zhang, T. (2010). "Innvandrere i arbeid: Hjelper arbeidsmarkedstiltak?" in Søkelys på arbeidsmarkedet, No. 4.

Hatland, A. (2011). "Innvandring og velferd" in A. Hatland (ed.) Veivalg $i$ velferdspolitikken Oslo Fagbokforlaget.

Heath, A. F., Rothon, C. \& Kilpi, E. (2008). "The Second Generation in Western Europe: Education, Unemployment, and Occupational Attainment", in Annual Review of Sociology,Vol. 34.

Hedetoft, U. (2006). "More than kin and less than kind - the Danish Politics of ethnic consensus and the Pluarlistic Challenge" in J. Campbell, J. Hall, O. K. Pedersen (eds.) National Identity and the Varieties of Capitalism - The Danish Experiment McGil-Queen's University Press.

Hemerijck, A., et al. (2013). "European Welfare States in Motion". NEUJOBS.

Hermansen, A. S. (2013). "Occupational Attainment Among Children of Immigrants in Norway: Bottlenecks into Employment--Equal Access to Advantaged Positions?", in European Sociological Review,Vol. 29, No. 3.

Hobson, B. (ed.) (2003). Recognition Struggles and Social Movements: Contested Identities, Agency and Power, Cambridge-New York Cambridge University Press Available.

Holm, P. \& Happonen, A. (2007). The working capacity of handicapped persons in 2007: comparisons with unemployed persons. Helsinki, Pellervo Economic Research Institute.

Hvinden, B. (1995). "Poverty, exlusion, and agency". Research in Community Sociology. Vol. 5

Hvinden, B. (2010). "The Nordic Welfare Model and the Challenge of Globalisation". The Nation-state in transformation : economic globalisation, institutional mediation and political values. Aarhus Universitetsforlag. 
Icelandic Human Rights Centre. (2009). Discrimination in Iceland. Survey carried out for the Icelandic Human Rights Centre and the Ministry of Social Affairs and Social Security compared to Special Eurobarometer 317. Reykjavik Icelandic Human Rights Centre.

Icelandic Human Rights Centre. (2011). Bann við mismunun: Tilskipanir ESB um jafnrétti óháð fötlun, kynpætti, pjóðernisuppruna, kynhneigð, aldri og trú/lifsskoðun (Prohibition of discrimination: EU directives on equal treat-ment regardless of disability, race, national origin, sexual orientation, age, religion/beliefs). Reykjavík Icelandic Human Rights Center.

Icelandic Red Cross. (2010). Hvar prengir ađ?

Inghammar, A. (2006). Funktionshindrad - med rätt til arbete? En komparativ studie av arbetsrättsliga regleringar kring arbete och funktionshinder [Disabled with a right to work? A comparative study of labour law regulations of work and disability in Sweden, England and Germany] Lund Juristförlaget.

Lauglo, J. (2000). Unge fra innvandrerfamilier og sosial kapital for utdanning. Norges forskningsråd Oslo.

Jensberg, H., Mandal, Roland \& Solheim, Erling (2012). "Det kjønnsdelte arbeidsmarkedet, 1990-2010". Trondheim: Rapport NTNU/SINTEF

Jonsson, J. O. (2007). "The Farther They Come, the Harder They Fall? First- and Second-Generation Immigrants in the Swedish Labour Market" in A. F. Heath, S. Y. Cheung (eds.) Unequal Chances. Ethnic Minorities in Western Labour Markets Oxford, Oxford University Press.

Jordana, J. \& Levi-Faur, D. 2004 "The politics of regulation in the age of governance", in Jordana \& Levi-Faur (Eds) The Politics of Regulation, Edward Elgar.

Kieselbach, T. (2004). "Psychology of unemployment and social exclusion. Youth unemployment and the risk of social exclusion" in D. Gallie (Ed) Resisting Marginalization. Unemployment Experience and Social Policy in the European Union. Oxford University Press, Oxford.

King, R. (2007). The Regulatory State in an Age of Governance, Palgrave.

Kjeldsen, M. M., Houlberg \& H. S., Høgelund, J. (2013a). Handicap og beskjæftigelse, Udviklingen mellem 2002 og 2012. Copenhagen, SFI - Det nationale forskningscenter for velfærd.

Kjeldsen, M. M., Houlberg \& H. S., Høgelund, J. (2013b). Handicap og beskæftigelse. Udviklingen mellem 2002 og 2012. Copenhagen, SFI - The Danish National Centre for Social Research.

Kluve, J. (2006). "The Effectiveness of European Active Labor Market Policy". IZA Discussion Paper. Bonn IZA Institute for the Study of Labor.

Koning, J. D. (2007). "Is the changing pattern in the use of active labour market policies consistent with what evaluations tell us about their relative performance?" in J. D. Koning (ed.) The Evaluation of Active Labour Market Policies: Measures, PublicPrivate Partnership and Benchmarking, . Aldershot Edward Elgar.

Korkiasaari, J. \& Söderling, I. (1998). "Finland: From a country of emigration into a country of immigration", in Teoksessa I. Söderling,(toim.) A changing pattern of 
migration in Finland and its surroundings. Väestöntutkimuslaitoksen julkaisusarja D, Vol. 32 .

Kuivalainen, S. \& Nelson, K. (2012). "Eroding minimum income protection in the Nordic countries? Reassessing the Nordic model of social assistance" in J. Kvist, J. Fritzell, B. Hvinden, 0. Kangas (eds.) Chaing social inequality. The Nordic welfare model in the 21st century Bristol, Policy Press.

Kymlicka, W. (2002). Contemporary Political Philosophy: An Introduction OxfordNew York. Oxford University Press.

Kymlicka, W. (2012). Multiculturalism: Success, Failure, and the Future. Washington, DC, Migration Policy Institute.

Laiho, V., et al. (2010). "The working capacity of unemployed and disabled persons". PTT Reports Helsinki Pellervon taloustutkimus PTT.

Lauglo, J. (2000). "Social capital trumping class and cultural capital? Engagement with school among immigrant youth" in S. Baron, J. Field, T. Schuller (eds.) Social Capital. Critical Perspectives. Oxford, Oxford University Press.

Lawson, A. (2008). "Disability and Equality Law in Britain. The Role of Reasonable Adjustment". Hart Publishing.

Leibig, T. (2007). "The Labour Market Integration of Imigrants in Denmark". OECD Social Employment amnd Migration Working Papers Paris OECD.

Leibig, T. (2009). "Jobs for Immigrants: Labour Market Integration in Denmark". OECD Social Employment and Migration Working Papers. Paris OECD.

Liisberg, M. V. (2011). Disability and Employment: A Contemporary Disability Human Rights Approach Applied to Danish, Swedish and EU Law and Policy. Maastricht, Intersentia.

Linnenkangas, R., et al. (2006). Uuden alussa vai umpikujassa? Vammaiset matkalla yhdenvartaiseen kansalaisuuteen. Helsinki Stakes.

Majone, G. (1993). "The European Community between social policy and social regulation" Journal of Common Market Studies, 31: 2, 153-70.

Magnus, E. (2009). Student, som alle andre: en studie av hverdagslivet til studenter med nedsatt funksjonsevne. Trondheim, Norges teknisk-naturvitenskapelige universitet.

Marin, B., Prinz, C. \& Queisser, M. (eds.). (2004). Transforming disability welfare policies: towards work and equal opportunities, Ashgate Available.

Mathiesen, Thomas 1972 (1965). The Defences of the Weak. A Sociological Study of a Norwegian Correctional Institution. London: Tavistock Publications.

Midtbøen, A. \& Rogstad, J. (2012). Diskrimineringens omfang og årsaker. Etniske minoriteters tilgang til norsk arbeidsliv. Report 2012:001 Institutt for samfunnsforskning Oslo.

Mitchell, T. L. \& Kovera, M. B. (2006). "The Effects of Attribution of Responsibility and Work History on Perceptions of Reasonable Accommodations". Law and Human Behavior, 30(6), 733-748.

MMI. (2006). Telefonunders $ø$ kelse om betydning av nedsatt funksjonsevne ved ansettelser i arbeidslivet. Oslo MMI Univero. 
Moene, K. O. \& Wallerstein, M. 2001. "Inequality, Social Insurance, and Redistribution", in The American Political Science Review,Vol. 95, No. 4.

Molden, T. H. \& Tøssebro, J. (2012). "Disability measurements: impact on research results", in Scandinavian Journal of Disability Research, Vol. 14, No. 4.

Molden, T. H., Wendelborg, C. \& Tøssebro, J. (2009). Levekår blant personer med nedsatt funksjonsevne, analyse av levekårsundersøkelsen blant personer med nedsatt funksjonsevne 2007. Trondheim NTNU Samfunnsforskning.

Morel, N., Palier, B., Palme, J. (eds.). (2012). Towards a Social Investment State? Ideas, Policies and Challenge, Bristol, Policy Press. Available.

Mykletun, A. \& Knudsen, A. K. (2009). Psykiske lidelser i Norge: Et folkehelseperspektiv. Report 2009:8. Norsk Folkehelseinstitutt Oslo

Nelson, K. (2013). "Social Assistance and EU Poverty Thresholds 1990-2008. Are European Welfare Systems Providing Just and Fair Protection Against Low Income? ", in European Sociological Review,Vol. 29 No. 2.

Nilsson, A. \& Bäckman, O. (2014). Unge vuxna som varken arbetar eller studerar risikofaktorer och konsekvenser i fyra födelseskohorter. in J. Olofsson (ed.), Studentlitteratur.

NOSOSCO. (2011). Youth Unemployment in the Nordic Countries - A Study on the Rights of and Measures for Young Jobseekers. Copenhagen Nordic Social Statistical Committee.

OECD. (1994). "Employment Protection regulation and Labour Market Performance". OECD Employment Outlook. Paris OECD.

OECD. (2009). "Sickness, Disability and Work. Keeping Track in the Economic Downturn. Background paper". High-Level Forum, Stockholm, 14-15 May 2009. Paris OECD.

OECD. (2010). Off to a Good Start? Jobs for Youth. Paris OECD Publishing.

OECD. (2012). OECD Employment Outlook 2012. Paris OECD Publishing.

OECD. (2012) Education at a Glance 2012 OECD Indicators Paris OECD Publishing

OECD. (2013). OECD Employment Outlook 2013. Paris OECD.

OECD, Canadian Policy Research Networks. (2005). From Education to Work. A Difficult Transition for Young Adults with Low Levels of Education. Paris OECD Publishing.

Olsen, B. (2012). Unge med innvandrerbakgrunn i Skandinavia. Hvor mange er $i$ arbeid eller utdanning? Statistics Norway Oslo.

Orupabo, J., Jensen, R. S. \& Storvik, A. E. (2009). Midtveisevaluering av forsøk med moderat kvotering av personer med ikke-vestlig bakgrunn. Oslo, Institutt for samfunnsforskning

Ose, S. O., et al. (2013). Evaluering av IA-avtalen (2010-2013) Trondheim SINTEF.

Perduco. (2010). "Topplederundersøkelsen 2010". Norges Næringslivsundersøkelser, Oslo Perduco.

Prinz, C. (ed.) (2003). European disability pension policies: 11 country trends 19702002. Ashgate. Available. 
Quintini, G. \& Martin, S. (2006). "Starting Well or Losing their Way? The Position of Youth in the Labour Market in OECD Countries". OECD Social, Employment and Migration Working Papers Paris, OECD.

Røed, K. \& Raaum, O. (2006) "Do Labour Market Programmes Speed Up the Return to Work?", Oxford Bulletin of Economics and Statistics, 68, 5, 541-68

Raitasalo, R. \& Maaniemi, K. (2011). "Nuorten mielenterveyden häiriöiden aiheuttamat sairauspoissaolot ja työkyvyttömyys vuosina 2004-2009". Helsinki Kelan tutkimusosasto.

Ramböll Management Consulting. (2010). "Nordiska länders insatser mot ungdomsarbetslöshet - kartläggning och analys". TemaNord. Copenhagen, Nordic Council of Ministers.

Sandal, G. M. (ed) (2009). Kulturelt mangfold på arbeidsplassen. Fagbokforlaget Oslo.

Schneider, A. \& Ingram, H. (1993). "Social construction of target populations: implications for politics and policy", American Sociological Review 87: 2 (334-347).

Schröder, L. (2007). "From problematic objects to resourceful subjects: An overview of immigrant-native labour market gaps from a policy perspective", in Swedish Economic Policy Review. Vol. 14, No. 1.

Shakespeare, T. (2006). Disability Rights and Wrongs. Routledge, London.

Simmel, G. (1950). The Sociology of Georg Simmel. New York, The Free Press

Social Insurance Administration. (2011). Tafla 1.20. Fjöldi örorku-, endurhæfingarlífeyrispega og örorkustyrkpega 1986-2011. Reykjavik, Tryggingastofnun.

Statistics Sweden. (2009). "Funktionsnedsattas situation på arbetsmarknaden - 4:e kvartalet 2008", Information om utbildning och arbetsmarknad. Stockholm SCB.

Statistics Sweden. (2013). "Ungdomsarbetslöshet- jamförbarhet i statistiken mellan ett antal europeiska länder". Arbetsmarknads- och utbildningsstatistik. Stockholm, SCB.

Stehr, N. (2004). The Governance of Knowledge. Transaction Publishers.

Strauss, A. L. 1988 (1978). Negotiations. Varieties, Contexts, Processes, and Social Order. San Francisco: Jossey-Bass Publishers.

Svalund, J. \& Hansen, I. L. S. (2013). Inkludering av personer med nedsatt funksjonsevne i arbeidslivet. Oslo, FAFO.

Swedish Government (2013). Nordic Poket Facts. Statistics on Integration 2013. Stockholm Government Offices of Sweden.

Taylor, C. (1992). "The Politics of Recognition", in A. Gutmann (ed.) Multiculturalism and The Politics of Recognition. Princeton, Princeton University Press.

Teigen, M. (2012). "Gender Quotas for Corporate Boards in Norway - Innovative Gender Equality Policy" In Fagan, C., González Menéndez, M., Gómez Ansón (Eds), Women on Corporate Boards and in Top Management: European Trends and Policy. Palgrave.

Tronstad, K. R. (2010). Mangfold og likestilling i arbeidslivet. Holdninger og erfaringer blant arbeidsgivere og tillitsvalgte. Report 2010:39. FAFO, Oslo.

UN (2006). The Convention on the Rights of Persons with Disabilities. (A/RES/61/106) Resolution adopted by the general assembly. New York. 
UN (2009). "General recommendation No 32. The meaning and scope of special measures in the International Convention on the Elimination of Racial Discrimination. Committee on the Elimination of Racial Discrimination. 75 session, August 2009.

Vandenbroucke, F., Hemerijck, A. \& Palier, B. (2011). "The EU needs a Social Investment Pact", OSE Paper Series.

Vedung, E. (1998). "Policy instruments: Typologies and theories" in M.-L. Bemelmans-Videc, R. C. Rist, \& E. Vedung (Eds.), Carrots, sticks, and sermons: Policy instruments and their evaluation. New Brunswick, NJ: Transaction.

Venn, D. (2009). "Legislation, collective bargaining and enforcement: Updating the OECD employment protection indicators". OECD Social, Employment and Migration Working Papers. Paris OECD.

Waddington, L.B. (2007). "Reasonable Accommodation". In D. Schiek, L. Waddington \& M. Bell (Eds.), Cases, Materials and Text on National, Supranational and International Non-Discrimination Law. Oxford: Hart Publishing.

Ward T. \& Grammenos, S. (Eds) (2007). Men and women with disabilities in the EU: Statistical analysis of the LFS ad hoc module and the EU-SILC. APPLICA and CESEP and ALPHAMETRICS.

WHO (2001). "ICF The International Classification of Functioning, Disability and Health". World Health Assembly,resolution WHA 54.21 May 2001.

Whittle, R. \& Halvorsen, R. (2007). "From disabling barriers to participation: the opportunities created by the EU equality strategy" in B. Hvinden, H. Johansson (eds.) Citizenship in Nordic Welfare States London, Routledge.

Williams, J.F. (1995). "Race, Ethnicity, Gender and Class in Welfare States", Social Politics: International Studies in Gender, State and Society. 2.1: 127-159. 



\section{Norsk sammendrag:}

\section{Ny politikk for å fremme inkludering av ungdom i arbeidsmarkedet?}

\section{Tilpasning av mangfold i arbeidslivet}

Rune Halvorsen og Bjørn Hvinden

Norsk Institutt for forskning om oppvekst, velferd og aldring, HiOA.

Rapporten presenterer ny kunnskap om betydningen av sosial regulering for mulighetene til arbeidsmarkedsdeltakelse blant unge voksne med minoritetsbakgrunn og unge funksjonshemmede (16-29 år) i de nordiske landene.

Med sosial regulering sikter vi i denne rapporten hovedsakelig til tre typer av politikkvirkemidler innrettet mot å sikre etnisk minoritetsungdom og unge funksjonshemmede muligheter til å ta og beholde lønnet arbeid $\mathrm{i}$ det ordinære arbeidsmarkedet: politiske virkemidler for å hindre negativ forskjellsbehandling (sikre likebehandling), politikkvirkemidler for å kompensere for ulemper i en overgangsfase gjennom positiv forskjellsbehandling, og rimelig tilpasning av ansattes behov på arbeidsplassen.

Rapporten argumenterer for at de nordiske landene har endret balansen mellom omfordelingspolitiske og reguleringspolitiske virkemidler for å fremme sysselsetting blant unge voksne generelt og unge voksne med minoritetsbakgrunn og unge funksjonshemmede spesielt. De nordiske velferdsstatene har hatt en tradisjon for generøse omfordelingspolitiske ordninger for å gjøre personer utenfor arbeidsmarkedet mer attraktive å 
ansette for arbeidsgivere og sikre inntekt i perioder uten lønnet arbeid. Reguleringspolitiske virkemidler for å oppnå velferdspolitiske målsettinger har vært relativt mindre utviklet. Fra 1990-tallet har imidlertid de nordiske landene innført ny lovgivning, økonomiske insentiver og frivillige avtaler for å fremme inkludering i arbeidslivet.

Prosjektet begynte med å spørre under hvilke betingelser sosial regulering har størst mulighet for å forbedre arbeidsmarkedsdeltakelsen fra minoritetsungdom og unge funksjonshemmede. I løpet av prosjektet har vi imidlertid i økende grad diskutert hvordan følgene av det sosiale reguleringssystemet må ses i sammenheng med ulikheter mellom de nordiske tjenestesystemet (grad av selektivitet og arbeidserfaring i utdanningssystemene, bruk av aktive arbeidsmarkedstiltak) og inntektssikringssystemet.

Det reviderte fokuset var dels en anerkjennelse av vanskene med å isolere betydningen av sosiale regulering og å kontrollere for andre faktorer. Dels var det et resultat av uventede problemer med å fă tilgang til relevante og sammenlignbare tidsseriedata i de fem nordiske landene.

Rapporten har tydeliggjort behovet for bedre data. Tilgjengelige statistikk har ikke gjort det mulig å fastslå noen effekt (positiv eller negativ) av sosial regulering for graden av sysselsetting blant de to gruppene av unge voksne. Prosjektet har imidlertid identifisert prosesser og mekanismer som påvirker iverksettingen eller implementeringen av den sosiale reguleringspolitikken. 


\section{Annex: Employment, education and NEET among minority ethnic youth in the Nordic countries}

Figure 1: Denmark. Youth in employment (incl. apprenticeships). Both sexes. Total 15-28 years old. Percent

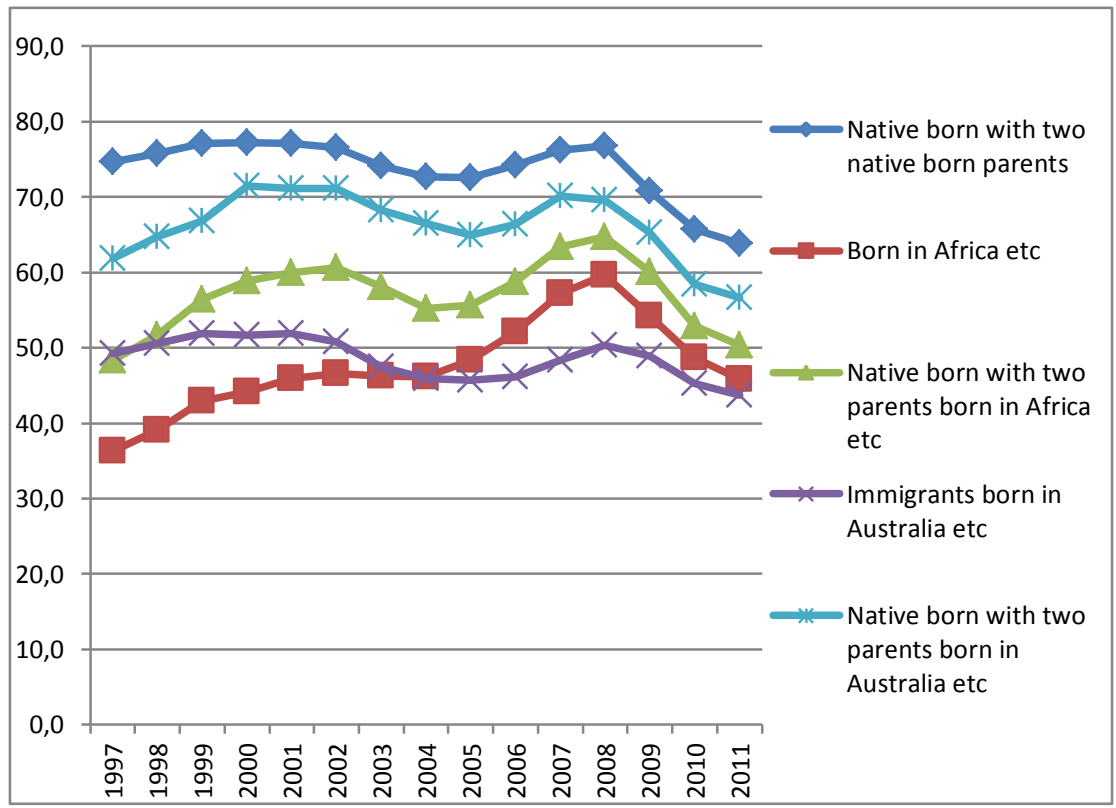


Figure 2: Finland. Youth in employment. 18-29 years old. Both sexes. 1997-2010 Percent

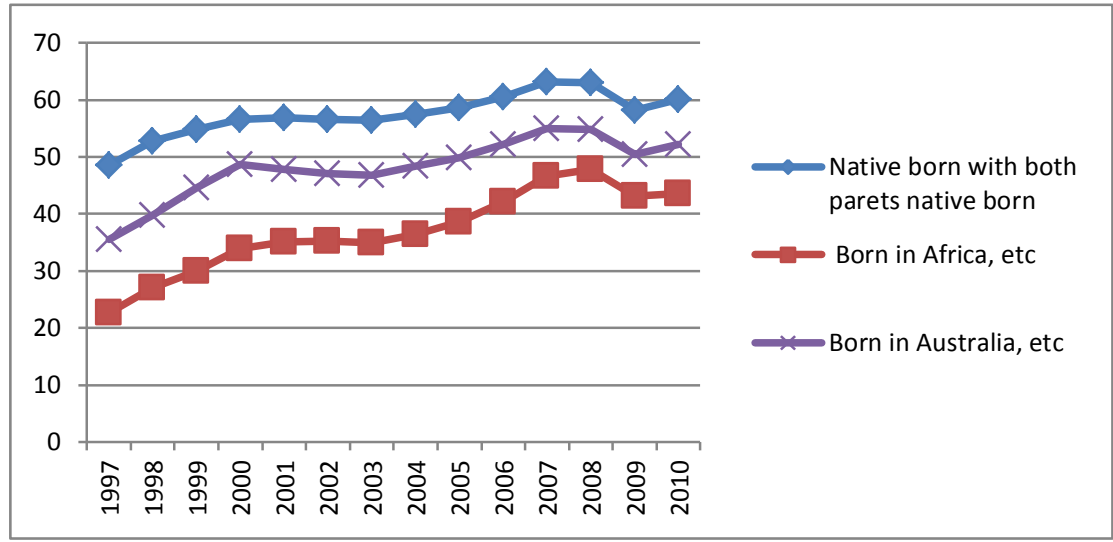

Figure 3: Norway. Youth in employment. 16-29 years old. Both sexes. Q4. 2001-2011 Percent

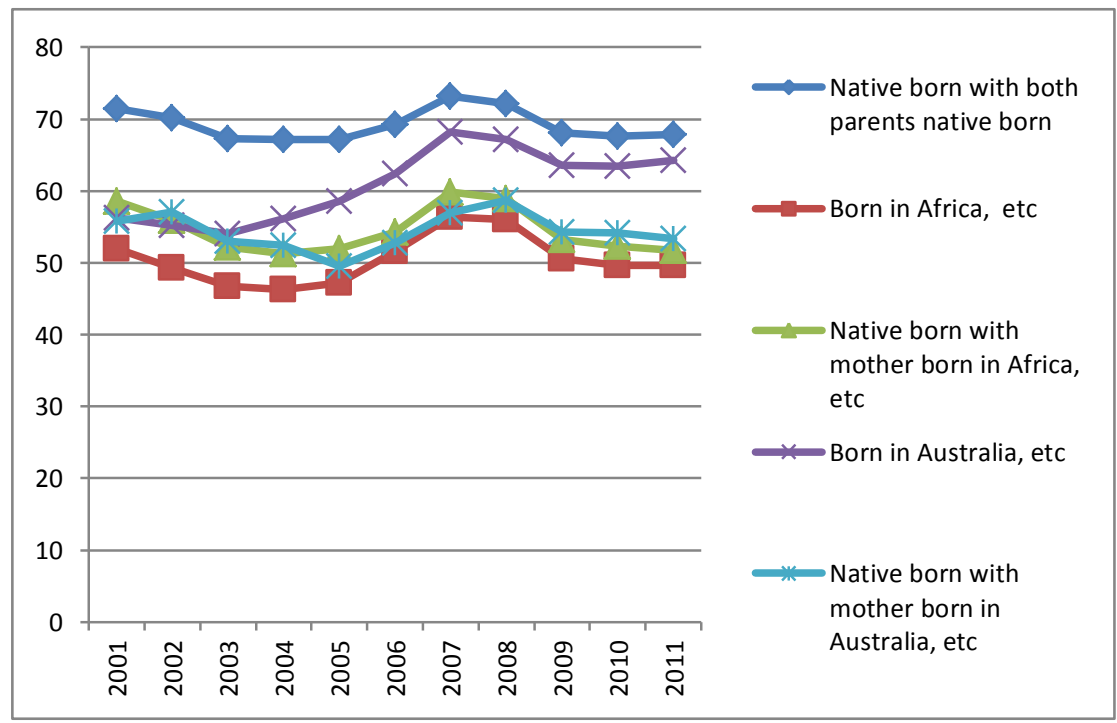


Figure 4: Sweden. Youth in employment. 16-29 years old. Both sexes. 1997-2010 Percent

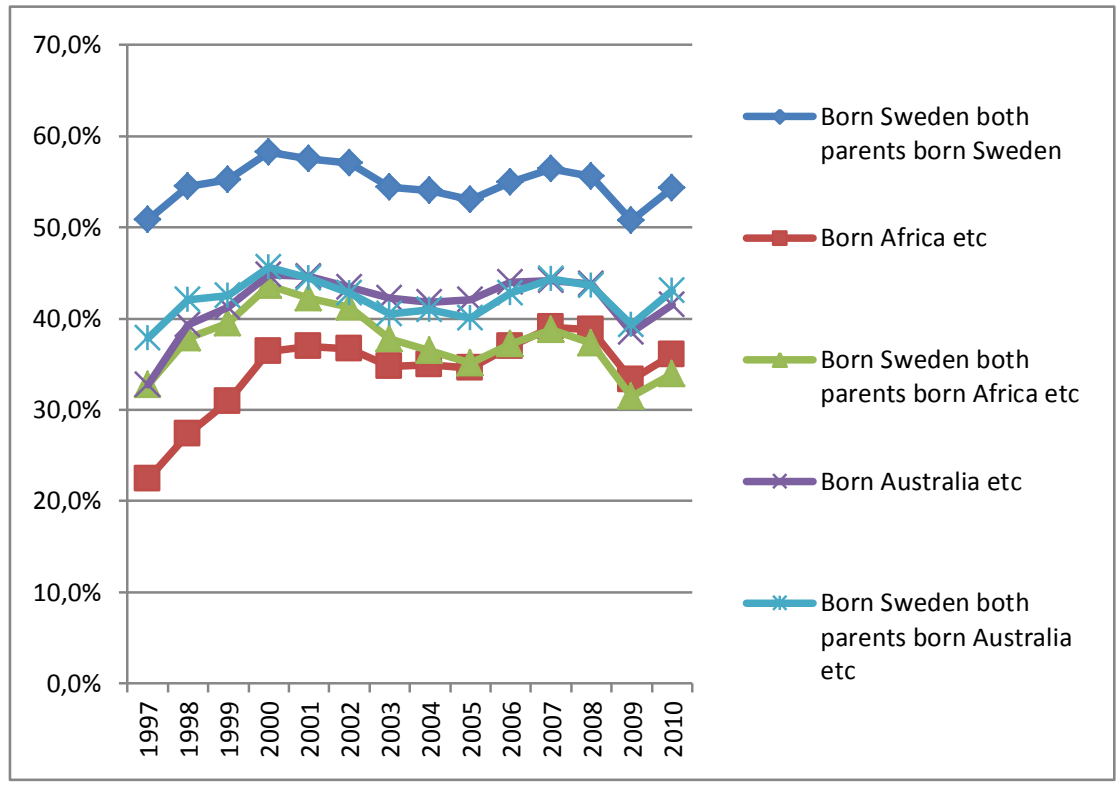

Figure 5: Denmark. Youth in education. 15-28 years old. Both sexes. 1997-2010 Percent

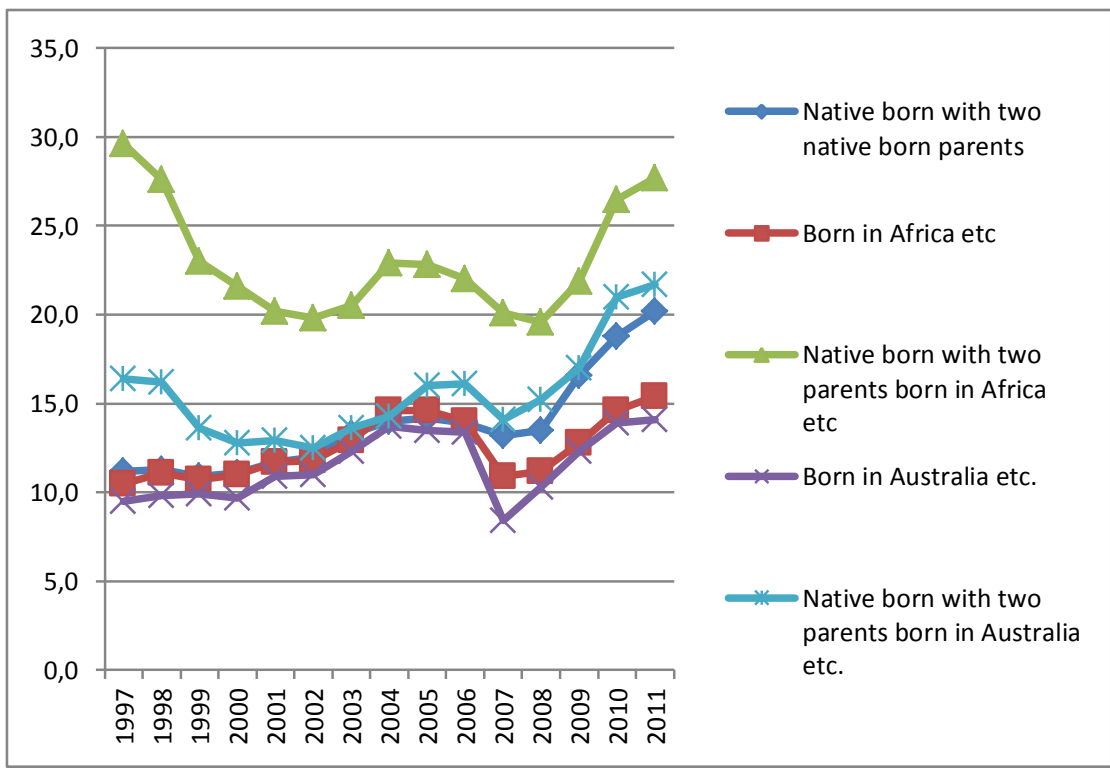


Figure 6: Finland. Youth in education. 18-29 years old. Both sexes. 1997-2010 Percent

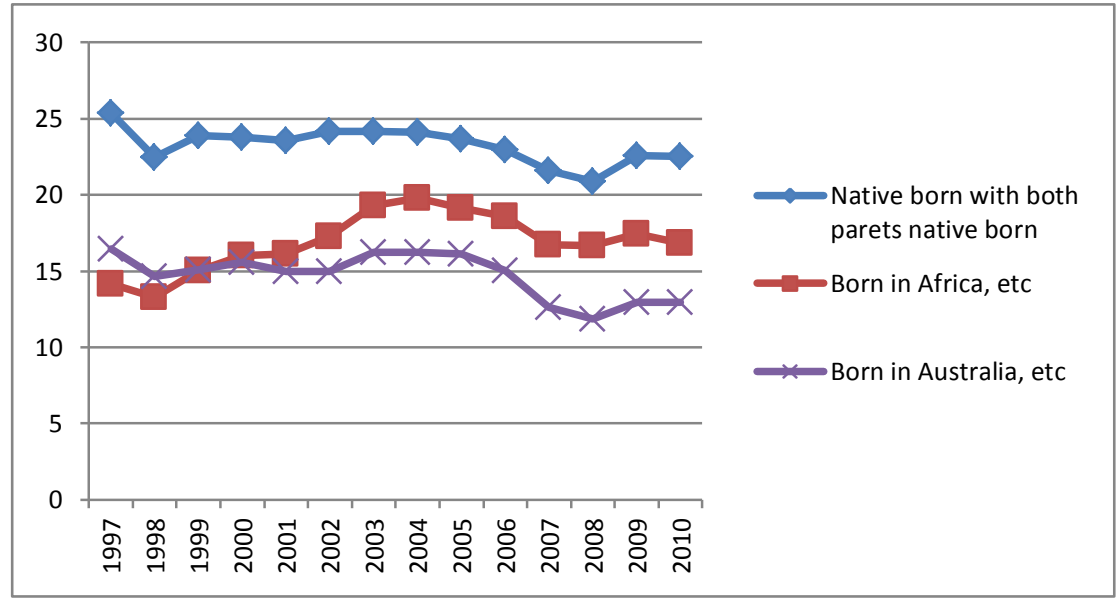

Figure 7: Norway. Youth in education. 16-29 years old. Both sexes. 2001-2011 Percent

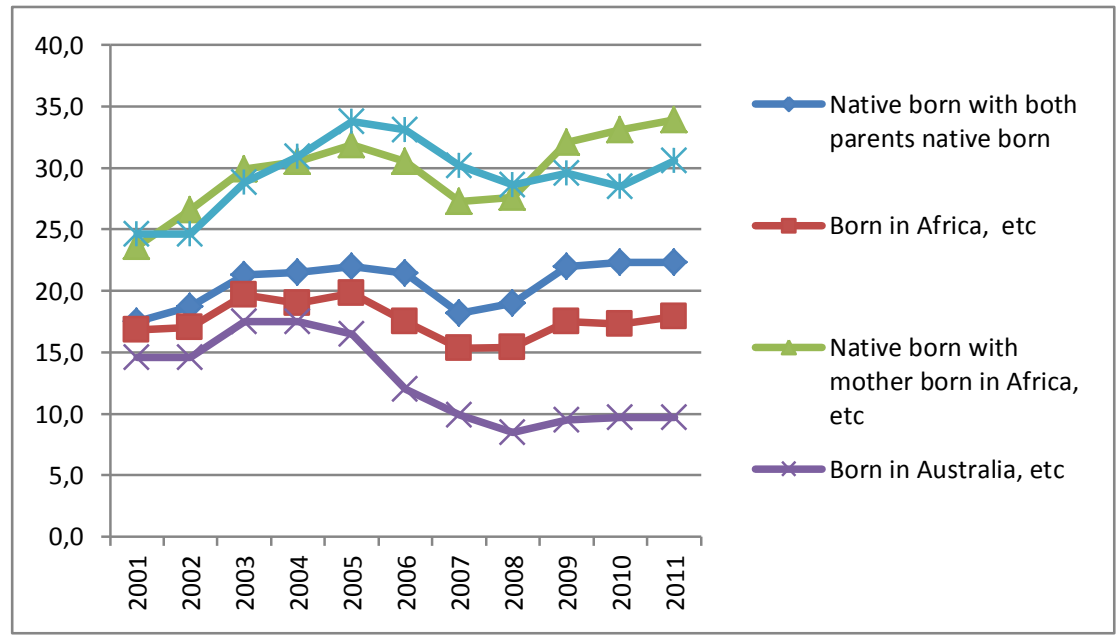


Figure 8: Sweden. Youth in education. 16-29 years old. Both sexes. 1997-2010 Percent

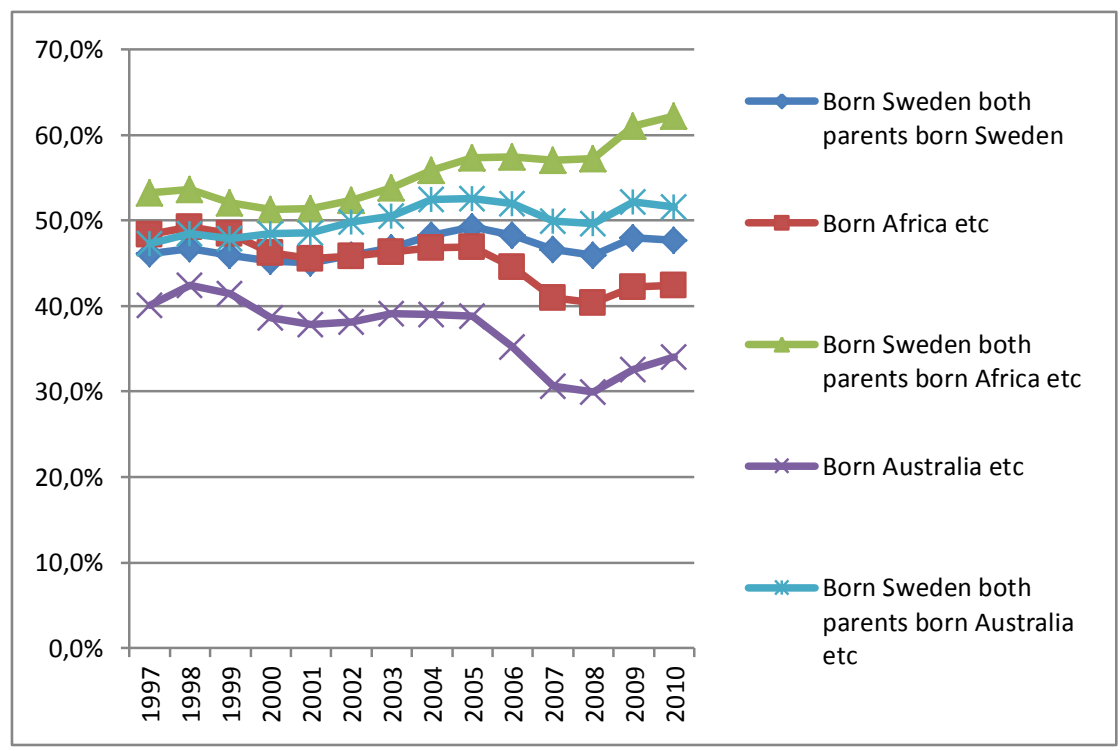


Figure 9: Denmark Share of youths aged 15-28 not in education or employment, 1997-2010. Percent

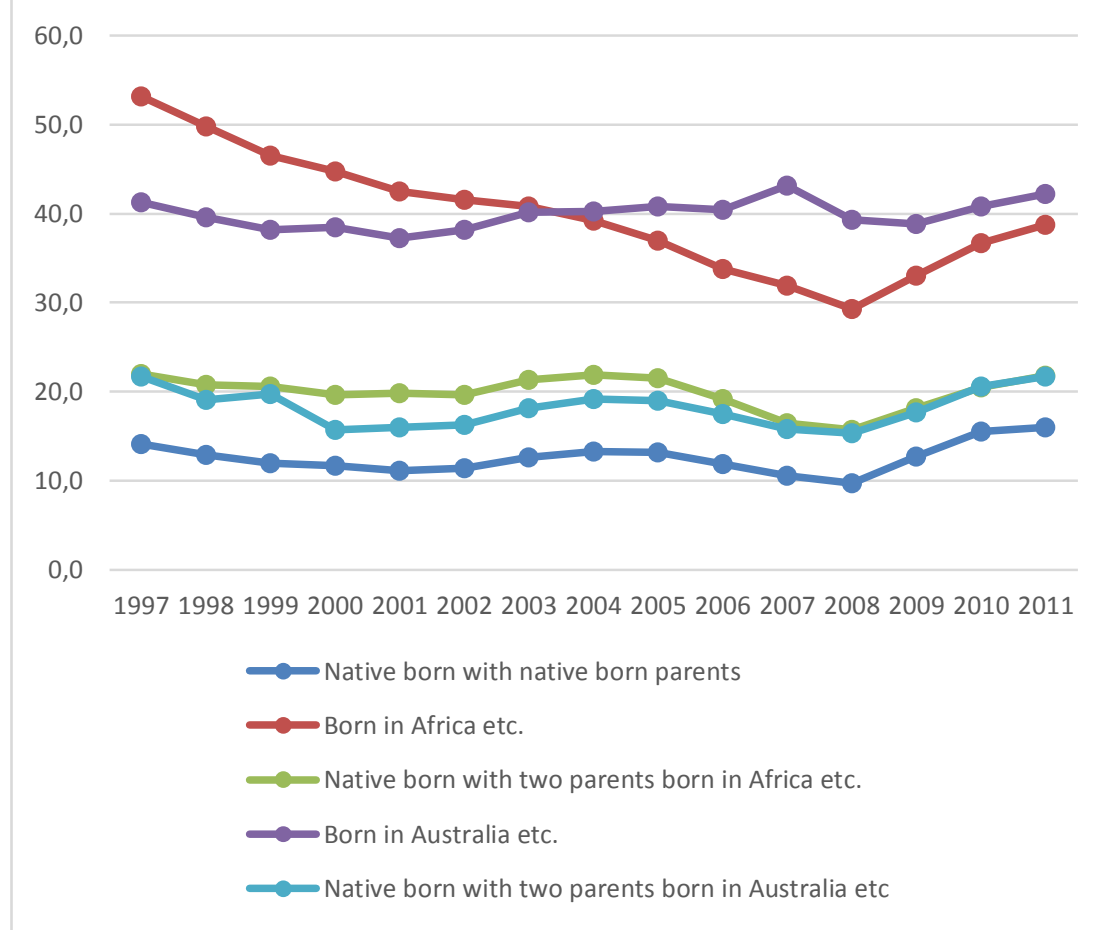


Figure 10: Finland. Share of youths aged 18-29 not in education or employment, * 1997-2010. Percent

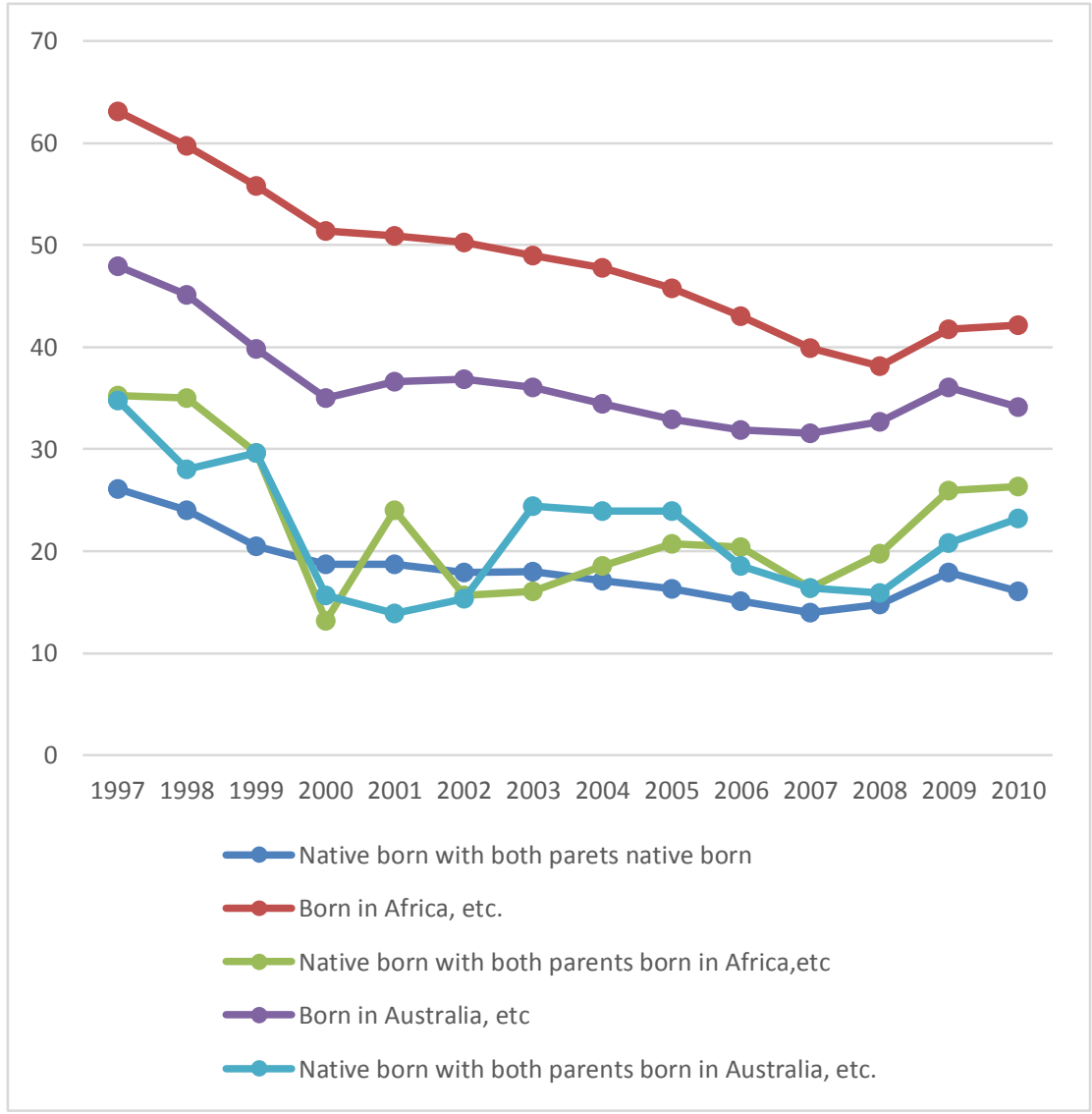

* Includes people in military service (both conscripts and people in non-military service). 
Figure 11: Share of youths aged 16-29 not in education or employment in Norway, 2001-2011. Percent

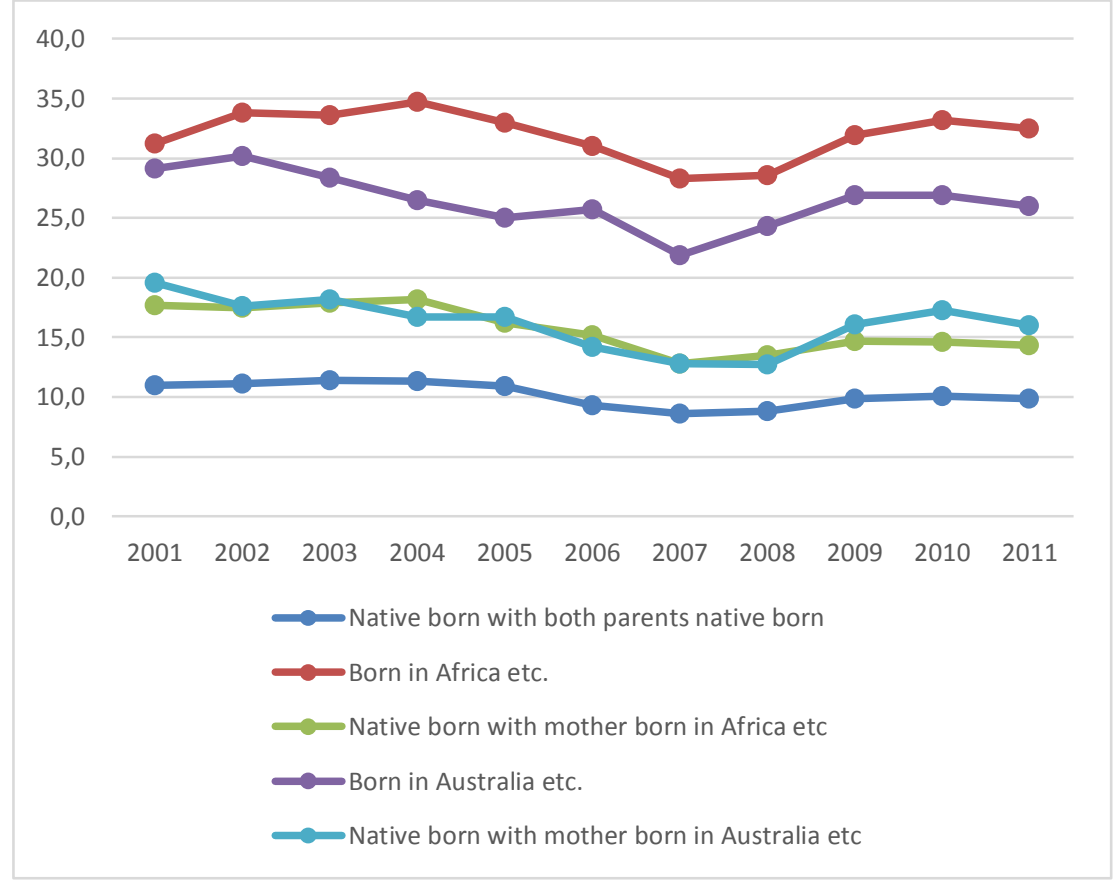


Figure 12: Share of youths aged 16-29 not in education or employment in Sweden, 1997-2010. Percent

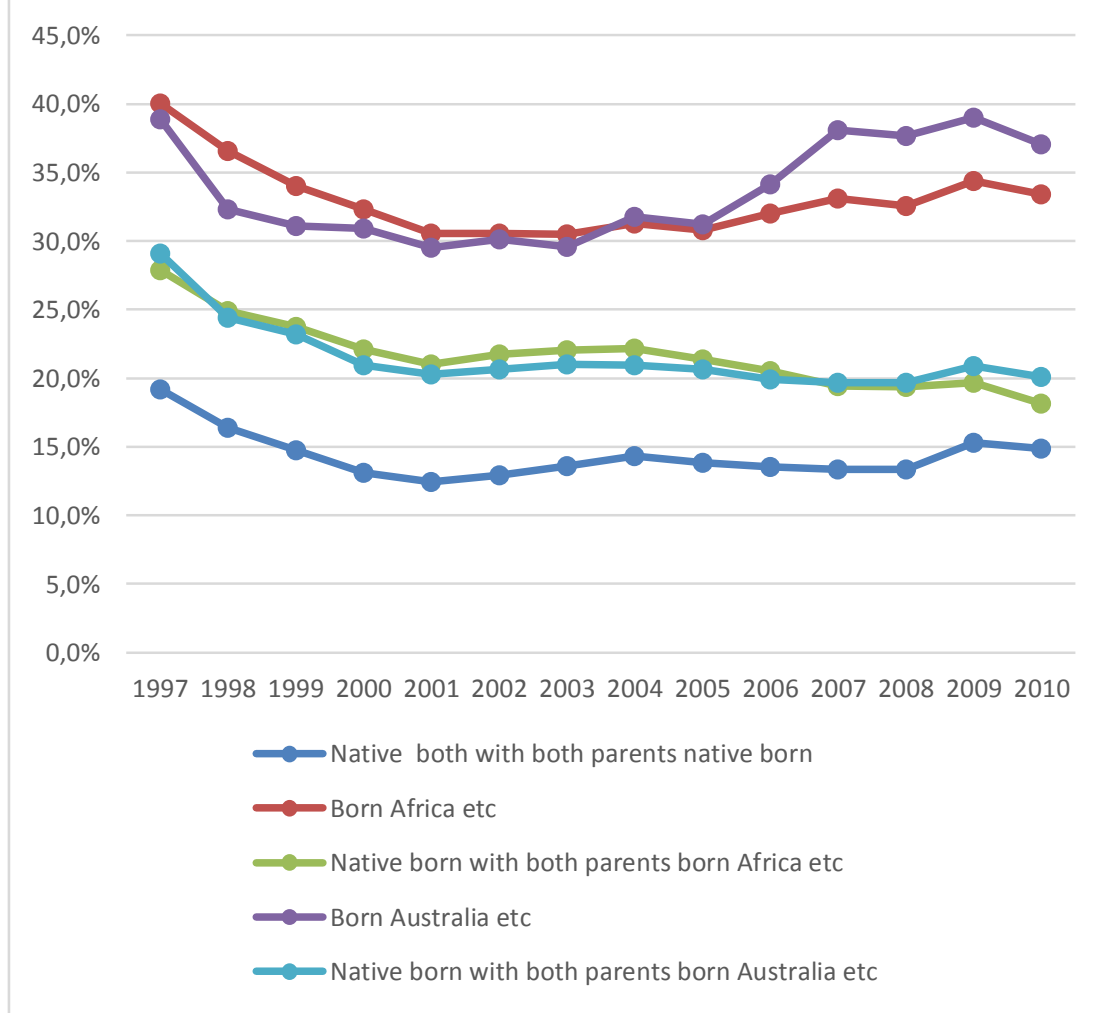


Table 1: Cohort specific employment rate (percent). Total men (TM) and men born in Africa (AFM). Age. Norway

\begin{tabular}{|c|c|c|c|c|c|c|c|c|c|c|c|c|}
\hline & -19 & 20- & 25- & 30- & 35- & $40-$ & 45- & $50-$ & 55- & $60-$ & $65-$ & 70- \\
\hline TM1935 & & & & & & & & & & 62 & 32 & 22 \\
\hline TM1945 & & & & & & & & 85 & 78 & 67 & & \\
\hline TM1955 & & & & & & 87 & 85 & 85 & & & & \\
\hline TM1965 & & & & 87 & 85 & 86 & & & & & & \\
\hline TM1975 & & 76 & 80 & 85 & & & & & & & & \\
\hline TM1985 & 43 & 71 & & & & & & & & & & \\
\hline AFM1935 & & & & & & & & & & 36 & 22 & 8 \\
\hline AFM1945 & & & & & & & & 52 & 41 & 35 & & \\
\hline AFM1955 & & & & & & 53 & 50 & 49 & & & & \\
\hline AFM1965 & & & & 57 & 52 & 58 & & & & & & \\
\hline AFM1975 & & 51 & 48 & 59 & & & & & & & & \\
\hline AFM1985 & 17 & 46 & & & & & & & & & & \\
\hline
\end{tabular}

Source: Statistics Norway 2001, 2004, 2009. 4Q.

Table 2: Cohort specific employment rate (percent). Total men (TM) and men born in Asia (ASM). Age. Norway

\begin{tabular}{|c|c|c|c|c|c|c|c|c|c|c|c|c|}
\hline & -19 & 20- & 25- & $30-$ & $35-$ & $40-$ & 45- & $50-$ & $55-$ & $60-$ & $65-$ & 70- \\
\hline TM1935 & & & & & & & & & & 62 & 32 & 22 \\
\hline TM1945 & & & & & & & & 85 & 78 & 67 & & \\
\hline TM1955 & & & & & & 87 & 85 & 85 & & & & \\
\hline TM1965 & & & & 87 & 85 & 86 & & & & & & \\
\hline TM1975 & & 76 & 80 & 85 & & & & & & & & \\
\hline TM1985 & 43 & 71 & & & & & & & & & & \\
\hline ASM1935 & & & & & & & & & & 30 & 15 & 8 \\
\hline ASM1945 & & & & & & & & 52 & 45 & 35 & & \\
\hline ASM1955 & & & & & & 64 & 59 & 58 & & & & \\
\hline ASM1965 & & & & 67 & 64 & 67 & & & & & & \\
\hline ASM1975 & & 63 & 62 & 72 & & & & & & & & \\
\hline ASM1985 & 28 & 59 & & & & & & & & & & \\
\hline
\end{tabular}

Source: Statistics Norway 2001, 2004, 2009. 4Q. 
Table 3: Cohort specific employment rate (percent). Total men (TM) and men born in New EU member states (NEUM). Age. Norway

\begin{tabular}{|c|c|c|c|c|c|c|c|c|c|c|c|c|}
\hline & -19 & $20-$ & 25- & $30-$ & 35- & $40-$ & 45- & $50-$ & 55- & $60-$ & 65- & $70-$ \\
\hline TM1935 & & & & & & & & & & 62 & 32 & 22 \\
\hline TM1945 & & & & & & & & 85 & 78 & 67 & & \\
\hline TM1955 & & & & & & 87 & 85 & 85 & & & & \\
\hline TM1965 & & & & 87 & 85 & 86 & & & & & & \\
\hline TM1975 & & 76 & 80 & 85 & & & & & & & & \\
\hline TM1985 & 43 & 71 & & & & & & & & & & \\
\hline NEUM35 & & & & & & & & & & 59 & 36 & 20 \\
\hline NEUM45 & & & & & & & & 76 & 68 & 60 & & \\
\hline NEUM55 & & & & & & 79 & 77 & 71 & & & & \\
\hline NEUM65 & & & & 78 & 79 & 75 & & & & & & \\
\hline NEUM75 & & 62 & 74 & 77 & & & & & & & & \\
\hline NEUM85 & 30 & 68 & & & & & & & & & & \\
\hline
\end{tabular}

Source: Statistics Norway 2001, 2004, 2009. 4Q. 
Nordic Council of Ministers

Ved Stranden 18

DK-1061 Copenhagen K

www.norden.org

New Policies to Promote Youth Inclusion

This report examines changes over time among young adults who have experienced particular difficulties in achieving and retaining paid work in the ordinary labour market: youth with family background from non-Nordic countries and youth with disabilities in the Nordic countries. The report identifies processes and mechanisms enabling or preventing the labour market prospects of the two youth groups. The report focuses on policy measures aiming at tackling demand-side barriers to employment for the two youth groups. While available data have not made it possible to determine robust evidence of an effect (positive or negative) of the social regulation policies for the employment of vulnerable youth groups in statistical terms, the report identifies processes and mechanisms through which social regulation policies make a difference. 